Illinois State University

ISU ReD: Research and eData

Theses and Dissertations

$10-9-2017$

\title{
Fermenting Solutions to New World Problems: Bioremediation of Blue Agave and Cocoa Pod Wastes
}

Daniel Hart

Illinois State University, vindicator1975@yahoo.com

Follow this and additional works at: https://ir.library.illinoisstate.edu/etd

Part of the Chemistry Commons

\section{Recommended Citation}

Hart, Daniel, "Fermenting Solutions to New World Problems: Bioremediation of Blue Agave and Cocoa Pod Wastes" (2017). Theses and Dissertations. 806.

https://ir.library.illinoisstate.edu/etd/806

This Thesis is brought to you for free and open access by ISU ReD: Research and eData. It has been accepted for inclusion in Theses and Dissertations by an authorized administrator of ISU ReD: Research and eData. For more information, please contact ISUReD@ilstu.edu. 


\title{
FERMENTING SOLUTIONS TO NEW WORLD PROBLEMS: BIOREMEDIATION OF BLUE AGAVE AND COCOA POD WASTES
}

\author{
Daniel Jay Carl Hart
}

\section{Pages}

Waste, minimizing it, and maximizing profit from it are major foci of most agricultural production processes today. Waste from two major production processes, namely tequila production and cocoa production, share several characteristics. Both these processes are still carried out as they have been for hundreds of years. They are both relatively concentrated in location; all tequila is produced in a small region of Mexico while cocoa pods only grow in tropical environments within $18^{\circ}$ of the equator. In addition, both processes used to produce these commodities remain fairly inefficient; they generate huge amounts of waste that goes mostly unused. With both these processes, a new source of income is explored while major waste products, agave leaves from the tequila industry and cocoa pod husks from the cocoa industry, are utilized.

Agave leaves, which constitute about half the mass of mature Blue Agave plants, are discarded when agave hearts are harvested to produce tequila. Agave leaves are known to contain reducing sugars and inulin, as well as modest amounts of proteins. The nutrients contained in these leaves can be utilized by single celled organisms and converted into commodities. If the juice is pressed from them prior to fermentation, only the nutrients that fermenting organisms use is consumed, while solid portions, presumably, remain unaffected and available for other applications. Fermentation by 
strains of Kluyveromyces marxianus and Yarrowia lipolytica $F$ of the nutrient-rich juice pressed from the leaves of a mature Blue Agave plant is explored in this work in an effort to generate valuable commodities such as the yeast themselves, ethanol and ammonia.

Cocoa pod husks are piled and left to rot in equatorial rain forest climates when cocoa farmers harvest the ripe pods and collect the precious cocoa beans from them. Cocoa pod husks possess a polysaccharide known as pectin, which can be metabolized by some single celled organisms. The husks, similar to agave leaves, constitute about half the mass of the whole pods; thus, the 4.5 million metric ton cocoa bean harvest forecast for this (2017-2018) growing season will leave about the same mass of waste behind. Fermentation of this waste by $K$. marxianus $7-1$ and $K$. marxianus $8-1$, then $Y$. lipolytica $F$ in an effort to add value to this waste is explored in this work.

Fermentations with $K$. marxianus yeast strains were carried out using either agave leaf juice or cocoa pod husk pieces in water. Fermentations were allowed to progress for 72 hours from inoculation. Samples were collected at pre-determined time points and analyzed for colony forming units, reducing sugar concentration, soluble protein concentration, ethanol concentration, and the presence or absence of amines and sugars, both simple and complex. Upon termination of some of the K. marxianus fermentations, subsequent, second stage fermentations with Yarrowia were carried out by Mr. Mitchell Lindquist of the USDA through continued collaborative work with the Jones' Lab. Again, fermentations were sampled at pre-determined time points and, with Yarrowia fermentations, analyzed for colony forming units and ammonia concentrations. 
Results from these fermentations and subsequent analyses indicate that fermenting these waste products is an effective means of bioremediation. The unused portions of these two enormous cash crops can be used to produce commodities such as ethanol and yeast proteins. These commodities are not nearly as valuable as the cash crop that generate these wastes; however, they do hold substantial value. If the value of the waste products and commodities produced from them can be shown to be substantial enough, this may motivate crop farmers to use these current wastes instead of discarding them.

KEYWORDS: Bioremediation; Agave waste; Cocoa pod waste; Kluyveromyces marxianus; Yarrowia lipolytica F; Biphasic fermentation 


\title{
FERMENTING SOLUTIONS TO NEW WORLD PROBLEMS: BIOREMEDIATION OF BLUE AGAVE AND COCOA POD WASTES
}

\author{
DANIEL JAY CARL HART
}

A Thesis Submitted in Partial Fulfillment of the Requirements for the Degree of MASTER OF SCIENCE

Department of Chemistry ILLINOIS STATE UNIVERSITY 
Copyright 2017 Daniel Jay Carl Hart 


\title{
FERMENTING SOLUTIONS TO NEW WORLD PROBLEMS: BIOREMEDIATION OF BLUE AGAVE AND COCOA POD WASTES
}

\author{
DANIEL JAY CARL HART
}

COMMITTEE MEMBERS:

Marjorie Jones, Chair

Jeremy Driskell

Christopher Weitzel 


\section{ACKNOWLEDGMENTS}

I would first like to thank God, through whom all things are possible. Without his hand in my life I might still be working swing shift in a mine. I am certain that if He were not leading me, tequila and chocolate would not be making a positive change in my life...

I would like to thank Dr. Jones for all that she has done for me. Dr. Jones' tireless devotion to learning and teaching are not only inspiring, but also life changing. She has the uncanny ability to know what her students need and how to help us make it happen. Whether we need a pat on the back, or a kick a little lower, Dr. Jones cares enough to help us to get there. Thank you, Dr. Jones.

I would like to thank Dr. Stephen Hughes. Dr. Hughes not only provided the agave, the cocoa pods, the yeasts and some of the methodology with which these fermentations and analyses were carried out, his enthusiasm for this work and so much more are inspirational. Any time that the work started to feel mundane, coffee with Dr. Hughes was more than enough to refocus and find the desire to continue learning from the research. Thank you, Dr. Hughes.

I would like to thank Mr. Mitch Lindquist. Mr. Lindquist and his work with the ethanol analyses and second stage fermentations was and is greatly appreciated. The work that Mr. Lindquist is doing at the USDA in Peoria, Illinois is important. Thank you, Mr. Lindquist.

I would like to thank the Department of Chemistry at Illinois State University. The Chemistry Department not only provided the space and supplies to perform this research, but also the support that made it possible. The Department, the students that 
comprise it and those who run it treated me with respect and earned mine. I would like to thank all the representatives of Illinois State University Department of Chemistry. Thank you.

Last but certainly not least, I would like to thank my family and friends that helped me in so many ways. My mother and father, my uncle, my brother, my daughters and so many others helped me in more ways than I could list, more ways than I am even aware of. My accomplishments are not my own, but the results of work and sacrifice of so many wonderful people in my life. I cannot express the depth of gratitude for the things that you have done for me. Thank you.

Thank you all for everything...

D.J.C.H. 


\section{CONTENTS}

Page

ACKNOWLEDGMENTS

CONTENTS

iii

TABLES

vi

FIGURES

vii

CHAPTER I: INTRODUCTION

CHAPTER II: MATERIALS AND METHODS 15

$\begin{array}{ll}\text { Blue Agave Leaf Juice Preparation } & 15\end{array}$

$\begin{array}{ll}\text { Cocoa Pod Husk Preparation } & 17\end{array}$

$\begin{array}{lr}\text { Fermentation Preparation } & 19\end{array}$

Yeast Strains Selected $\quad 21$

$\begin{array}{ll}\text { Fermentations } & 22\end{array}$

$\begin{array}{ll}\text { Sampling } & 22\end{array}$

$\begin{array}{ll}\text { Analytical Methods Employed } & 24\end{array}$

$\begin{array}{ll}\text { Separations } & 31\end{array}$

Cocoa Pod Husk $\quad 31$

Blue Agave Leaf Skin 32

Multi Stage Fermentations 33

CHAPTER III: RESULTS

Cocoa Pod Husk (CPH) Description 34

Blue Agave Leaf Description $\quad 34$

Cocoa Pod Husk Fermentations Appearance 35 
Sample Appearance

Colony Forming Units

Cocoa Pod Husk Fermentations

Agave Leaf Juice Fermentations

Reducing Sugars

Cocoa Pod Husk Fermentations

Agave Leaf Juice Fermentations

Soluble Proteins

Cocoa Pod Husk Fermentations

Agave Leaf Juice Fermentations

Ethanol

52

Cocoa Pod Husk Fermentations

Agave Leaf Juice Fermentations

Data Overlays

Cocoa Pod Husk Fermentations

Agave Leaf Juice Fermentations

Data Normalizations

Cocoa Pod Husk Fermentations

Agave Leaf Juice Fermentations

$\mathrm{pH}$

62

Cocoa Pod Husk Fermentations

Agave Leaf Juice Fermentations 
Thin Layer Chromatography

$\begin{array}{ll}\text { Two Stage Fermentations } & 66\end{array}$

$\begin{array}{ll}\text { Separations } & 68\end{array}$

$\begin{array}{ll}\text { Cocoa Pod Husk } & 68\end{array}$

$\begin{array}{ll}\text { Agave Leaf } & 70\end{array}$

CHAPTER IV: DISCUSSION AND CONCLUSIONS 71

$\begin{array}{ll}\text { Fermentations } & 71\end{array}$

$\begin{array}{ll}\text { Agave Leaf Juice Fermentations } & 71\end{array}$

$\begin{array}{lr}\text { Cocoa Pod Husk Fermentations } & 80\end{array}$

$\begin{array}{ll}\text { CHAPTER V: FUTURE WORK } & 84\end{array}$

$\begin{array}{ll}\text { REFERENCES } & 91\end{array}$ 


\section{TABLES}

$\begin{array}{lll}\text { Table Page } & \end{array}$

1. TLC Plates Key 65

$\begin{array}{ll}\text { 2. Fermentations summary } & 67\end{array}$

3. Ethanol production comparisons $\quad 79$

4. Summary of agave leaf juice fermentation products 79 


\section{FIGURES}

$\begin{array}{lll}\text { Figure Page } & \end{array}$

1. Picture of a Blue Agave Harvest 5

2. Picture of a Cocoa Pod 9

3. Picture of Blue Agave leaf pieces $\quad 15$

4. Picture of Blue Agave leaf juice extraction methods 17

5. Picture of cocoa pod husk pieces in water 18

6. Picture of sterilized Blue Agave leaf juice 20

7. Picture of Pasteur pipettes used for sample collection 23

8. Picture of colony forming unit plate 25

9. Picture of plate spreader 25

10. Graph of reducing sugar calibration curve 27

11. Graph of soluble protein calibration curve 28

12. Picture of cocoa pod husk cross section 31

13. Picture of Blue Agave leaf skin removal 32

14. Picture of cocoa pod husk fermentation appearance changes 35

15. Picture of agave leaf juice fermentation appearance changes 37

16. Picture of agave leaf juice fermentation sample in pipette 38

17. Picture of agave leaf juice fermentation centrifuged samples 39

18. Picture of agave leaf juice fermentation centrifuged samples 39

19. Graph of cocoa pod husk fermentation colony forming units 41

20. Graph of cocoa pod husk fermentation colony forming unit mean 42

21. Graph of agave leaf juice fermentation colony forming units 43 
22. Graph of agave leaf juice fermentation colony forming unit mean

23. Graph of cocoa pod husk fermentation reducing sugars

24. Graph of cocoa pod husk fermentation reducing sugar mean

25. Graph of agave leaf juice fermentation reducing sugars

26. Graph of agave leaf juice fermentation reducing sugar mean

27. Graph of cocoa pod husk fermentation soluble proteins

28. Graph of cocoa pod husk fermentation soluble protein mean

29. Graph of agave leaf juice fermentation soluble proteins

30. Graph of agave leaf juice fermentation soluble protein mean

31. Graph of agave leaf juice fermentation ethanol mean

32. Overlay of cocoa pod husk colony forming units and reducing sugar

33. Overlay of cocoa pod husk colony forming units and soluble protein

34. Overlay of agave leaf juice colony forming units and reducing sugar

35. Overlay of agave leaf juice colony forming units and soluble protein

36. Overlay of agave leaf juice colony forming units and ethanol

37. Graph of cocoa pod husk normalized colony forming units

38. Graph of cocoa pod husk normalized colony forming units

39. Graph of agave leaf juice normalized colony forming units

40. Graph of agave leaf juice normalized colony forming units

41. Picture of cocoa pod husk pH strips

42. Picture of developed TLC plates

43. Picture of cocoa pod husk layer separations 
45. Graph of agave leaf juice yeast cell added protein 


\section{CHAPTER I: INTRODUCTION}

Tequila has been a national symbol and source of pride for Mexico and its people for hundreds of years ${ }^{1}$; approximately 275 million liters of tequila were distilled and bottled in the Jalisco region of Mexico in $2016^{1,2}$. The cocoa industry forecasts a harvest of more than 4.5 million metric tons of cocoa beans for the $2016 / 2017$ growing season $^{3}$. At least $51 \%$ of sugars used to produce tequila must come from the piñas of mature Blue Agave (Agave tequilana) plants ${ }^{1}$ while cocoa beans are used to produce cocoa powder and cocoa butter ${ }^{4}$. Though these products are very different, they do share a common characteristic: they generate large amounts of bio-waste when they are harvested. These waste products are currently mostly unused; thus, tons of potentially valuable materials are left in fields to rot. With the work described herein, the potential value of the wastes generated by these traditional products and practices is examined.

Tequila production began in Mexico in the $16^{\text {th }}$ century, and the distilling process has remained relatively unchanged for hundreds of years. The drink was born of a European process applied to a native plant; it eventually became a source of pride and identity for the Mexican people, as well as one of their most profitable exports. Its blend of the Old World and New is a reflection of the people that produce and consume the unique spirit. Tequila is a specific type of mezcal; by regulation tequila must be produced in a specific region and made of a specific portion of a specific agave species $^{1}$.

Blue Agave is grown in huge, red fields, mostly in the Jalisco region of Mexico. This region is dry and arid; elevations range from 1,500 to 7,500 feet and the region has 
an annual rainfall of about one meter per year ${ }^{3}$. The blue-green plants are grown in long rows, and their long, spike-shaped leaves stand out against the red, iron-rich earth from which they grow. When fields full of Blue Agave plants ripen after eight-to-ten years, the plants develop maroon spots. These spots indicate to an experienced jimador (agave farmer) that the plant has reached maturity and its sugar stores are rich enough to be harvested for tequila production. The jimador uses a coa (sharp, circular blade on a long, wooden handle) to cut the plant off just below the piña (pineapple shaped heart of the plant in which most of the sugars are stored). He then removes the meter-long leaves which constitute approximately half of the mass of the plant and leaves them in the fields to rot or, eventually, be thrown into surrounding rivers or lands. A skilled jimador can process a ton of agave piñas every hour, which are picked up, often placed into baskets carried by donkeys, taken to trucks and transported to tequila distilleries ${ }^{5}$. With every ton of piña harvested, between 0.8 and 4.0 tons of waste are estimated to be left in the field ${ }^{6,7}$. When the rate at which these plants are harvested is considered, it is not hard to see that this process has an enormous, detrimental impact on the local environment.

According to the Consejo Regulador del Tequila (CRT), tequila was developed in the mid- $16^{\text {th }}$ century, when a Spaniard, after consuming all of his imported spirits, was desperate for a strong drink. The Blue Agave plants were used by natives for many applications, from roofing materials to ropes and mats to fuel for fires to soap. Even needles and punches were made from this useful plant ${ }^{5}$. It is believed that the conquering Spaniards noticed children chewing pieces of the hearts of the Blue Agave plants as a sweet treat. Once the high sugar content in the hearts of these plants was 
discovered, European distilling practices were quickly applied to the agave plants, and both tequila and mezcal were born. Tequila was outlawed by Spanish governors, as were all spirits not produced in Europe. Tequila and other spirits produced in colonial lands were eventually allowed to be distilled so that they could be taxed by colonial Spain in the $17^{\text {th }}$ century. The drink, eventually, helped fund Mexican independence from Spain in the late 1800s. In the 1940s American prohibition lead to increased exportation of tequila and, once popularity of the drink grew, so did the name tequila. Reports of "tequila" being made in Spain and France prompted the Mexican government to take action. In 1958, the Mexican government applied for, essentially, a patent on tequila known as the "Lisbon Agreement". This declaration was amended several times throughout the 1970s and into the 1980s. In 1994, the Mexican government formed the Consejo Regulador del Tequila (CRT) to govern the production of tequila, protect its integrity and assure its quality 1 .

The CRT states that at least $51 \%$ of the carbohydrates used to produce tequila must come from the Blue Agave piña, though good tequila is always made from 100\% Blue Agave. The agave must be grown in or near a small region in Mexico known as Jalisco, and the drink must be distilled and bottled in this region as well ${ }^{1}$. The first time that $100 \%$ Blue Agave tequila sales outpaced that of mixed or inexpensive tequila was 2008. That trend continued until 2013 when mixed tequila retook the largest share of production. Since $2016,100 \%$ Agave is back on top, and that trend holds true to date ${ }^{2}$. Each year since 2007, about one million metric tons of agave hearts are harvested to produce tequila; each heart weighs between 40 and $90 \mathrm{~kg}^{1}$. Estimates on the mass of waste leaves range from $50 \%$ to $75 \%$ of the total mass of the plant ${ }^{6,7}$. Since all Blue 
Agave that is used to produce tequila must be grown in the Jalisco region of Mexico as defined and enforced by the $\mathrm{CRT}^{1}$, the waste generated from these harvests is both enormous and regionally concentrated.

The leaves from Blue Agave plants that are raised in Jalisco for tequila production are, almost exclusively, left lying where they are cut off (Figure 1), or thrown into rivers or onto adjacent lands when the piñas are harvested ${ }^{8}$. The land on which these plants are grown is rocky and dry while the plants are fibrous and resilient; therefore, composting the leaves on the fields from which the plants are harvested is not effective. The thick skin that enable these plants to grow in hot, dry climates and the tough fibers that run throughout the leaves resist breakdown in the dry, rocky soil after the hearts are harvested. Though the leaves contain a large amount of sugars, as much as $9.7 \%$ reducing sugars by weight ${ }^{7}$, they are tough, fibrous and known to contain oxalic acid and calcium oxalate ${ }^{9}$. The toughness and the content of irritating, unpalatable compounds mean that these leaves are not desirable for livestock feed. Traditional applications like their use as roofing material, as firewood or for weaving into ropes and mats are no longer practiced on any sort of scale that would consume a significant portion of this waste ${ }^{3}$.

The work described in this thesis is, by no means, the first research done with the leaves from Blue Agave plants. About 5,350 articles were found in 0.10 seconds when a Google Scholar search was conducted for Blue Agave Leaf Waste on June 22, 2017. Less than one fourth of these articles were published more recently than five years ago, so these leaves have been studied extensively for a long time. From biofuels and alternative energy $6,8,10$ to paper production ${ }^{11}$ and genetics mapping ${ }^{12}$ for 
the preservation and protection of the species, Blue Agave has been and is being studied by many researchers.

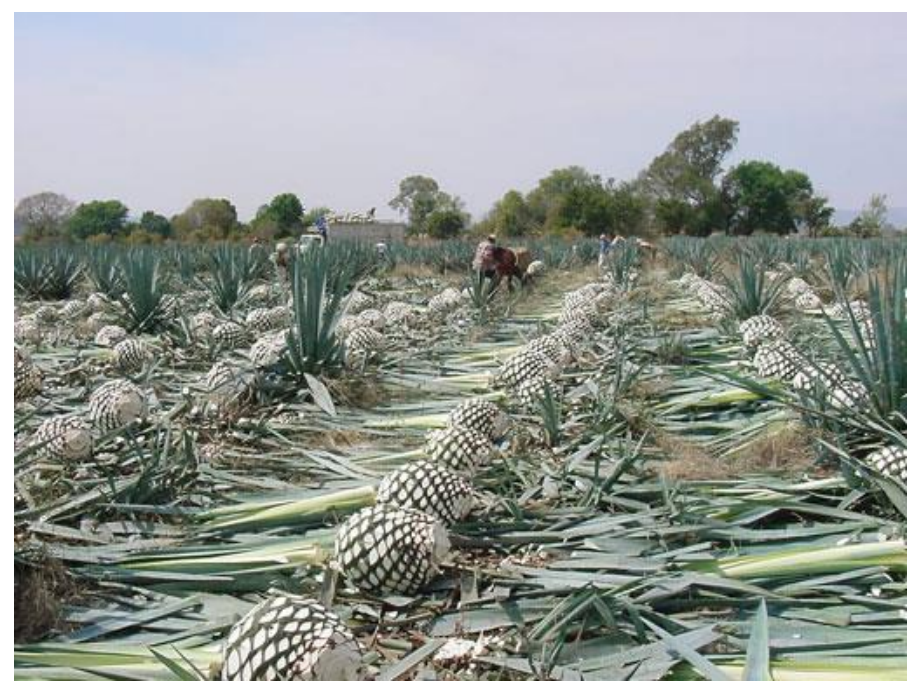

Figure 1. Picture of a Blue Agave Harvest. An approximate million metric tons of these piñas are harvested every year to produce tequila. An equal amount or more of waste is also generated ${ }^{5-7}$.

Though the topics of research on this plant are vastly different, most share a common characteristic: they focus on a single product or problem. The research described in this thesis, however, explores several different processes through which these leaves can be converted from a waste problem into valuable commodities. The processing of these leaves, specifically, pressing the juice from them and removing the skins allows for the production of many commodities. With the processes described herein, the juice is pressed from the leaves; sugars and other nutrients are, thus, removed from the leaf portions in the juice. This allows for the bio-conversion of the sugars into ethanol through fermentation with select yeast strains. Subsequently, in a second fermentation, ammonia and oils can be produced. The fibers from the leaves are left unaffected by fermentation and are sent to other areas of research like making 
paper ${ }^{11}$, reinforcing plastics ${ }^{13}$ or other building products ${ }^{14}$. The skins and the mycosporine like amino acids that they contain can be extracted and characterized; applications of these amino acids can be explored ${ }^{15}$. Maximizing applications for which each leaf can be utilized not only increases potential profit from this waste, it also increases the likelihood that collecting this waste for use will be attractive to land owners and farmers.

Before Spaniards ran out of hard spirits in the New World and were motivated to begin tequila distillation in Central America, they were sending "the food of the gods" or chocolate back to Europe ${ }^{4}$. Conquistadores took chocolate from the Aztecs, but the Mayans were the first to record the consumption of chocolate. Typically, Mayans drank chocolate and often it was used in betrothal and marriage ceremonies. Coincidentally, in all Mayan accounts of drinking chocolate, it is sweetened with agave nectar ${ }^{5}$. Spain held a monopoly on the European chocolate market for nearly a century, but it was not well received until sugar (sucrose) was added. Once the Spanish secret got out, this divine food quickly spread to French and English royal courts. The Industrial Revolution in Europe made drying and grinding the little brown beans affordable enough for common people to enjoy this "food of the gods"4.

Cocoa pods, from which the beans used to make chocolate come, are another crop that is still harvested as it has been for hundreds of years. Cocoa pods ripen perennially in equatorial rainforests; the 20 -cm-long, yellow to brown, football-shaped pods are picked off the trees from which they grow by farm laborers. The thin stems are carefully cut so as not to damage the pod, nor the delicate bark of the tree. Cocoa farms are all within $18^{\circ}$ of the equator and more than $90 \%$ of cocoa farms are small, 
family owned and operated establishments ${ }^{16}$. The cocoa tree (Theobroma cacao) does best at an average temperature range of $18^{\circ} \mathrm{C}$ to $32^{\circ} \mathrm{C}$, with an annual rainfall of 1.5 to 2.0 meters. The tree can tolerate only very short periods of drought, less than three consecutive months of rainfall less than $100 \mathrm{~mm}$ per month can be tolerated ${ }^{16}$. These trees are delicate; genetic mapping indicates that all three major cocoa tree varieties came from one parent species ${ }^{16}$. A shallow gene pool makes it difficult to breed in resistances to diseases caused by fungal and bacterial infections. The low tolerance to climactic variation, as well as susceptibility to disease and infection contribute to estimates of between $30 \%$ and $40 \%$ of crops being lost each year, worldwide ${ }^{4,16}$.

The cocoa industry, which produced about 3.5 million metric tons of cocoa in 2004 and has increased steadily since, estimates that the 2016/17 growing season will yield the largest harvest to date. They expect that approximately 4.5 million metric tons will be brought to market before this growing season ends ${ }^{3}$. This will also produce an estimated 13.5 million metric tons of waste in the form of cocoa pod husks over the same timeframe ${ }^{17}$. A small portion of this waste will be composted on the land where the cocoa beans were raised, harvested, fermented, dried and, finally, brought to market. While some of the husk can be composted to return some of the nutrients back to the soil, it rarely is; most family farms that raise cocoa are both secluded and impoverished. Without much contact with the outside world, modern composting methods, pesticides and fertilizers are not available to the people who own and work these small cocoa farms. Without knowledge of alternative uses for the husks and other waste generated by the cocoa harvests, husks are typically left to rot or piled up and burned $^{18}$. 
Cocoa pod husks, like the one shown in Figure 2, are split and discarded, almost always, at the small farms where they are raised. Traditionally, the beans are piled, covered with large leaves from banana trees or tarps and allowed to ferment for up to a week with the meat that clings to the beans still attached. This meat holds moisture and, when exposed to the equatorial rainforest environment, ferments naturally. It is believed that the native flies which feed on the cocoa meat carry microorganisms that thrive on this cocoa meat. The fermentation of the meat attached to the piled beans generates heat and an alkaline $\mathrm{pH}$ which removes some of the bitterness associated with freshly harvested cocoa beans. After open-air fermentation is complete, cocoa beans are spread out and dried in the sun. Once the moisture content of the beans is reduced as much as possible by these methods, usually to around $15 \%$, beans are transported to market and sold to cocoa production companies ${ }^{5,16}$. These companies have begun to build enormous cocoa processing facilities in the areas where cocoa pods are picked. However, while these factories process beans more efficiently, they make the husk waste a bigger problem, as the husks are concentrated in huge piles, miles away from the fields from which they were taken.

The enormity of the millions of metric tons of waste that constitute the cocoa pod husks discarded when cocoa beans are harvested make research into these husks an enticing undertaking. These crops are grown in areas where laborers earn only a dollar or two per week ${ }^{19}$; if value can be extracted from these husks, even a small amount, it could change many lives for the better. These beans have been cultivated for hundreds of years, attracting researchers and profiteers to search for applications of these discarded husks for many years as well. Published research from the 1970s may be 
the first time in which research shows that the husks can be processed for harvesting a commodity, specifically, the carbohydrate polymer known as pectin ${ }^{20}$. Prior to this work, the only applications located by a Google Scholar internet search on June 22, 2017 indicated that cocoa pod husks were being used as a low value poultry or sheep feed additive $^{21}$ and the ash as a soil buffering additive ${ }^{22}$. Processing the husks for a feed additive and for the pectin content are the extent of scholarly article publication topics until research into the husks gained popularity in the last 15 years.

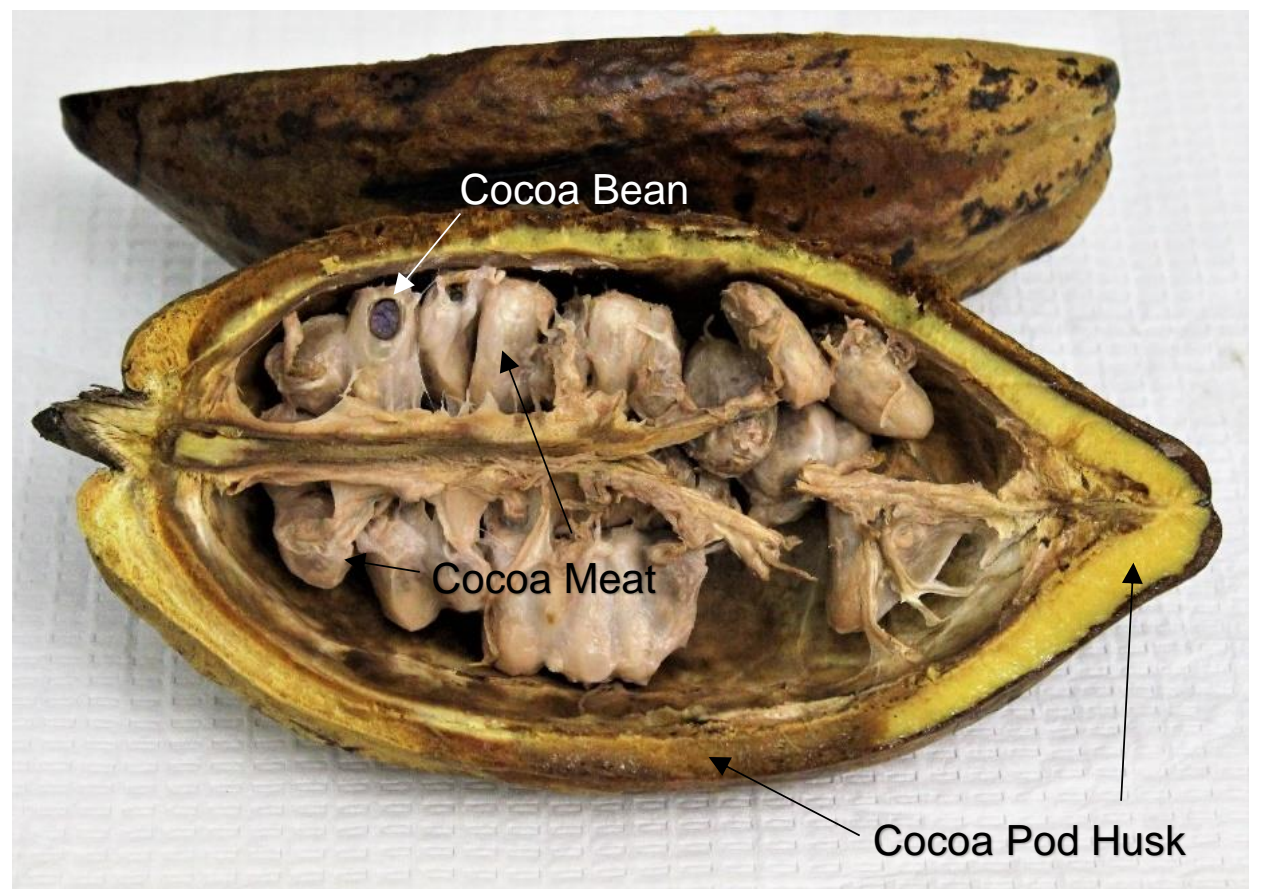

Figure 2. Picture of a Cocoa Pod. The cocoa pod used in this study before the beans and meat directly attached to the beans were removed.

Within the last 15 years, research into this major waste product of the cocoa industry has increased. Several disease outbreaks which greatly affected cocoa harvests prompted companies like Mars ${ }^{\circledR}$ and Hershey ${ }^{\circledR}$ to fund the mapping of the cocoa genome of two sub-species of cocoa tree. Enormous outbreaks of Black Pod Rot 
in Africa and Witches' Broom Disease in Central and South America raised concern by chocolate companies into diseases affecting cocoa trees and their prevention ${ }^{23}$. Upon successfully mapping cocoa tree genomes, the owners of the research published the results for all to learn from. Their motivation was the development of disease and pest resistance in this precious yet delicate crop. This increased interest and research into the development of disease resistance, pesticides and herbicides for the protection and preservation of the cocoa trees, pods and beans ${ }^{24}$ has prompted research into the use of the discarded husks to increase as well.

Research into the use of the waste generated from cocoa harvesting, namely cocoa pod husks, has also increased. Examples of continued attempts at using these husks as a low value, low nutrient filler in poultry ${ }^{25}$, sheep ${ }^{21}$, goat ${ }^{26}$ and cattle ${ }^{27}$ feeds are still being explored. Research into their use as a fish food additive is another area in which the husks have been studied recently. The husks have been studied as a substitute for corn in the diets of farm raised tilapia ${ }^{28}$ (Oreochromis niloticus) and farm raised catfish (Clarias isheriensis) ${ }^{29,} 30$ with apparent success. The test feed groups grow and reproduce similar to control fish populations in these studies. Fish of both species mentioned above that were raised on food pellets in which some of the corn was replaced by cocoa pod husk grew without significant difference in size or reproductive ability relative to the control fish populations ${ }^{28-30}$. In addition to feeding this product to fish and livestock, some researchers have used the husks to grow edible fungi ${ }^{31,32}$.

Fungal fermentations of cocoa pod husks by mushrooms have been conducted by research scientists. These fermentations are characterized by the drying of the 
husks, grinding them to a powder and rehydrating to a specific moisture content. The substrate is sterilized, evenly spread on sheet trays and covered. These solid substrate fermentations were carried out in open air with selected edible mushrooms. The studies are terminated after many weeks and focus on the added protein content of the solids; the application of these undertakings is in the improvement of the nutritive value of the husks as a feed additive. In addition to the fungus, supplements such as $\mathrm{Mn}^{2+}$ ions are also added to these fermentations. With such low nutritive value contained in cocoa pod husks $(\mathrm{CPH})$, supplements are added to improve the number of organisms that the substrate can support during fermentation ${ }^{31,32}$. In contrast to the other research being done with both agave leaf waste and $\mathrm{CPH}$, the research described in this thesis uses only the waste product and selected yeast species to metabolize these bio-wastes. For the purpose of this thesis, fermentation refers to metabolic activity of fungus and yeasts, and not specifically to ethanol production.

The yeast strains used to ferment these waste products in the first stage fermentations have been, essentially, designed for the job which they are being used to do. Both strains of $K$. marxianus used in this research were mutated from wild type $K$. marxianus ${ }^{33}$; they have been used to ferment a variety of substrates. The KM 7-1 and KM 8-1 yeasts have previously been used to ferment agave leaf waste solids, coffee waste solids and other sugar sources ${ }^{33,34}$. They have the ability to produce a variety of enzymes that enable them to metabolize a large variety of polysaccharides. This allows them to use sources of energy that are not available to other organisms. The ability of these yeast strains to utilize a variety of polymers present in many waste products give these yeast strains a unique advantage in the bioremediation field of research. In 
addition to the wide range of substrates which these $K$. marxianus yeasts can ferment, they possess additional qualities, such as heat stability and alcohol tolerance, which are desirable for this type of application ${ }^{33,34}$. Not only are metabolic products that are produced by the yeast of interest, like ethanol and ammonia, but also enzymes that they produce, and the yeasts themselves.

As well as being able to ferment a variety of substrates, these $K$. marxianus yeasts are quite robust species. Strains KM 7-1 and KM 8-1 both possess high heat tolerances. In large-scale fermentations, heat is often generated; in order for organisms to be an effective means of bioremediation, they must be able to withstand the conditions of the fermentation. In addition to high heat tolerance, a broad $\mathrm{pH}$ tolerance range can be necessary for organisms that ferment these polysaccharides. Both $K$. marxianus species tolerate a wide temperature range, a wide $\mathrm{pH}$ range ${ }^{33}$, and preliminary fermentations with these substrates suggested that they compete very well with other species which thrive in these conditions. While the substrates were sterilized for research described in this thesis, both $K$. marxianus strains thrived in preliminary fermentations that were not sterilized before inoculation. While the species used in the second stage fermentations is not considered as robust as are those used in the first stage, it was developed for the job that it is used to do ${ }^{35}$.

The Yarrowia lipolytica $F$ yeast used in the second stage of fermentation was mutated from its wild type parent for the purpose of metabolizing proteins ${ }^{35}$. This yeast species does not ferment a vast variety of substrates, nor does it possess a high tolerance for heat or $\mathrm{pH}$. This strain was designed to metabolize proteins; often the protein source, in addition to the protein present in the waste substrate, is in the form of 
yeasts used to perform the first stage fermentation. The purpose of this strain of yeast is to produce ammonia and oils from protein sources in the substrate being fermented ${ }^{34,35}$. This second fermentation is the next step in an effort to maximize consumption of bio-wastes and increase the number of harvestable commodities from fermentation broths as well as to continue the bioremediation process.

Green practice in industry is no passing trend; it is becoming a permanent, critical component of all industrial practices. More responsible use of assets has begun to reach even the most traditional of processes like those used in the tequila and cocoa industries. In 2015, the tequila industry left nearly a million metric tons of waste in the fields of Blue Agave farmers ${ }^{7}$. The leaves left in agave fields and the husks that form decomposing piles outside of cocoa processing facilities hold tremendous potential ${ }^{15}$, and can be converted into commodities which would increase profits, lessen the impact on the environment and greatly improve the efficiency of these processes.

Blue Agave leaves are a potential source of many valuable commodities.

These currently unused leaves are reported to contain approximately $9.7 \%$ by weight reducing sugars ${ }^{7}$, some of which are incorporated into a polysaccharide known as inulin, which is predominantly comprised of fructose ${ }^{36}$. Pressing these sugars and other water-soluble nutrients from the leaves before incubating the juice with yeast has been shown to be beneficial to incubation in preliminary studies. Utilization of this sugar is crucial for the bioremediation of this waste; therefore, a yeast that is known to produce an inulinase enzyme is the best choice for an organism that will be used to metabolize the juice that is pressed from these leaves. The skin and solid portions of the leaf have been shown to possess potential for application in a wide variety of uses like the 
mycosporine-like amino acids in the skin and their potential for use as UV light absorbing or platform molecules ${ }^{15}$. The tough fibers that run the length of the leaves which were once used for traditional textiles and ropes have been shown to hold value as reinforcing and weight reducing components in plastics. Their effectiveness as a reinforcing additive to plastics has recently caught the attention of the Ford Motor Company. Recently a partnership was announced between tequila giant Jose Cuervo and Ford Motor Company to use the fibers from Blue Agave leaves as a reinforcing component for plastics to be used in Ford vehicles ${ }^{13}$. These robust fibers were used by native people to make mats and ropes in pre-colonial Central America before the Spaniards started making tequila with the heart of the plant; this discovery permanently changed the fate of the plant and the people who used it ${ }^{1}$.

These fibers are unaffected if the juice is incubated with yeast instead of fermenting the whole leaf. The mycosporine-like amino acids that can be extracted from the skin of the plant, when collected before the juice is pressed from the leaves, are not degraded during incubation. These may show promise as photostabilizers or sunscreen molecules as they absorb harmful, UVA light ${ }^{15}$. The enzymes produced during incubation and metabolic products from the yeast, as well as the yeast themselves, remaining proteins, ethanol, ammonia and oils found in the end product of the incubations all hold potential value ${ }^{15,37-39}$. These possible sources of income from items that are currently regarded as waste make analyzing these agave leaves and cocoa pod husks, as well as the incubation products of the husks and the juice pressed from the agave leaves, the focus of this thesis. 


\section{CHAPTER II: MATERIALS AND METHODS}

\section{Blue Agave Leaf Juice Preparation}

The Blue Agave leaves used in this study were supplied by Dr. Stephen Hughes from the United States Department of Agriculture. This live, mature Blue Agave plant had been recently harvested in the Jalisco region of Mexico. Upon receipt of the whole Blue Agave plant at ISU, it was photographed and processed. The leaves were removed from the piña with a large knife, and the spikes at the edges and ends of each leaf were removed. The leaves were cut into sections, then frozen and stored at $-80^{\circ} \mathrm{C}$ until used ${ }^{15}$. When a fermentation was planned, a few leaf pieces from the base, middle portion and tip of the leaf (Figure 3) were taken from frozen storage, sealed and thawed in the walk-in cooler at $4^{\circ} \mathrm{C}$ while the starter cultures were being incubated.

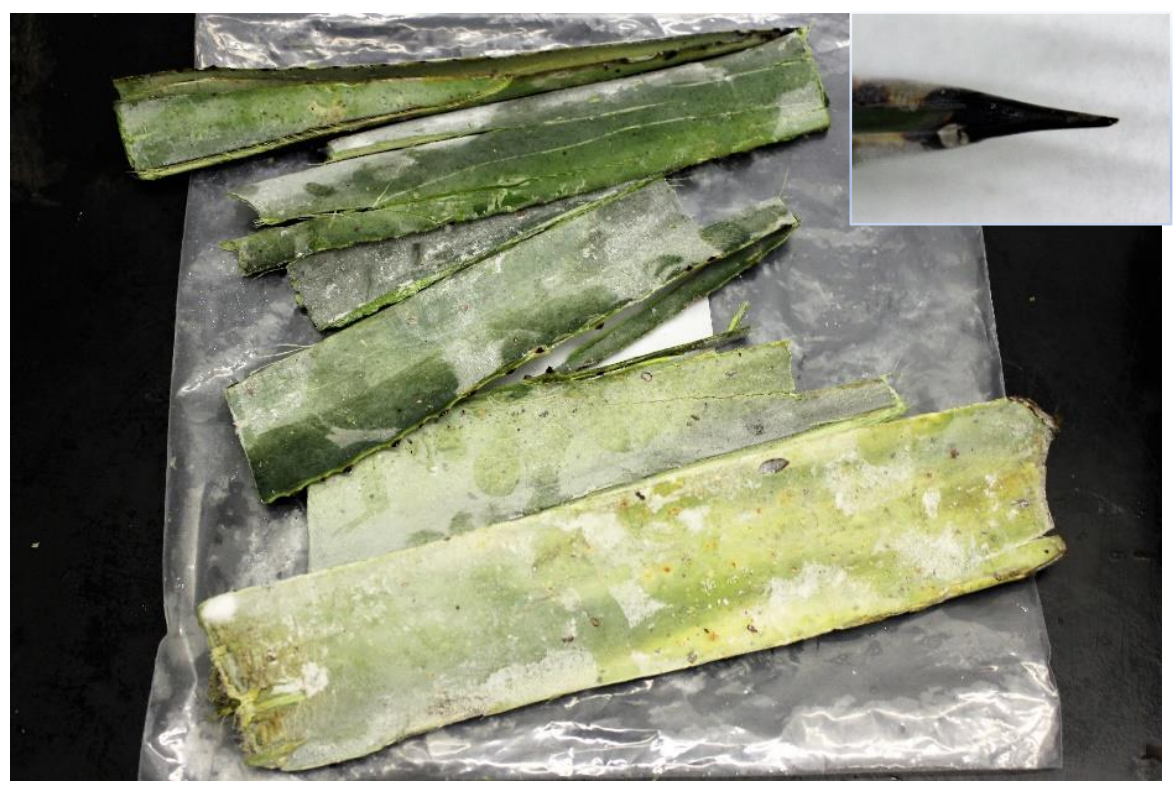

Figure 3. Picture of Blue Agave leaf pieces. Blue agave leaf pieces from the base, middle and tip of a leaf were used. Some of the leaf pieces still have a few thorns, including the tip of an agave leaf (shown in inset). The tips and thorns were removed and discarded for the current research. 
Once the leaves were sufficiently thawed, they were then pressed to obtain the juice. Initially, the leaves were pressed in an improvised juicer, which consisted of a new, clean mop-wringer as shown in Figure 4 (a). However, before these larger scale fermentations were carried out, it was determined that wringing the leaves out by hand was the most efficient way of obtaining the juice [Figure 4 (b)]. Initially, wringing by hand following mechanical pressing was the method used but eventually, the leaves were not pressed mechanically, as it did not seem to improve the volume of juice collected. Freezing and thawing the leaves facilitated obtaining juice in this manner, but did not appear to compromise the integrity of the leaf fibers. However, future work should assess this more rigorously. Once the juice was obtained, the volume was roughly measured, then it was sterilized in an autoclave ( 21 minutes, $20 \mathrm{psi}, 250^{\circ} \mathrm{F}$ ) and divided into sterile fermentation flasks under sterile conditions. The sterilized, divided juice was either inoculated with yeast strain KM 7-1 or KM 8-1 fermentation starters or no cell addition as a control, each as 3 replicate flasks. Stock samples of these yeast strains were collected from storage and growth medium consisting of yeast extract, peptones and dextrose (YPD) in water was inoculated with a colony collected from $K$. marxianus 7-1 or K. marxianus 8-1(KM 7-1 and KM 8-1, respectively) and grown in an incubator at $37^{\circ} \mathrm{C}$ and constantly shaken at 200 RPM. 


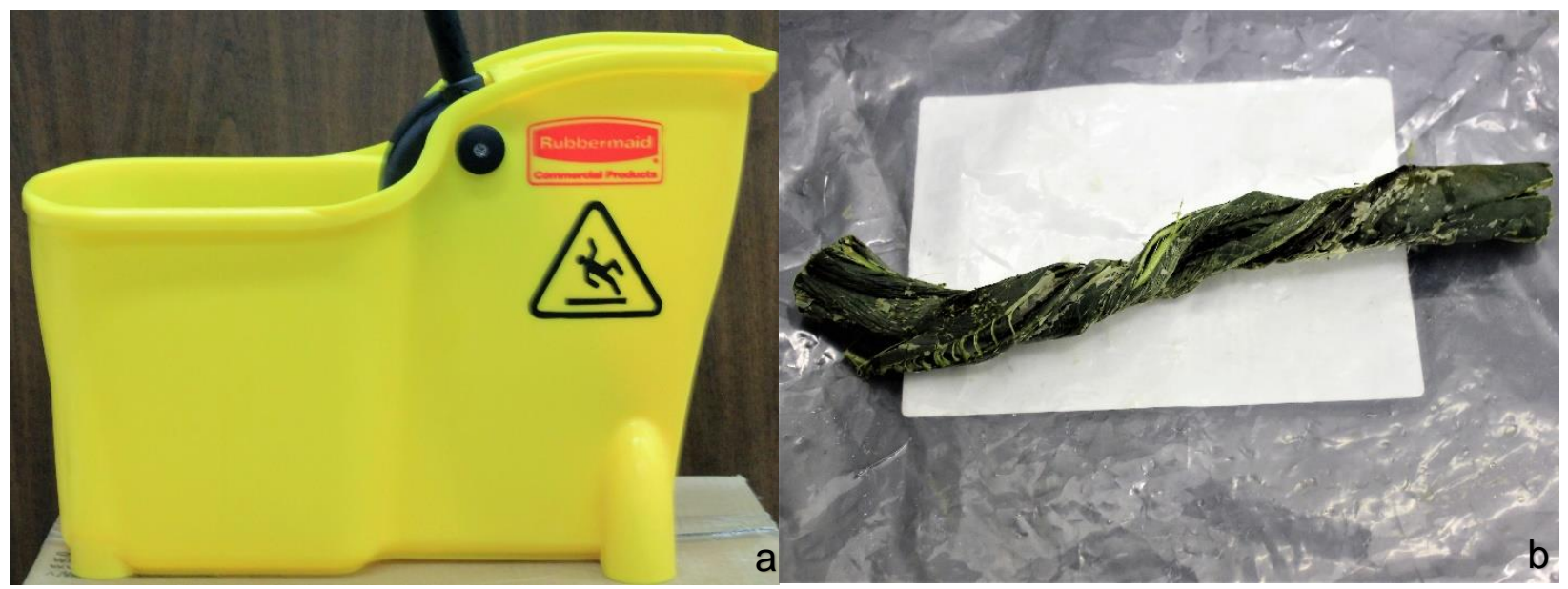

Figure 4. Picture of Blue Agave leaf juice extraction methods. (a) Initially, juice from Blue Agave leaves was obtained with a makeshift juicer; comprised of a mop wringer and bucket. This worked, but not as well as simply wringing the thawed leaves out by hand. (b) Hand wringing the leaves was the method used for the fermentations in this work; the leaf on the right was processed by the hand method.

After 1 to 4 days, these incubations are ready to be used as fermentation starters. In order to standardize inoculations, optical densities were measured with starter culture samples as described below. With similar spectrophotometric responses and identical, controlled conditions under which they were incubated, yeast populations in multiple flasks are assumed to be reasonably comparable.

\section{Cocoa Pod Husk Preparation}

The cocoa pod husk used in this study was supplied by Dr. Stephen Hughes from the United States Department of Agriculture. Dr. Hughes sent the whole, frozen cocoa pod (harvested in Ghana) to Dr. Marjorie Jones of Illinois State University to be studied in her research laboratory. Upon receipt of the whole cocoa pod, it was photographed, and measured; the pod was sliced open and the cocoa beans were removed; the husk was weighed, frozen and stored at $-80^{\circ} \mathrm{C}$ until it was used. To 
prepare for fermentation, the husk was sliced into sections, weighed, then finely sliced, separated, and suspended in nano-pure water (Figure 5). Three replicate flasks were set up for each treatment. Then this suspension was sterilized by autoclave (21 minutes, $20 \mathrm{psi}, 250^{\circ} \mathrm{F}$ ). Once this sterilization was finished and cooled to room temperature, the cocoa pod husk in water was incubated with yeast strain KM 7-1 or KM 8-1 or no cells were added as a control. Stock samples of these yeast strains are collected from storage; YPD growth medium was inoculated with a colony collected from KM 7-1 or KM 8-1 stocks. The YPD medium containing yeast cells was then placed into an incubator at $37^{\circ} \mathrm{C}$ and constantly shaken at $200 \mathrm{RPM}$. After 2 to 4 days, these incubations are ready to be used as fermentation starters. In order to standardize inoculations, optical densities of starter culture samples were measured with spectrphotometry as described in the fermentation preparation section below. With similar spectrophotometric responses and identical, controlled conditions under which they were incubated, yeast populations in multiple flasks are assumed to be reasonably comparable ${ }^{15}$.

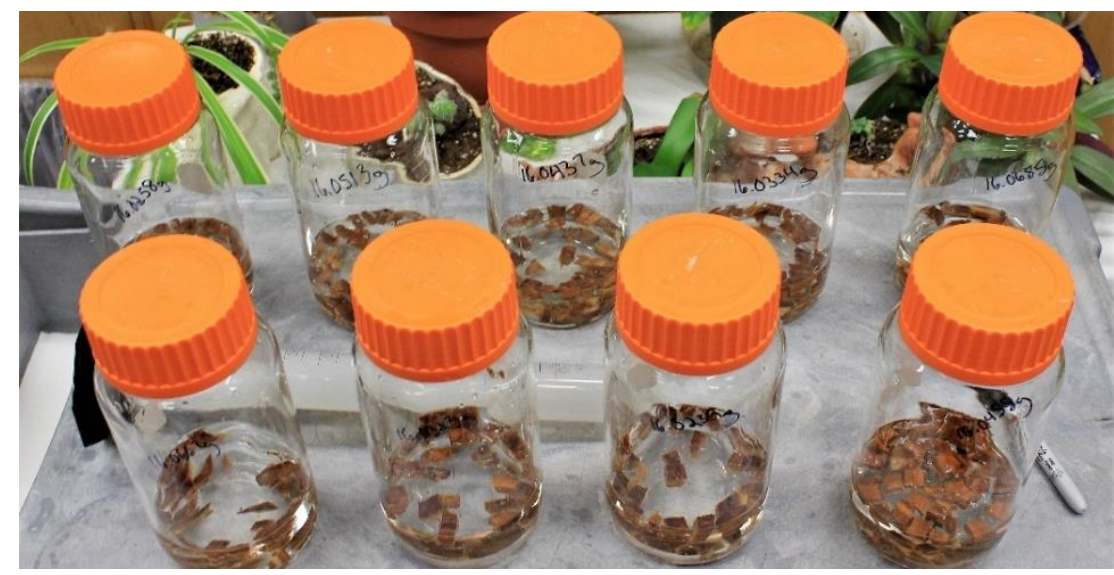

Figure 5. Picture of cocoa pod husk pieces in water. The cocoa pod husk (CPH) had been thawed, weighed, divided and suspended in nanopure water. Once autoclaved and cooled, the CPH was inoculated with one of two strains of yeast, or used as a control with no cells added. 


\section{Fermentation Preparation}

In preparation for a fermentation, the Blue Agave leaves or cocoa pod husk were

thawed. Starter cultures of yeast strains, taken from stock cultures, were inoculated into yeast growth medium sterilized by autoclave ( 21 minutes, $20 \mathrm{psi}, 250^{\circ} \mathrm{F}$ ) which consists of Yeast extract, peptones, and dextrose (YPD) (Bacto ${ }^{\mathrm{TM}}$, Becton, Dickinson and Company, Sparks, Maryland, 21152, USA) in nanopure water (10 g: $20 \mathrm{~g}: 20 \mathrm{~g}: 1 \mathrm{~L})$. The KM 7-1 and KM 8-1 stocks were grown and maintained on solid support petri dishes with YPD-plus- 2\% agar growth medium (YPD + $20 \mathrm{~g}$ agar / L). A single colony from each strain was used to inoculate $15 \mathrm{~mL}$ of sterile YPD growth medium in separate sterile flasks. A flask that contained the same amount of sterile growth medium, but no added yeast cells, was also prepared to be used as a control and to scrutinize possible contamination. The three flasks were placed into an incubator (200 RPM, $37^{\circ} \mathrm{C}$ ) and allowed to grow for 30 to 96 hours until used to inoculate the substrate to be fermented.

Both substrates (CPH or agave) were prepared for fermentation in a similar manner, aside from the division of the substrate. The solid CPH was divided and suspended in nanopure water before sterilization (Figure 5), while Blue Agave juice was sterilized in one large container, then divided with aseptic technique just before it was inoculated (Figure 6). The solid pieces of $\mathrm{CPH}$ can be divided more consistently if it is done before suspending them in water. The juice was divided after sterilization to allow for the use of appropriate sized fermentation vessels. Sterilization of liquids in an autoclave requires a container that is three times the size of the liquid it holds; therefore, a $125-\mathrm{mL}$ flask is not large enough to sterilize $60 \mathrm{~mL}$ of juice. 
Once the substrate was ready to be fermented, the fermentation yeast starter cultures were collected. An approximately $1 \mathrm{~mL}$ sample from each of the three flasks was collected under sterile conditions and transferred to a cuvette for analysis by spectroscopy. The control flask sample (no cells) was used as the blank. The spectrophotometer (Hewlett Packard ${ }^{\mathrm{TM}} 8453$ Spectrophotometer, HPCORE ChemStation $^{\text {TM }}$ software; HP Inc. 1501 Page Mill Road, Palo Alto, CA, 94304, USA) was used to determine optical densities at $600 \mathrm{~nm}$ which is dependent on the number of yeast cells present. The more cells present, the more light is scattered, thus the larger the spectrophotometric value. This measurement is, therefore, a measure of light scattering and not absorbance. Km 7-1 and KM 8-1 starter cultures were subsequently diluted with control medium until they had the same $A 600 \mathrm{~nm}$ response of 1.0 so that they both, presumably, contain a similar number of cells. These diluted samples were then used to inoculate the $\mathrm{CPH}$ suspension or agave juice to begin fermentation ${ }^{15}$.

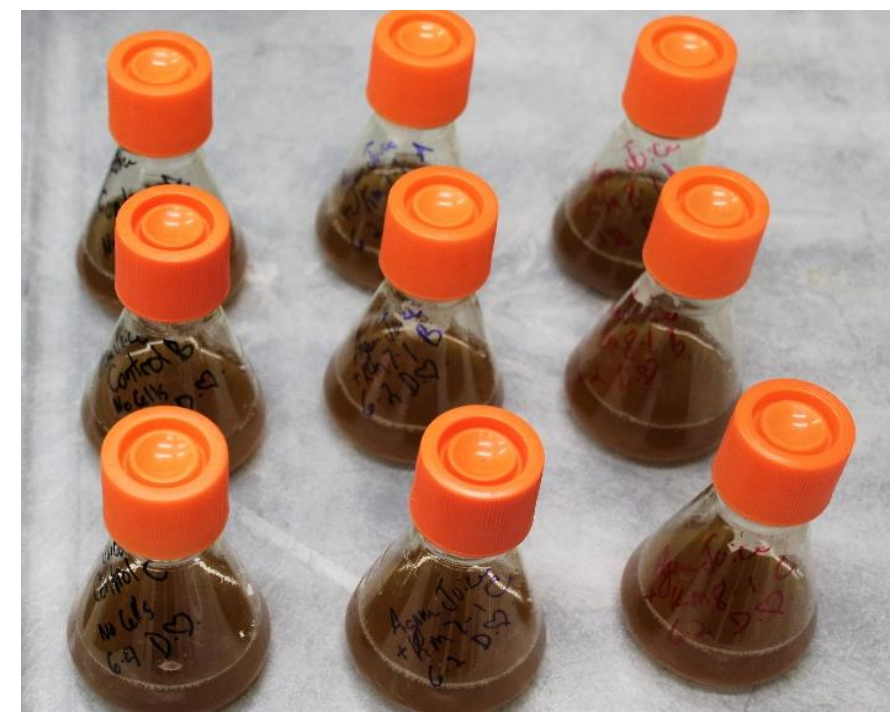

Figure 6. Picture of sterilized Blue Agave leaf juice. The juice was sterilized in a single container, then divided under sterile conditions. Once equally divided, the juice was inoculated with yeast or used as control into which no cells are added. 
A total of 18 fermentations were carried out for the purpose of this study; nine fermentations with $\mathrm{CPH}$ as a substrate and nine fermentations in which Blue Agave leaf juice was the substrate. All fermentations were allowed to progress for 72 hours from the point at which the yeast cells were inoculated into the substrate. Four-mL samples were collected at $0,6,12,24,48$, and 72 hours after inoculation for all fermentations. All fermentations were terminated by placing the fermentation flasks into the $-80^{\circ} \mathrm{C}$ freezer. In all CPH fermentations, the target mass of husk was $16 \mathrm{~g}$, and the average mass $(n=9)$ used was $16.0435 \pm 0.0164 \mathrm{~g}$. With $\mathrm{CPH}$, every gram of substrate is suspended in $15 \mathrm{~mL}$ of nanopure water; therefore, each 16-g portion of husk was suspended in $240 \mathrm{~mL}$ of nanopure water. These $\mathrm{CPH}$ fermentations were carried out in 1-liter, large mouth, screw top, Pyrex® fermentation flasks. The nine Blue Agave leaf juice fermentations were carried out in $125-\mathrm{mL}$ sterile, polystyrene Erlenmeyer Flasks with non-vented screw caps. Each flask contained $60 \mathrm{~mL}$ of sterilized agave leaf juice; the juice was pressed, collected and sterilized in a single container, then divided using a sterile $25 \mathrm{~mL}$ pipette by transferring $20 \mathrm{~mL}$ three times into each flask.

\section{Yeast Strains Selected}

The yeast strains selected for use in this work are K. marxianus 7-1 and K. marxianus 8-1 (KM 7-1 and KM 8-1 respectively). These strains were mutated from wild type Kluyveromyces marxianus ${ }^{33}$; which is one of many yeast strains used in the fermentation of Blue Agave in the production of tequila ${ }^{3}$. In addition to the ability to produce inulinase, an enzyme necessary to metabolize inulin, these yeast strains also produce a pectinase enzyme which enables the yeast to metabolize the pectin 
contained in $\mathrm{CPH}$. Additionally, both strains possess high heat tolerance which is important for industrial application, as heat is generated in large-scale fermentations. All these traits are desirable for fermentation of this waste product on an industrial scale $33-35$.

\section{Fermentations}

Fermentations were carried out under constant shaking (200 RPM) and at $37^{\circ} \mathrm{C}$; fermentations were allowed to progress for three days from the time they were inoculated with selected yeast strain. A total of 18 fermentations were conducted and are described in this work; nine fermentations were performed on the agave juice, and nine used $\mathrm{CPH}$ as the substrate. Samples were collected under sterile conditions at 0 , $6,12,24,48$ and 72 hours. Colony forming unit (CFU) plates were made immediately after sample collection with undiluted samples or serial dilutions (in sterile water) of the samples using petri dishes containing YPD-plus-agar growth medium following the method of Hughes et al. ${ }^{33}$. After the CFU plates were made, they were incubated at $37^{\circ} \mathrm{C}$ until evaluated for number of colonies.

\section{Sampling}

Sampling of fermentations was carried out with sterilized Pasteur Pipettes and sterilized, two-mL micro-centrifuge tubes. At 0, 6, 12, 24, 48 and 72 hours post yeast addition, four-mL samples were collected from each fermentation vessel. The collected samples were placed into two sterile two-mL micro-centrifuge tubes and labeled. Samples were separated by centrifugation (12,500 rpm, 2 minutes; EppendorfC 
Centrifuge 5415 C, Eppendorf North America, 102 Motor Parkway, Hauppauge, NY, 11788, USA). The supernatant was decanted from the pellet, and separated samples were labeled and frozen at $-80^{\circ} \mathrm{C}$ until the supernatant was further analyzed for reducing sugars, protein, saccharides and ethanol. For this thesis, only supernatant fractions were analyzed and reported.

The sterilized cocoa pod husk in water became difficult to sample with typical pipettes used to obtain a sterile sample because the husk readily broke down in water. To avoid clogging of the pipette used to sample the $\mathrm{CPH}$ in water, a Pasteur pipette was notched with a glass cutter and broken off such that the opening was large enough to prevent the small pieces of the $\mathrm{CPH}$ from clogging the pipette opening as shown in Figure 7. Both shortened pipettes and unmodified pipettes were wrapped in aluminum foil, labeled, sterilized by autoclave and stored in a sterile environment until used to sample the $\mathrm{CPH}$ fermentation. All other aspects of $\mathrm{CPH}$ fermentation sampling was identical to sampling the agave juice fermentations.

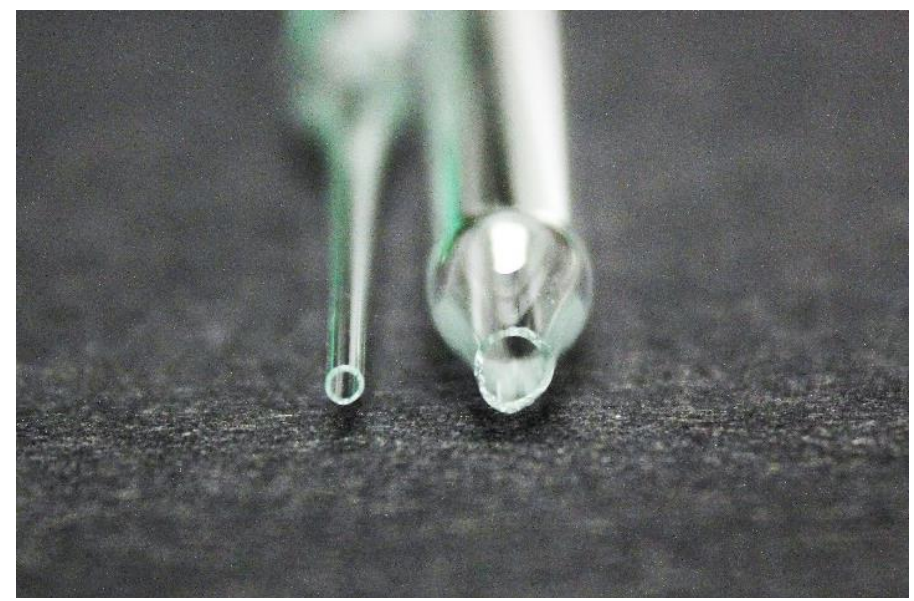

Figure 7. Picture of Pasteur pipettes used for sample collection. Pasteur pipettes used to collect samples from fermentations. Unmodified pipettes (left) were used to collect agave leaf juice fermentations while modified pipettes (right) were used to collect $\mathrm{CPH}$ fermentation samples. 


\section{Analytical Methods Employed}

The most quantitative method for analyzing the fermentations in terms of the number of viable yeast present in the fermentation is the colony forming unit (CFU) technique, following the method of Hughes et al. ${ }^{33,34}$. The plates are made from YPDplus-agar in sterile petri dishes. Agar is used because these yeasts do not possess enzymes necessary to metabolize the agar, therefore, the yeast cultures stay on top of the firm, gelatinous medium. Colonies can be easily counted for colony forming units, as Figure 8 shows, and checked for contaminating species; additionally, yeast stocks can be maintained so that working cultures can be generated from them. CFU plates are made by first collecting a sample from the fermentation vessels; the sample is either applied to the plate undiluted, or a serial dilution is performed with sterile, nano-pure water. Once the desired dilution is obtained, $10 \mu \mathrm{L}$ is spotted onto the center of a sterile petri dish containing the YPD-plus-agar growth medium, and spread with a sterile plate spreader like the one shown in (Figure 9). The CFU plate is then covered with the lid, sealed with Para-film $\AA$, labeled and placed into an incubator at $35^{\circ} \mathrm{C}$ until the colonies grow sufficiently to be visible and then are counted. It is assumed that each symmetrically round colony arose from a single, viable yeast cell. When CFU plates are made, the label includes, among other information, the dilution factor. Once the plates are evaluated after the incubation period, the number of colonies, amount spotted onto the plate and the dilution factor are used to calculate the concentration of cells in the original sample. 


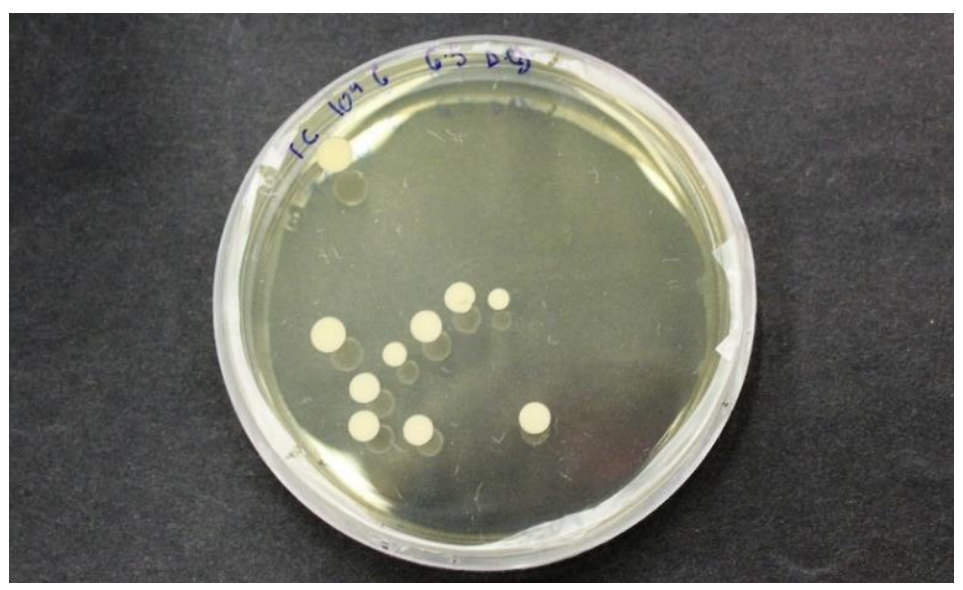

Figure 8. Picture of colony forming unit plate. This CFU plate was made with solid growth medium and a diluted fermentation sample. Each round colony is assumed to arise from a single, viable yeast cell. This plate, then, would indicate ten colonies.

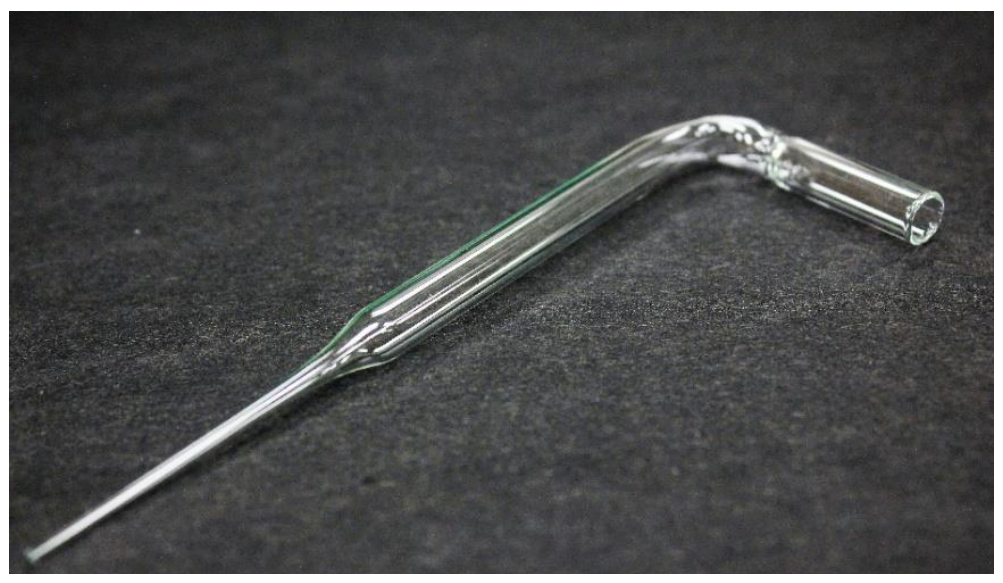

Figure 9. Picture of plate spreader. CFU plates were made by spreading samples on solid growth medium. This spreader was made by heating a Pasteur Pipette with a Bunsen Burner until soft enough to bend with forceps and an insulated glove. They were sterilized by autoclave and sealed until use.

Reducing sugar concentrations in the samples were measured by using dinitrosalicylic acid and the DNS Reducing Sugar Assay ${ }^{40}$. The name of this assay is derived from the active molecule in the assay: 3,5-DiNitro Salicylic acid (DNS). A reducing sugar is any sugar that can mutarotate, or undergo ring opening and closing in solution. When a reducing sugar is suspended in solution it can open; this ring opening 
exposes a reactive aldehyde or ketone. According to the description of this assay, the basic conditions of the reagent causes ketones, like fructose, to isomerize to an aldehyde ${ }^{40}$. This reactive aldehyde is easily oxidized and, in turn, reduces the molecule with which it reacts. With the DNS assay, $500 \mu \mathrm{L}$ of 3,5-dinitrosalicylic acid in basic solution is added to a sample. This solution is heated in boiling water for five minutes. The 3,5-dinitrosalicylic acid is reduced to 3-amino-5-nitro salicylic acid and the maximum absorbance of the molecule shifts to $575 \mathrm{~nm}$. Spectroscopy is performed on the resulting solution and a quantitative assessment of the concentration of reducing sugars in a sample can be calculated with a calibration curve made from known concentrations of a standard reducing sugar, fructose. The DNS reagent does not interact with complex carbohydrate molecules, such as inulin ${ }^{40}$. Each sample to be analyzed was diluted to three concentrations that fell on the linear portion of the trend line from a calibration curve made with a fructose standard and the DNS reducing sugar assay. The equation of the trend line, dilution factor and A $575 \mathrm{~nm}$ response from a DNS reducing sugar assay were used to calculate concentrations of reducing sugars in samples. One of the calibration curves used to calculate the concentration of reducing sugars in samples is included below (Figure 10). 


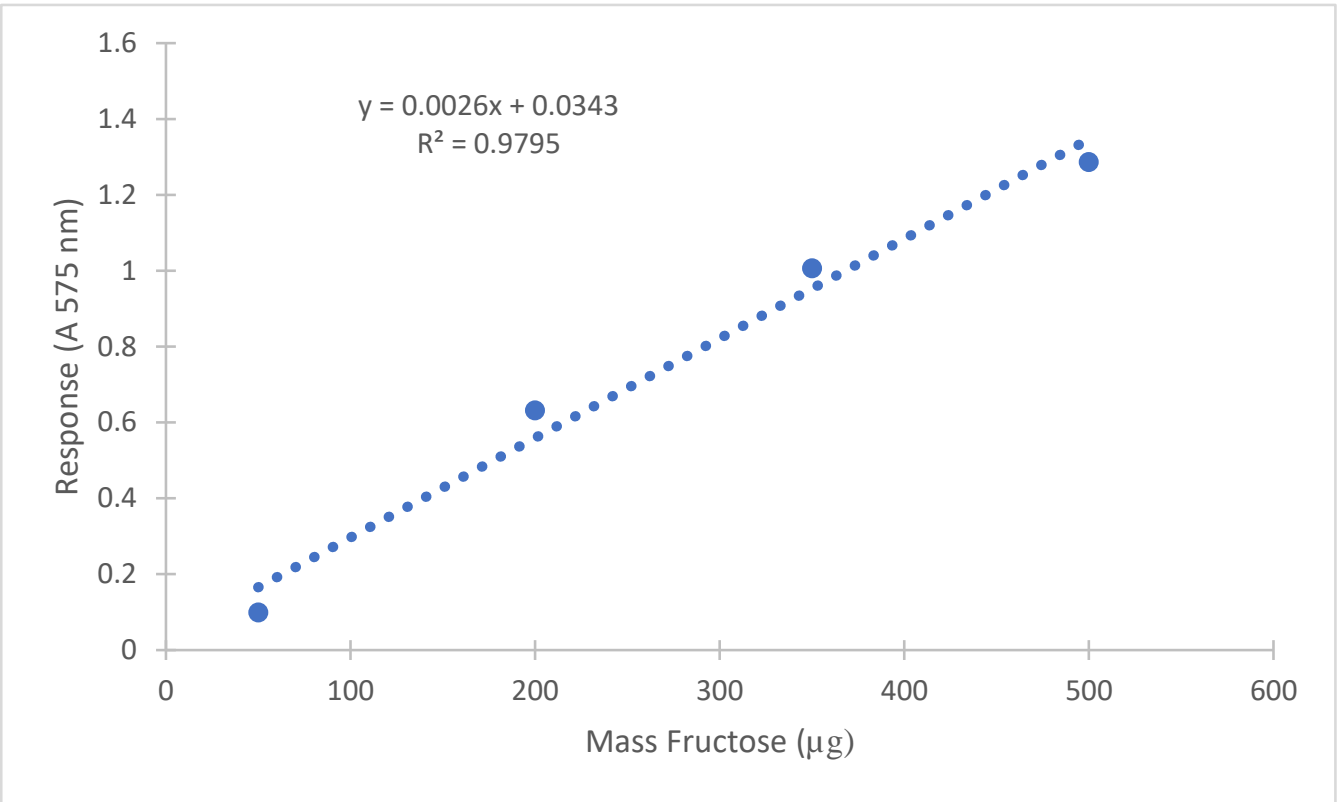

Figure 10. Graph of reducing sugar calibration curve. This graph was made with known masses of fructose and DNS reducing sugar assay. The equation of the trend line and known sample volumes were used to calculate reducing sugar concentrations in agave leaf juice or $\mathrm{CPH}$ in water fermentation samples.

Soluble protein concentrations were also monitored through spectroscopy, with the use of the BioRad(B Protein Assay and bovine serum albumin (BSA; $1 \mathrm{mg} / \mathrm{mL}$ water) as a standard. To determine protein concentration, the BioRad® reagent (Coomassie $\AA$ Brilliant Blue G-250 dye in acidic solution) was added to a sample and allowed to react at room temperature for at least five minutes. This dye, in the presence of basic and aromatic amino acids, undergoes a color change from a reddish color to a brilliant blue color. The change in color is accompanied by a shift in the maximum absorbance of the dye from $465 \mathrm{~nm}$ to $595 \mathrm{~nm}$ and is linear over a ten-fold concentration range. The use of a standard curve and application of Beer's Law allows calculation of the concentration of soluble protein in a sample ${ }^{41}$. Samples were, again, diluted to three different concentrations that fell within the linear portion of the trend line produced with 
the calibration curve and known amounts of BSA. The equation of the trendline and known dilution factor were used to calculate the concentration of soluble protein in samples from their A $595 \mathrm{~nm}$ response. One of the calibration curves used to calculate soluble protein concentration with a $\mathrm{CPH}$ in water fermentation is included below (Figure 11).

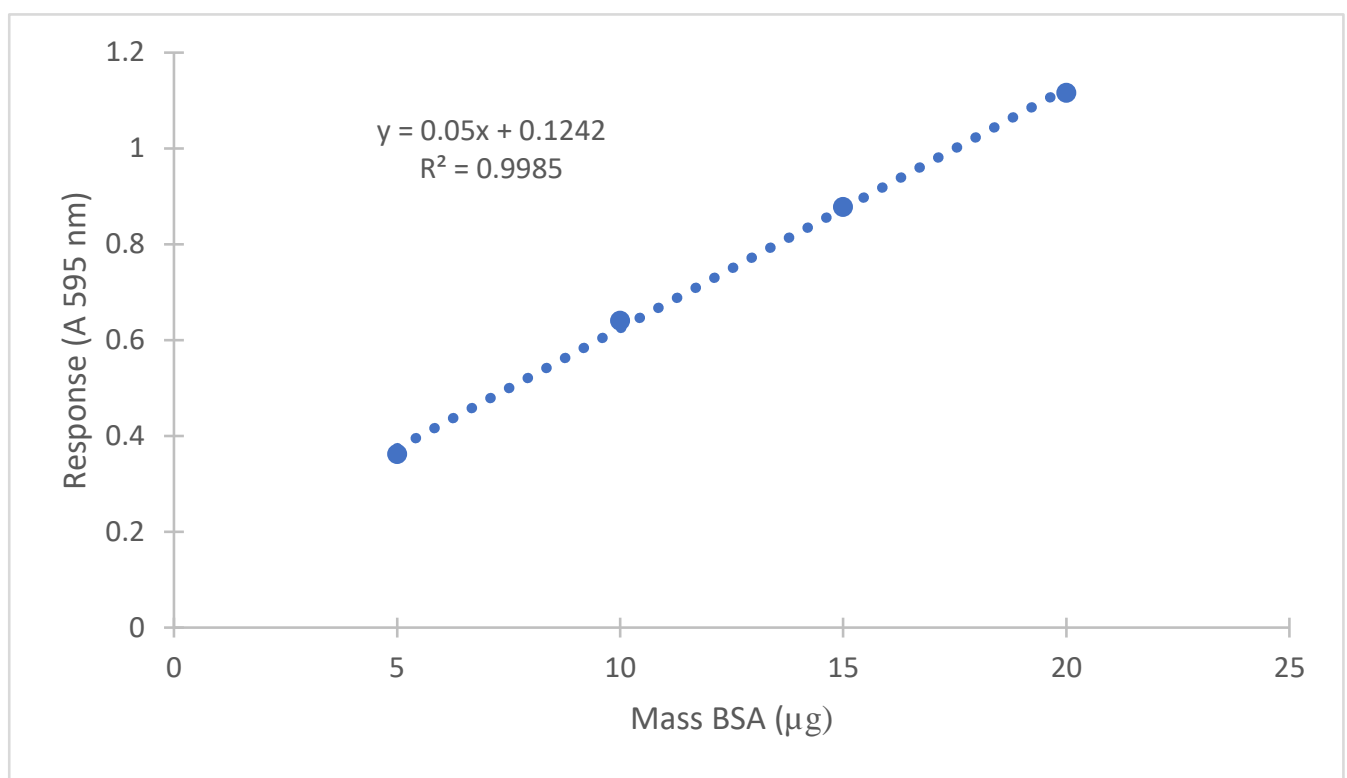

Figure 11. Graph of soluble protein calibration curve. This graph was made with BioRadB Protein Assay and known masses of BSA. The equation of the trend line and known sample volumes were used to calculate soluble protein concentration in samples collected from agave leaf juice or $\mathrm{CPH}$ in water fermentation samples.

Ethanol concentrations were analyzed by Mr. Mitch Lindquist of the USDA through High Performance Liquid Chromatography (HPLC) after he received the collected, frozen samples from fermentations at ISU. Supernatants from centrifuged samples were diluted with deionized water and analyzed using an HPLC separation system. This HPLC system consists of a solvent delivery system (P2000 pump, Spectra-Physics, San Jose, CA) with an autosampler (717, Waters Chromatography 
Division, Millipore Corp., Milford, MA) and a computer software based integration system (ChromQuest ${ }^{\text {TM }}$ 4.0, Spectra-Physics, San Jose, CA). Samples were injected into an ion moderated partition chromatography column (Aminex HPX 87H with Cation $\mathrm{H}$ micro-guard cartridge; Bio-Rad Laboratories, Inc., Hercules, CA) that is heated to $65^{\circ} \mathrm{C}$. Samples were eluted with $5 \mathrm{mM} \mathrm{H}_{2} \mathrm{SO}_{4}$ at a flow rate of $0.6 \mathrm{~mL}$ per minute and identified with a refractive index detector (410 differential refractometer, Waters Chromatography Division, Millipore Corp., Milford, MA). Peaks generated from the samples were identified and quantified by comparison to peaks generated from known standards ${ }^{42}$.

Thin layer chromatography (TLC) was used to assess the presence or absence of sugars, both polysaccharides and monosaccharides, as well as ninhydrin positive substances in samples. Standards used were inulin derived from chicory, pectin derived from orange peels, laboratory grade fructose, and bovine serum albumin (BSA), all at a concentration of one $\mathrm{mg}$ per $\mathrm{mL}$ in water. The TLC plates used were precoated, aluminum backed TLC sheets of silica gel 60 without fluorescence indicator, evenly spread in a layer at a thickness of $0.2 \mathrm{~mm}$ (EM Laboratories, Elmsford, NY, 10523). The mobile phase used to separate these supernatant solutes was 1-butanol: methanol: cyclohexane at a ratio of $7: 4: 2(\mathrm{v}: \mathrm{v}: \mathrm{v})^{15}$

Samples were spotted onto the TLC plate using 2 or $3 \mu \mathrm{L}$ at a time and allowed to air dry between application; 2, 3 or $6 \mu \mathrm{L}$ total sample was used per spot. Lanes were marked and labeled on TLC sheets cut appropriately to accommodate the number of samples to be analyzed. The plates were placed on the edge to which the samples were applied, in a covered chromatography chamber which contained the solvent 
described above and a large filter paper behind the plate, wet with solvent and on edge in the chamber. The chamber was covered, in a fume hood, until such time as the solvent front migrated sufficiently up the TLC plate so that there was significant separation of the components. Plates were removed from the chamber, allowed to dry and subsequently developed. To develop the plates, they were first sprayed with $1.0 \%$ ninhydrin in ethanol $(\mathrm{w} / \mathrm{v})$ and gently heated on a hot plate. This process indicates the presence of any amines (positive result is indicated by a yellow, pink or purple color). After this process is completed, the plate is sprayed with a $5.0 \%$ sulfuric acid in methanol (w/v) solution and, again, gently heated on a hot plate. This second process is used to detect the presence of any carbon containing molecules in the fermentation samples as indicated by charred spots ${ }^{43}$.

The $\mathrm{pH}$ of both agave leaf juice and $\mathrm{CPH}$ in water fermentation samples was analyzed. The $\mathrm{pH}$ of supernatant solutions was measured with Whatman® $\mathrm{pH}$ Indicator Paper. To measure $\mathrm{pH}$, approximately $60 \mu \mathrm{L}$ of undiluted, supernatant solution was spotted onto the $\mathrm{pH}$ paper. Approximately $20 \mu \mathrm{L}$ of the solution being analyzed was spotted onto each of the three absorbent, $\mathrm{pH}$ sensitive pads that comprise each $\mathrm{pH}$ indicator paper. The solution being analyzed was allowed to rest on the indicator paper until the $\mathrm{pH}$ sensitive pads no longer changed color. The solution was then blotted off and the $\mathrm{pH}$ indicator paper was evaluated with the key on the Whatman ${ }^{\circledR} \mathrm{pH}$ Indicator Paper container. 


\section{Separations}

\section{Cocoa Pod Husk}

After thawing the $\mathrm{CPH}$ to be used in the first of multiple fermentations, several distinct layers were visible in the cross section of the husk as shown in Figure 12. Layers were separated in an effort to determine the composition of each, and to see which, if any, might have an inhibitory effect on the $K$. marxianus yeast strains used in this research. The meat of the cocoa pod that was attached directly to the beans was not analyzed nor used in any of the fermentations performed with $\mathrm{CPH}$. A small piece of the husk was obtained, weighed and separated based on the layers present with a medium X-acto $\circledast$ knife and \#2 blade. The mass and physical characteristics of the layers are described in the results section.

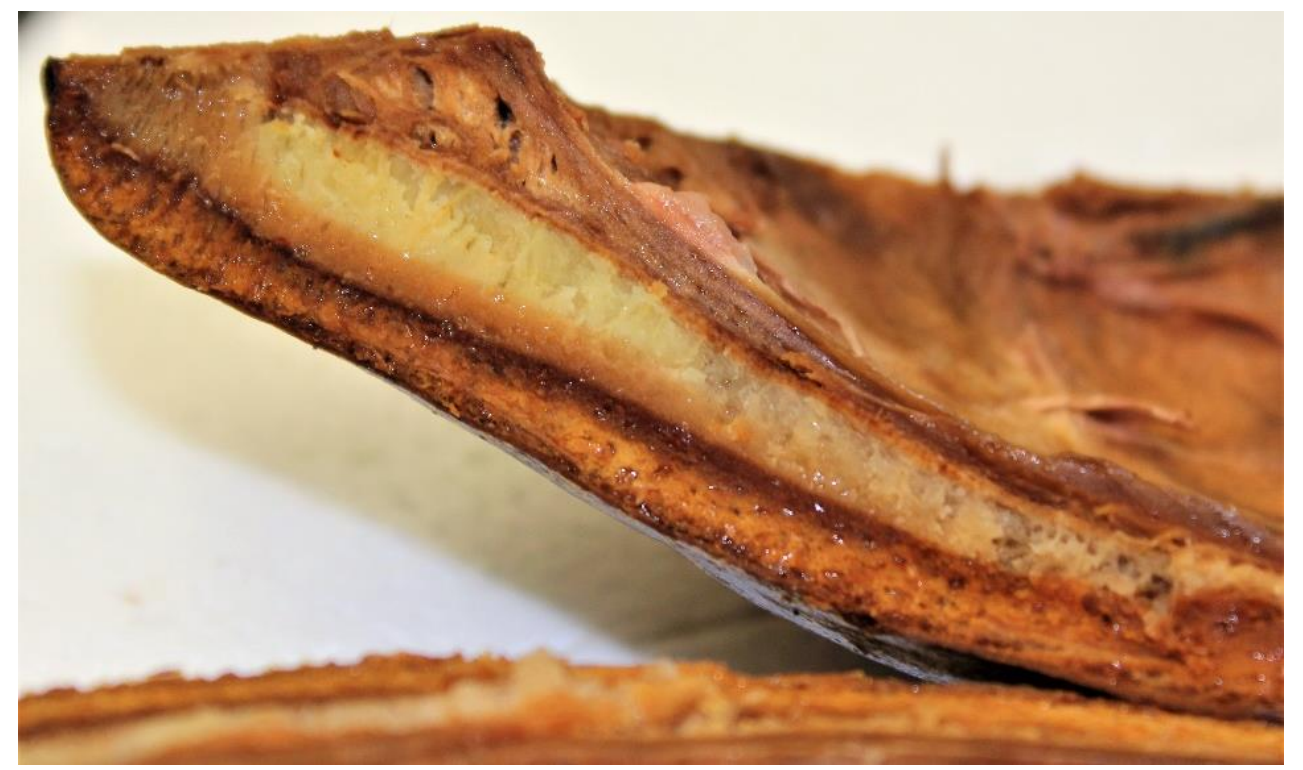

Figure 12. Picture of cocoa pod husk cross section. This photo depicts the multiple layers present in the husk. 


\section{Blue Agave Leaf Skin}

The removal of the skin from Blue Agave leaves was done with the use of a sharp knife. The knife was held perpendicular to the leaf; the skin was scraped off by applying a small amount of pressure to the knife and moving it the length of the leaf portion. Skin separated from the agave leaf came off in two portions: an opaque, waxy portion and a dark green, velvety portion as seen in Figure 13. The opaque portion was the outermost layer of the leaf; this waxy layer helps this desert plant retain moisture in the hot, arid climate. The dark green layer lay directly below the waxy layer; this layer may contain molecules that absorb harmful, ultraviolet light. Inhibitory effects that this skin may have on the $K$. marxianus yeast strains used to ferment it were analyzed by adding a small amount of the removed skin to a solid support growth medium plate inoculated with.

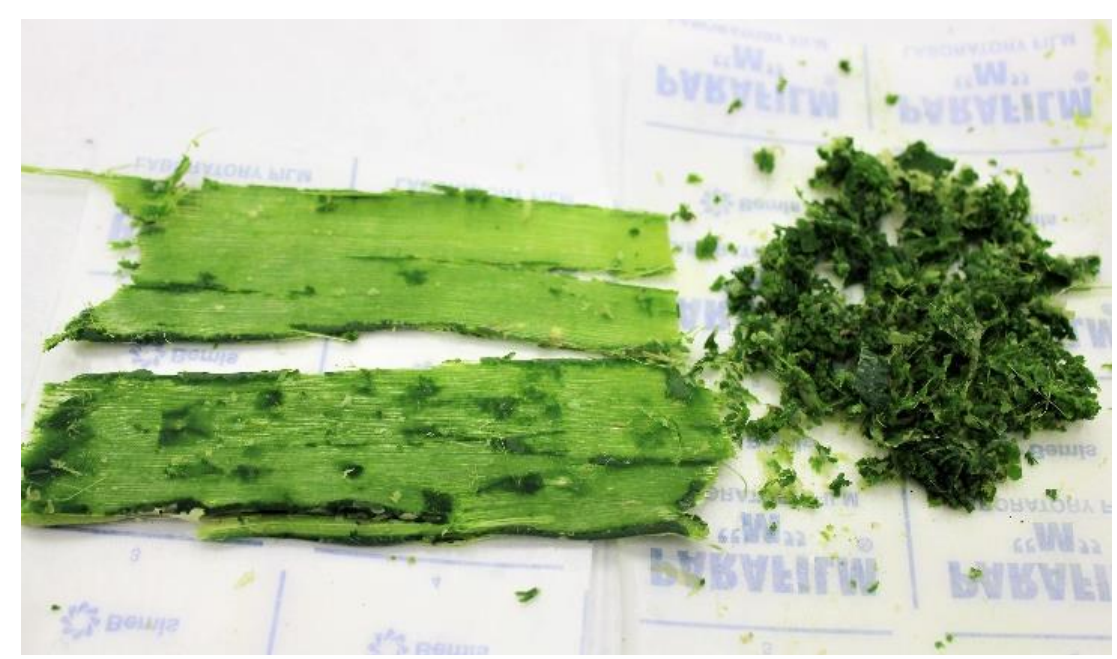

Figure 13. Picture of Blue Agave leaf skin removal. The skin of a small piece of Blue Agave leaf was removed by scraping with a sharp knife. 


\section{Multi Stage Fermentations}

Both agave juice fermentations and cocoa pod husk fermentations, after termination, were frozen at $-80^{\circ} \mathrm{C}$. These fermentations were thawed and the alcohol was removed by evaporation using a stream of $\mathrm{N}_{2}$ gas. They were then refrozen, packed with dry ice in a cooler and sent to the USDA to undergo a second fermentation with another yeast strain after re-sterilization. Yarrowia lipolytica $F$ was used as the second strain in the fermentation of these substrates through a collaborative effort with the USDA. Yarrowia does not ferment sugars well, and it does not produce significant quantities of ethanol but instead, utilizes proteins in solution, in the yeast cells and other solids that are present from the first stage fermentation. Yarrowia uses proteins instead of sugars, and produces ammonia and oils instead of ethanol ${ }^{35}$. 
CHAPTER III: RESULTS

\section{Cocoa Pod Husk (CPH) Description}

The cocoa pod husk used in this experiment was harvested ripe; it was tan to medium brown in color. The pod was football-shaped, approximately $20 \mathrm{~cm}$ long, with a diameter of approximately $10 \mathrm{~cm}$. The outer skin of the husk was smooth and slick; the husk had thick and thin areas that run lengthwise, similar to an acorn squash. These lengthwise channels, along with the smooth, slick skin would help to channel water off the pods which hang down from the bottom of a branch on a thin stem. Cocoa pods grow in equatorial countries; they grow best in warm, wet environments which make shedding water quickly and protecting the beans or seeds necessary. The husk, after the beans were removed, weighed approximately $330 \mathrm{~g}$. In all $\mathrm{CPH}$ fermentations, the target mass of husk was $16 \mathrm{~g}$, and the average mass ( $\mathrm{n}=9$ fermentations) used was $16.0435 \pm 0.0164 \mathrm{~g}$. With $\mathrm{CPH}$, every gram of substrate is suspended in $15 \mathrm{~mL}$ of nanopure water; therefore, each $16.0 \mathrm{~g}$ portion of husk was suspended in $240 \mathrm{~mL}$ of nanopure water.

\section{Blue Agave Leaf Description}

With Blue Agave leaf juice fermentations, the juice was wrung from the leaves as described in the materials and methods section. It took approximately $1.831 \mathrm{~g}$ of leaf for each $\mathrm{mL}$ of juice. A total of 9 fermentations of agave leaf juice were conducted for this thesis; each of these fermentations started with $60 \mathrm{~mL}$ of sterilized agave leaf juice. The collection of $540 \mathrm{~mL}$ of juice required just less than a kilogram of agave leaves (approximately 990 grams). 


\section{Cocoa Pod Husk Fermentations Appearance}

The most obvious difference noticeable as the fermentations progressed was their appearances. With $\mathrm{CPH}$ in water, the appearance changed as a function of time, but the control fermentations, that contain no added cells, changed similarly to those with added yeast as time progressed, as shown in Figure 14. As the $\mathrm{CPH}$ in water was shaken at $200 \mathrm{RPM}$ and kept at $37^{\circ} \mathrm{C}$, the husk broke down and started to color the solution. This change was, typically, first noticeable in the flasks which contained added yeast cells but was also eventually evident in control flasks with no added yeast. The $\mathrm{CPH}$ fermentation appearances did change as a function of fermentation time, but their appearance was not indicative of fermentation progress since the changes were not consistently different from one incubate to another.

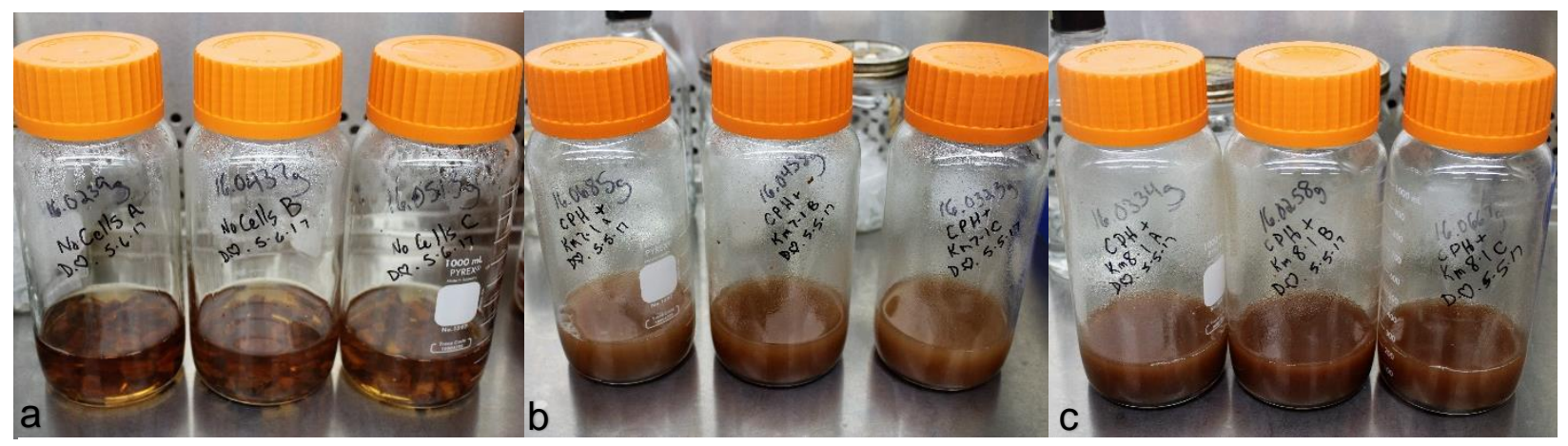

Figure 14. Picture of cocoa pod husk fermentation appearance changes. $\mathrm{CPH}$ fermentations at 0 (a), 24 (b) and 72 (c) hours. The appearances changed as time progressed, but the appearance of the broth in vessels which contained yeast did not change differently than those that contained no added yeast cells.

\section{Agave Leaf Juice Fermentations Appearance}

The appearance of fermenting agave juice with added yeast cells changed as a function of time. However, the agave juice that had not been inoculated with cells did 
not appear to change in color, texture or viscosity. The first visible color change occurred in vessels that had been inoculated with KM 7-1 as shown in Figure 15. The first, obvious difference was noticeable at around 12 hours in the flasks which contained KM 7-1 and agave juice. The KM 8-1 fermentations were noticeably different from the control flasks by 24 hours from inoculation with yeast. The lids of all six fermentation flasks containing added yeast cells bulged from the pressure created by the production of carbon dioxide during fermentation. This suggests that there was limited gas exchange with the environment due to tight fitting lids. By the 72-hour mark and the termination of the fermentations, the juice with no added cells still looked the same as it did when the incubations were started. The contents of the vessels which contain added yeast looked very different; the viscosity was noticeably decreased and the color was no longer brown, but off white or light tan (Figure 15c). Also, as the color changed, there was an accompanying odor change in the yeast fermented juice.

The odor of the fermentation vessels changed at about the same time as the color change had occurred. With KM 7-1, this change occurred at around the 12-hour mark, while KM 8-1 began to smell like alcohol at around 24 hours. The odor was unnoticeable before these time points; from these time points on, the fermented juice smelled like sourdough bread or a little like beer. These noticeable physical changes correlated well with the CFU plates (discussed below) that were made from each fermentation sample. 


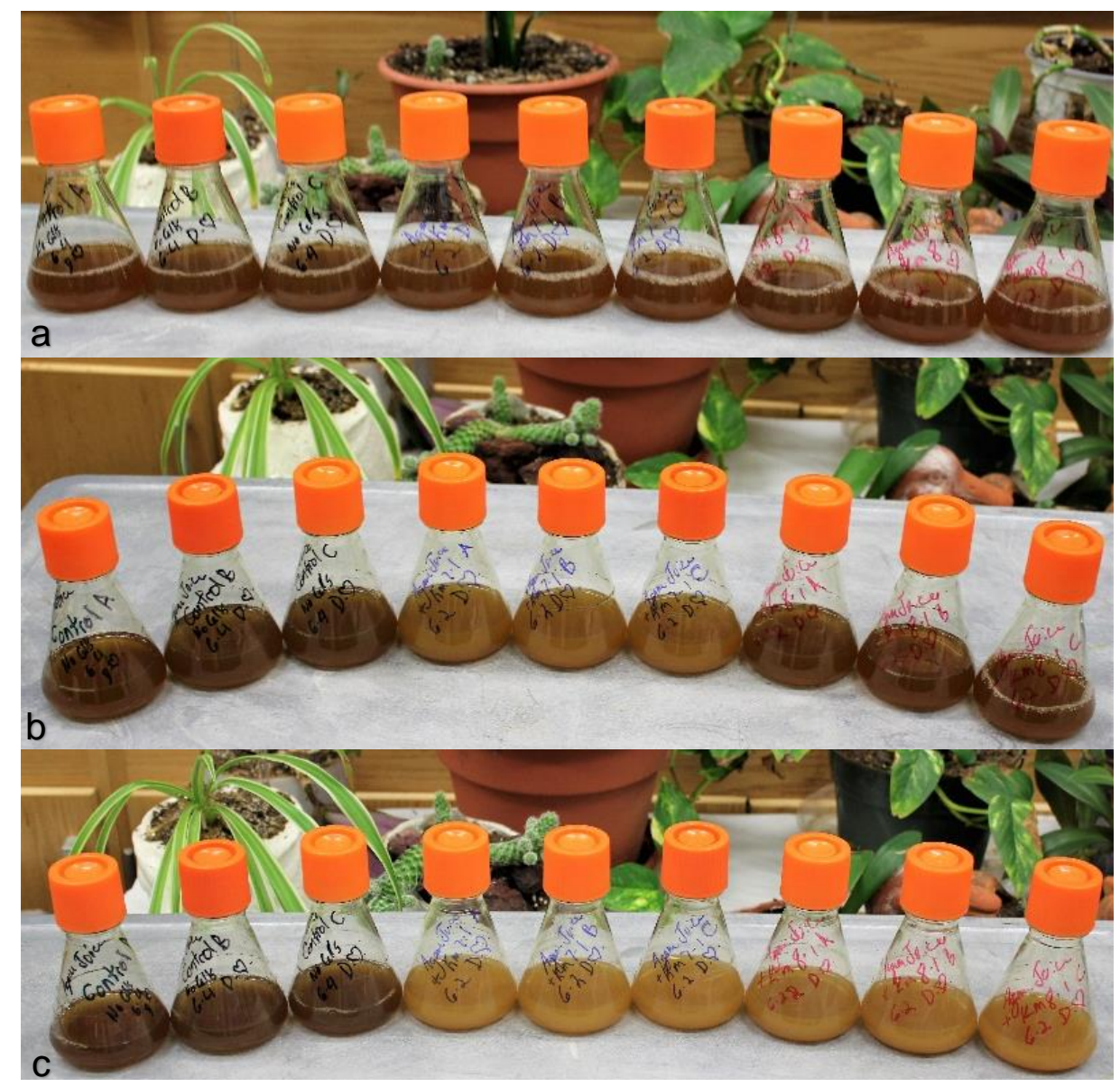

Figure 15. Picture of agave leaf juice fermentation appearance changes. Agave leaf juice fermentations looked similar from the start (a) until around the 12-hour mark (b), at which time the appearance of KM 7-1 flasks (center 3 flasks) started to change. By 24 hours (c) and for the duration of fermentations, KM 8-1 containing flasks (3 flasks on right) looked similar to KM 7-1 flasks; both looked very different from control flasks ( 3 flasks on left).

\section{Sample Appearance}

Changes in color of fermenting agave juice began with KM 7-1 at 12 hours and with both $\mathrm{KM} \mathrm{7-1}$ and $\mathrm{KM} \mathrm{8-1} \mathrm{peaked} \mathrm{at} 24$ hours, showing obvious signs of fermentation, as shown in Figure 15. In addition to the color, texture and viscosity changes described above, disturbing the fermentations to collect samples for analyses caused dissolved gas, presumably carbon dioxide, to escape from the samples both in 
the pipette used to collect the sample (Figure 16) and in the microcentrifuge tube used to store it. The activity of the escaping gas was so prolific in the 2-mL microcentrifuge tubes that it caused the samples to expand and spill from the tubes. In order to prevent this, the samples were drawn up into the pipette and forced out against the bottom of the tube several times. This caused enough of the dissolved gas to escape so that the samples did not expand and spill from the tubes. The escaping gas was barely evident with the 48 hour samples, and not noticed at all by 72 hours.

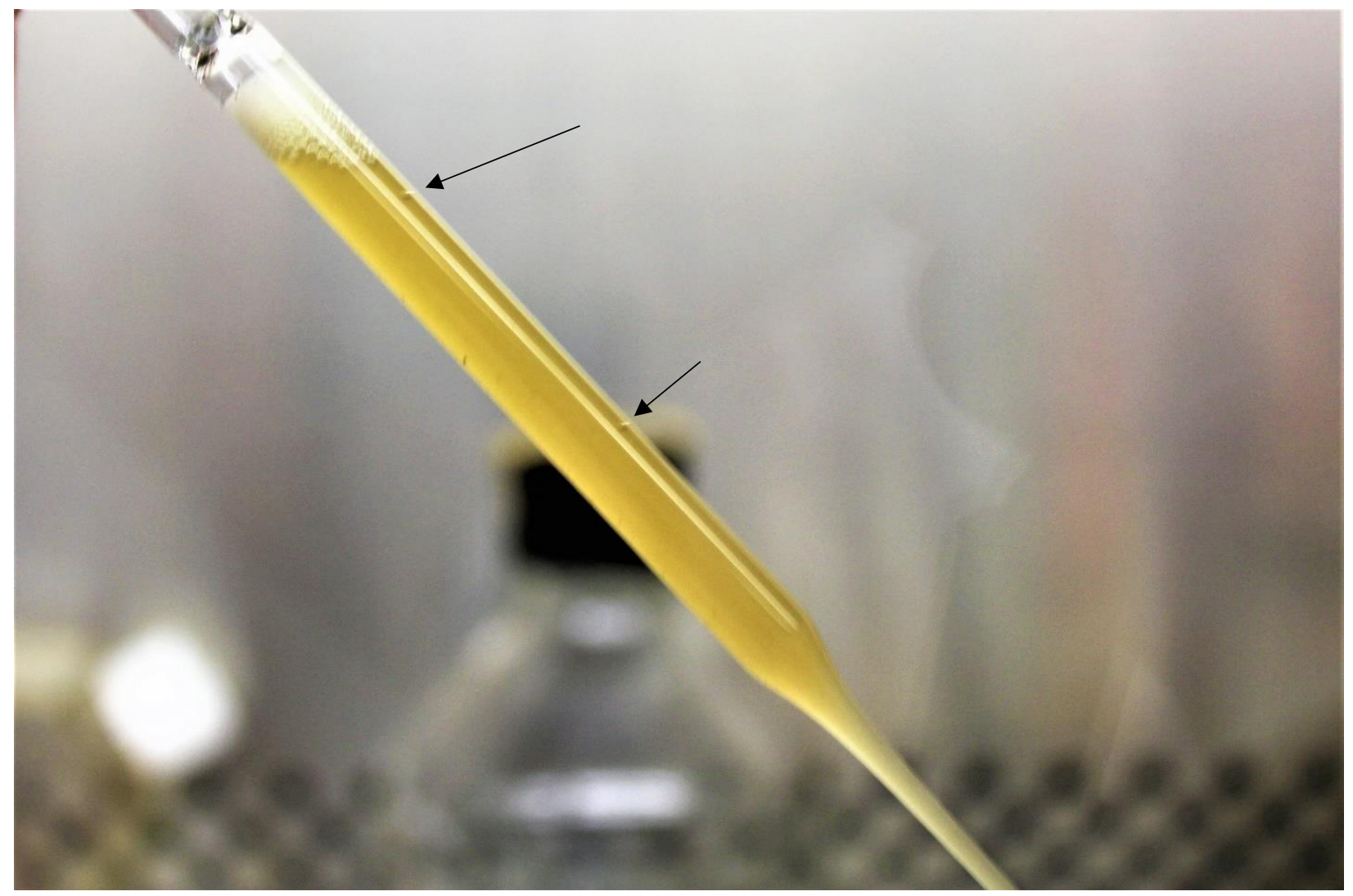

Figure 16. Picture of agave leaf juice fermentation sample in pipette. This agave juice sample appeared saturated with dissolved carbon dioxide at 24 hours as indicated by bubble formation at the top of the liquid in the pipette. Disturbing the fermentations by sampling causes some of the gas to escape from solution (arrows) 
Fermentation samples of $1.8 \mathrm{~mL}$, after being collected aseptically in a sterile environment and placed into a 2-mL microcentrifuge tube, were separated by centrifugation and the supernatant was decanted from the pellet before both were frozen at $-80^{\circ} \mathrm{C}$. The appearance of the pellet was another indicator of the progress of the fermentations, though not as obviously with the $\mathrm{CPH}$ as with the agave juice. As early as 6 hours into the agave fermentation, a tan layer of yeast cells became evident in the pellets of samples that were inoculated with yeast. Some of these samples were photographed and shown in Figures 17 (+ KM 7-1) \& 18 (No Yeast).

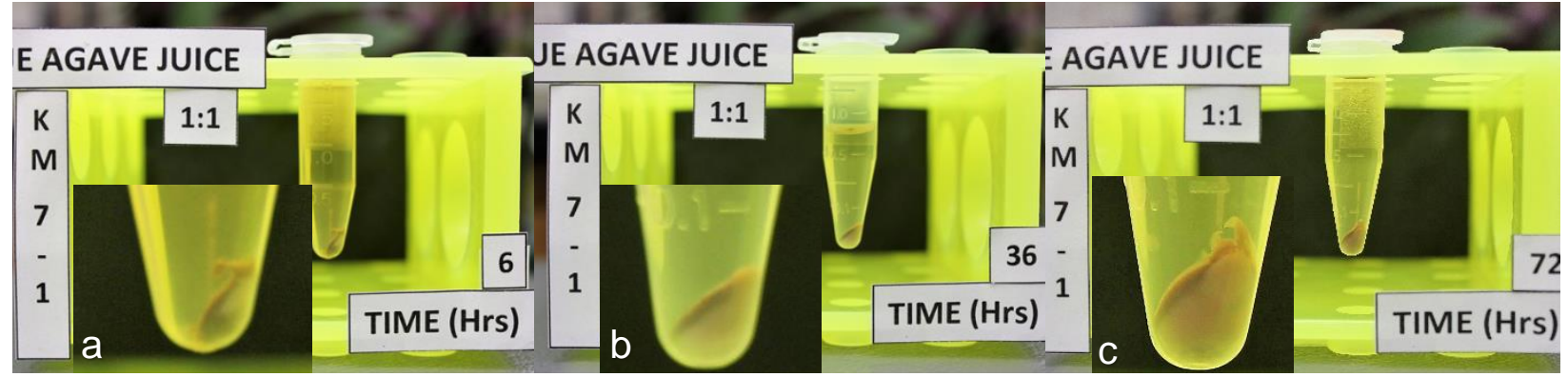

Figure 17. Picture of agave leaf juice fermentation centrifuged samples. The samples, after separation by centrifugation, showed evidence of yeast growth after only 6 hours(a). By 36(b) \& 72(c) hours, the yeast in the pellet had become several times the size of the insoluble material present in the juice.

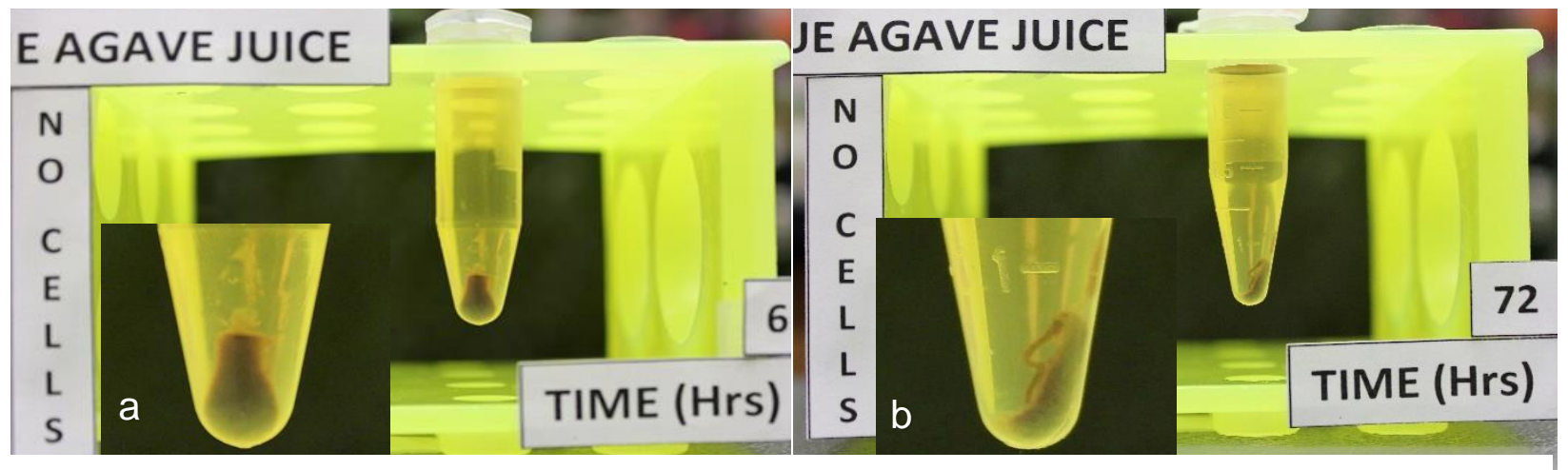

Figure 18. Picture of agave leaf juice fermentation centrifuged samples. These samples have no added yeast cells. The insoluble portion that was forced out of solution by centrifugation remained fairly constant in appearance from 6 hours (a) through the end of the fermentation at 72 hours (b). 


\section{Colony Forming Units}

The CFU plate was the most reliable way to assess the number of viable yeast and, thus, success of the fermentation. Samples were collected with aseptic technique in a sterile environment. Samples and dilutions were immediately spread onto petri dishes containing solid support growth medium which, in this case, was the YPD-plusagar plates previously described. These plates were covered after inoculation and yeast were allowed to grow in an incubator $\left(35^{\circ} \mathrm{C}\right)$ to show the number of viable yeast cells present per $\mathrm{mL}$ of fermentation broth. In addition, these plates can indicate whether or not the fermentation had been contaminated by another microscopic organism that thrives in these conditions. The colony forming units (CFU) from all cocoa pod husk and agave leaf juice fermentations were determined and results are presented below.

\section{Cocoa Pod Husk Fermentations}

$\mathrm{CPH}$ fermentations supported growth of both strains of yeast well; preliminary fermentations were performed to adjust parameters such as inoculation size and ratio of water to $\mathrm{CPH}$ mass. Size of inoculation was adjusted such that both strains would reach a CFU maximum by around 24 hours and initial inoculates contained about the same number of cells. The amount of water per gram of $\mathrm{CPH}$ was adjusted so that samples could be collected without clogging the modified pipette used to sample these fermentations. Fermentations were allowed to progress for 72 hours and terminated by freezing at $-80^{\circ} \mathrm{C}$. The results of the $9 \mathrm{CPH}$ fermentations performed in this work are shown below. 
A graph of all nine fermentation CFU plots (Figure 19) shows that each strain consistently followed the same trend. KM 8-1 strain reached its maximum value at around the 12-hour mark, while KM 7-1 strain reached its maximum value by 24 hours. The control fermentations with no added cells were graphed as an average, because no conatminants were evident on any of the CFU plates made with the control fermentation samples. While the CFU value varied, the same trends were evident with all flasks containing the same yeast strain. For easier comparison, the values for each strain were averaged, graphed again, and error bars added as shown in Figure 20. Both strains fermented the CPH similarly, though KM 8-1 showed a shorter lag phase. Both strains reached a CFU maximum of about 70 million cells per $\mathrm{mL}$, although $\mathrm{KM}$ 8-1 achieved its maximum value 12 hours earlier than did the KM 7-1 strain. The CFU of $\mathrm{CPH}$ fermentations remained at approximately $5 \times 10^{7}$ at the end of the fermentation indicating that these cells were obtaining sufficient nutrition to remain viable.

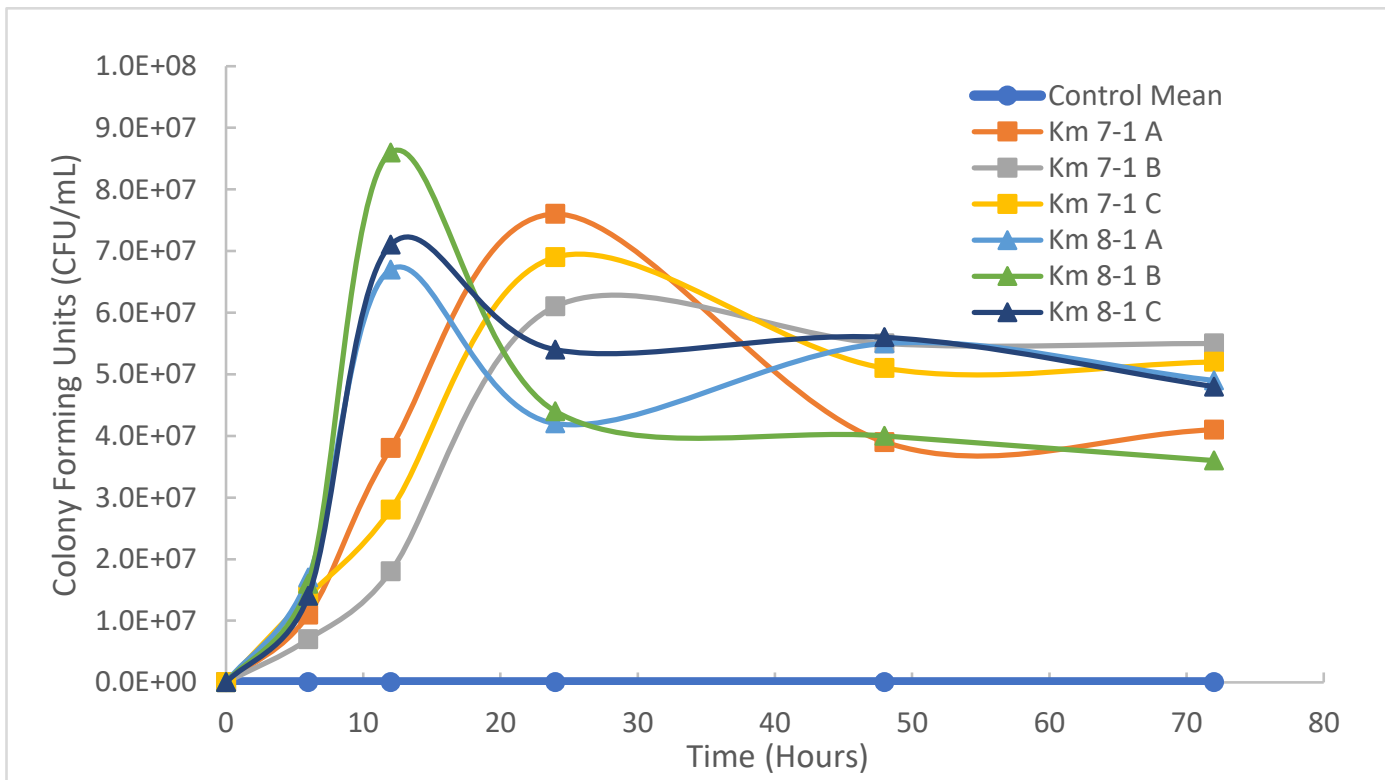

Figure 19. Graph of cocoa pod husk fermentation colony forming units. CFU as a function of time for all $9 \mathrm{CPH}$ fermentations. The control flasks are represented as a mean value because no cells were evident in any of the control flasks. 


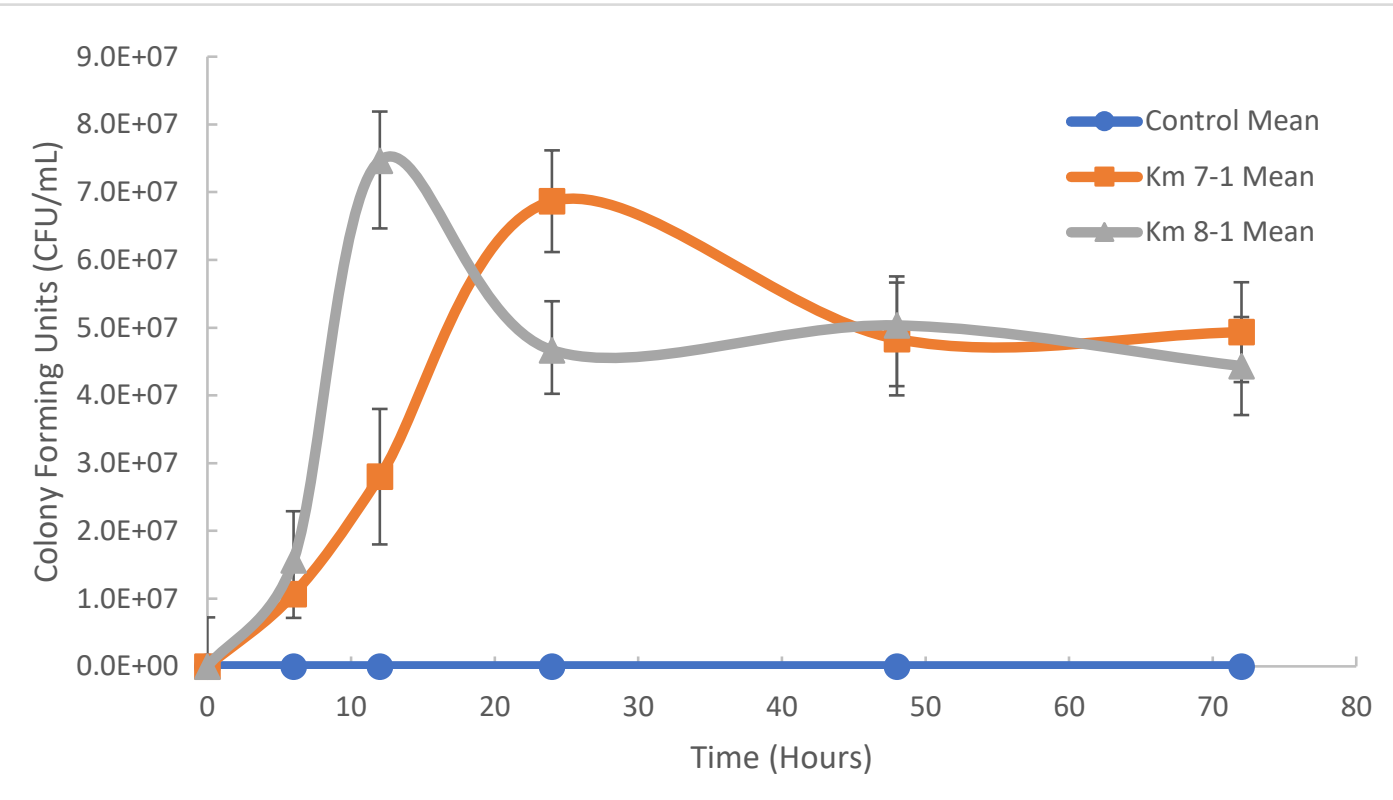

Figure 20. Graph of cocoa pod husk fermentation colony forming unit mean. Mean $\pm S D(n=3)$ CFU as a function of time graphed for $\mathrm{CPH}$ fermentations.

\section{Agave Leaf Juice Fermentations}

The juice extracted from Blue Agave leaves was fermented with either KM 7-1 or KM 8-1; nine, scaled-up fermentations were performed after several preliminary fermentations were carried out. CFU plates were prepared from samples taken from these 9 fermentations ( 6 with added yeast, 3 with no added yeast). The data collected from these plates are graphed below (Figure 21). The yeast strains again followed a similar trend between fermentations of the same yeast strain. The control fermentations with no added cells is graphed as an average, as the control fermentations contained no colonies on any CFU plate made from samples taken from control flasks.

These trends were quite similar to those observed with the fermentations of $\mathrm{CPH}$, although the KM 7-1 reached a 15\% higher maximum about 12 hours sooner than did KM 8-1. In addition to the different performance of each strain, another obvious difference was the substantial decrease in the yeast populations compared to $\mathrm{CPH}$ 
fermentations with both KM 7-1 and KM 8-1 at the end (72 hours) of these agave fermentations. Also, the agave leaf juice fermentations resulted in a much higher maximum yeast cells per $\mathrm{mL}$ of broth $\left(5.5 \times 10^{9} / \mathrm{mL}\right)$ relative to $\mathrm{CPH}\left(7.5 \times 10^{7} / \mathrm{mL}\right)$.

The CFU averages from the agave juice fermentation are plotted below (Figure 22).

Both $K$. marxianus strains fermented the juice from agave leaves very well, though $\mathrm{KM}$ 7-1 had a shorter lag phase with agave juice and higher CFU maximum. KM 7-1 reached about 5.5 billion cells per $\mathrm{mL}$, while $\mathrm{KM} 8-1$ grew to around 4.7 billion cells per $\mathrm{mL}$ fermentation broth.

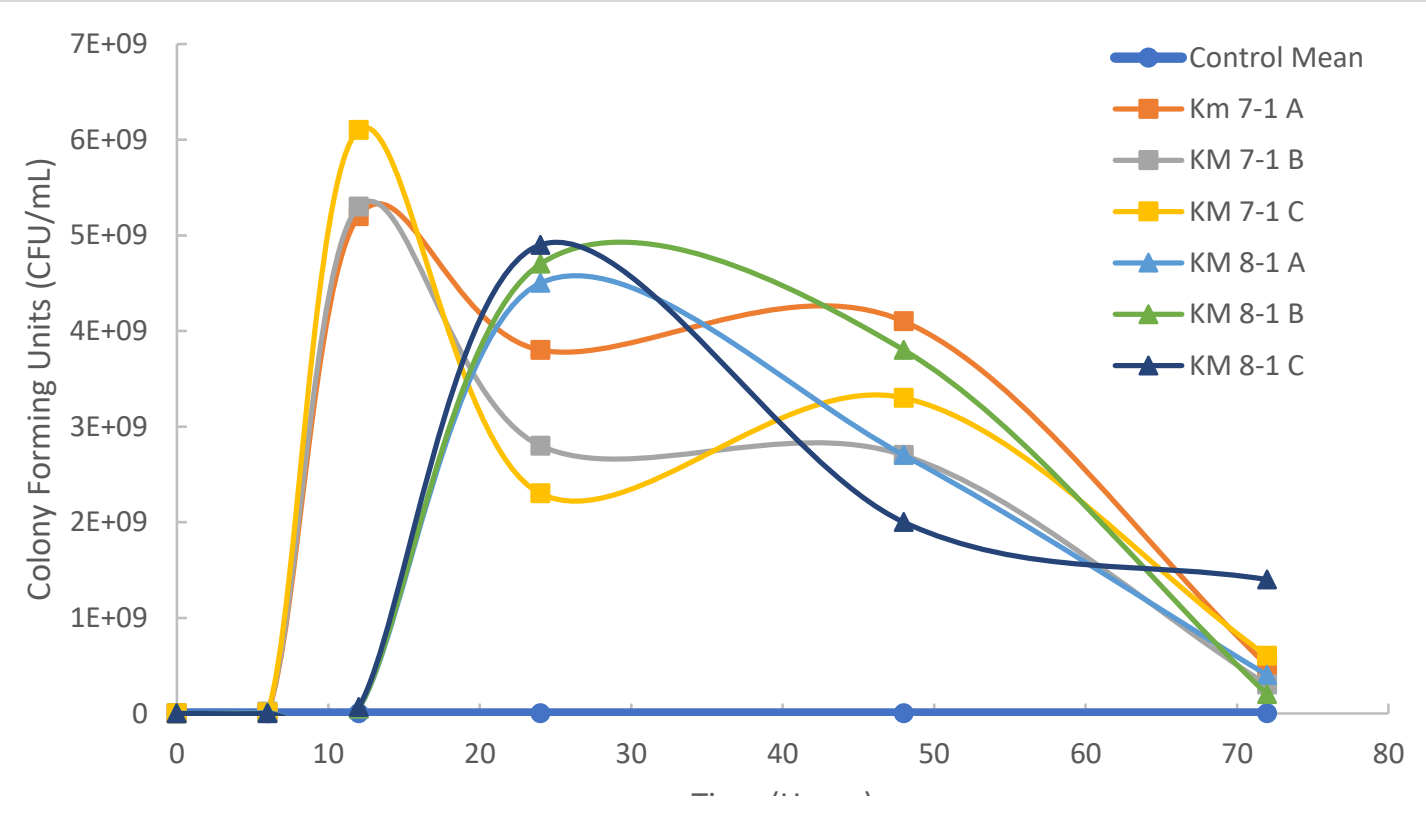

Figure 21. Graph of agave leaf juice fermentation colony forming units. CFU as a function of fermentation time for all nine agave juice fermentations. The control flasks are represented as a mean value as there were no cells evident in any of them. 


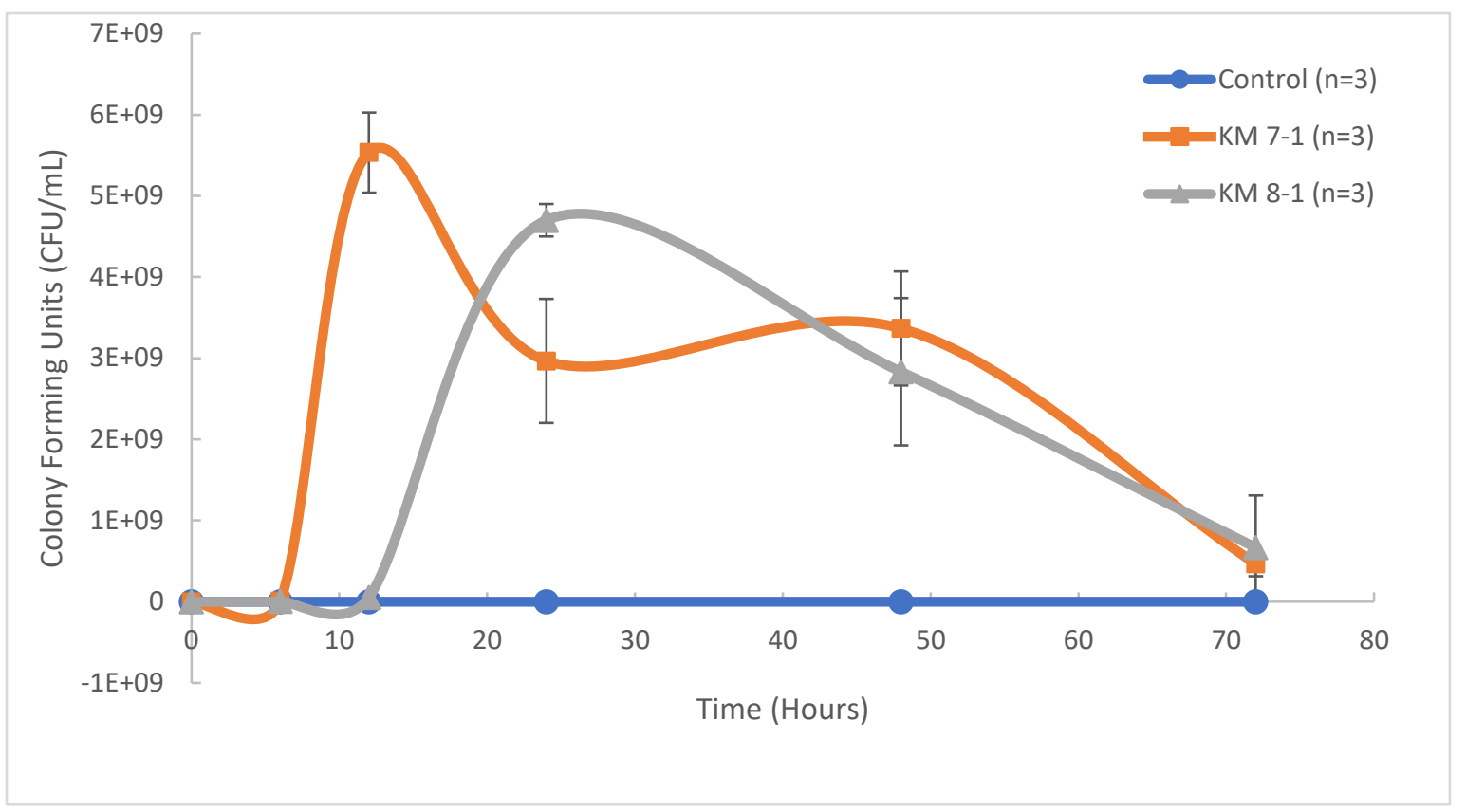

Figure 22. Graph of agave leaf juice fermentation colony forming unit mean. Mean $\pm S D(n=3)$ CFU as a function of time for agave juice fermentations.

\section{Reducing Sugars}

Reducing sugar concentrations of each fermentation were assessed via the DNS reducing sugar assay described in the methods section. Concentrations of reducing sugars started out about ten times higher in agave leaf juice fermentations than in cocoa pod husk in water fermentations. In all fermentations, these reducing sugars were consumed to just a fraction of initial levels by 24 hours after inoculation with $K$. marxianus yeasts. By 72 hours and the termination of these fermentations, the concentration of reducing sugars in all yeast containing flasks is reduced to less than one $\mathrm{mg} / \mathrm{mL}$. Although the general trend of reducing sugar consumption is similar with all fermentations, these yeasts performed slightly differently with the two different substrates. 


\section{Cocoa Pod Husk Fermentations}

The $\mathrm{CPH}$ fermentations were assessed at each time point for reducing sugar concentration. All $9 \mathrm{CPH}$ fermentations are graphed together; this time the control fermentations are graphed individually, as the reducing sugars were present and slightly different in these fermentation vessels. Reducing sugar concentrations all started between 5 and $7 \mathrm{mg} / \mathrm{mL}$ at fermentation time 0 and, at 72 hours, had decreased approximately $80 \%$, to less than $1 \mathrm{mg} / \mathrm{mL}$ in all flasks that contained yeast cells added (Figure 23). It is important to note that without added yeast, the reducing sugar concentration was constant; this indicates that these sugars were stable during incubations. Fermentations with added cells looked nearly identical, except the sugars were slightly more depleted at the 12-hour time point in the KM 8-1 flasks. Average reducing sugars are graphed in Figure 24 as a function of fermentation time. Both strains appear equally capable of fermenting reducing sugars by 24 hours after inoculation with yeast.

\section{Agave Leaf Juice Fermentations}

The agave leaf juice contained much higher concentrations of reducing sugars compared to the $\mathrm{CPH}$. Agave juice had approximately 10 -fold more reducing sugars than did $\mathrm{CPH}$ per $\mathrm{mL}$ of prepared material for fermentation. The K. marxianus strains used to ferment the agave leaf juice did very well with these readily available sugars. The maximum number of yeast per $\mathrm{mL}$ of agave fermentation broth reached into the billions, likely a reflection of the high concentration of reducing sugars available to the 
yeast. The reducing sugar graph from the agave leaf juice individual fermentations is shown in Figure 25.

These reducing sugar data were very consistent between fermentations with the same yeast strain. All these fermentations started out around $70 \mathrm{mg} / \mathrm{mL}$ reducing sugars; this sugar was quickly consumed by the K. marxianus yeast strains. Some $95 \%$ of the reducing sugars were used by either of the yeast strains in 24 hours. The mean values for each yeast strain with error bars which represent the standard deviation are shown in Figure 26. The decrease in reducing sugar concentration likely led to the time dependent decrease in CFU in late stage agave leaf juice fermentations. As with $\mathrm{CPH}$ fermentations that contain no added yeast, the reducing sugar concentrations were stable with time implying no spontaneous degradation of the polysaccharides and monosaccharides.

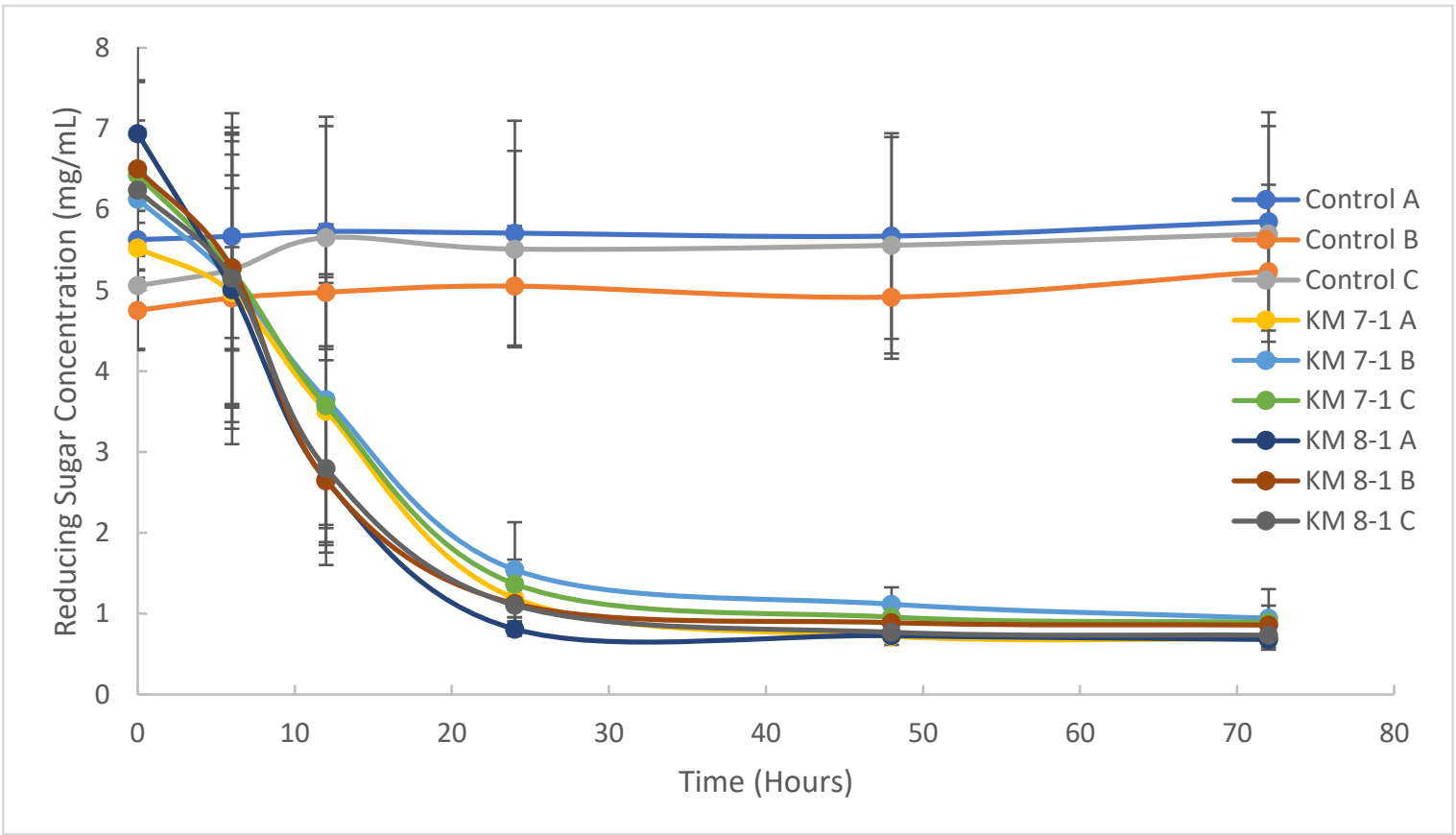

Figure 23. Graph of cocoa pod husk fermentation reducing sugars. Reducing sugar concentrations $\pm S D$ ( $n=3$ replicates from each fermentation) as a function of fermentation time for $\mathrm{CPH}$ in water fermentations. 


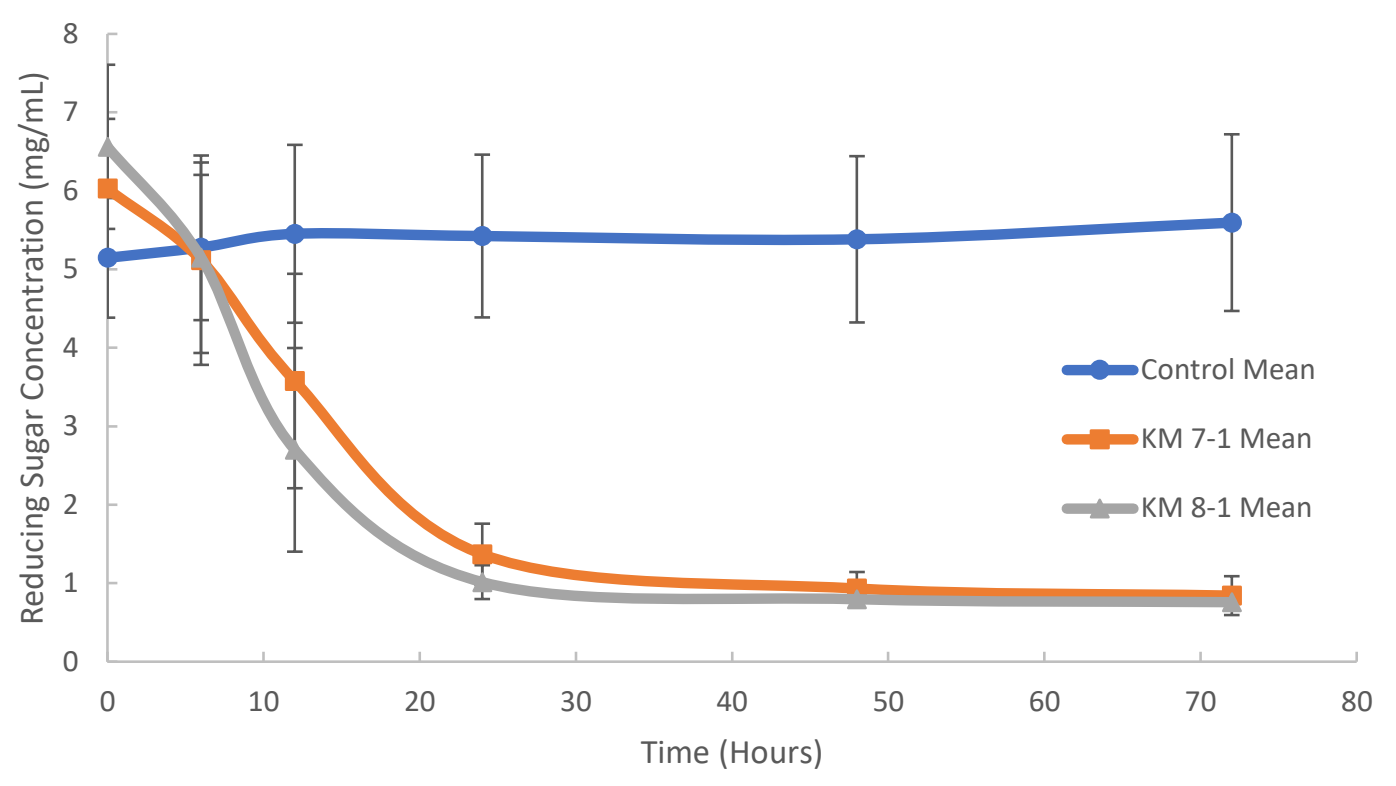

Figure 24. Graph of cocoa pod husk fermentation reducing sugar mean. Mean $\pm S D(n=9 ; 3$ replicates from each of the 3 fermentations) reducing sugar concentrations as a function of fermentation time for $\mathrm{CPH}$ in water fermentations.

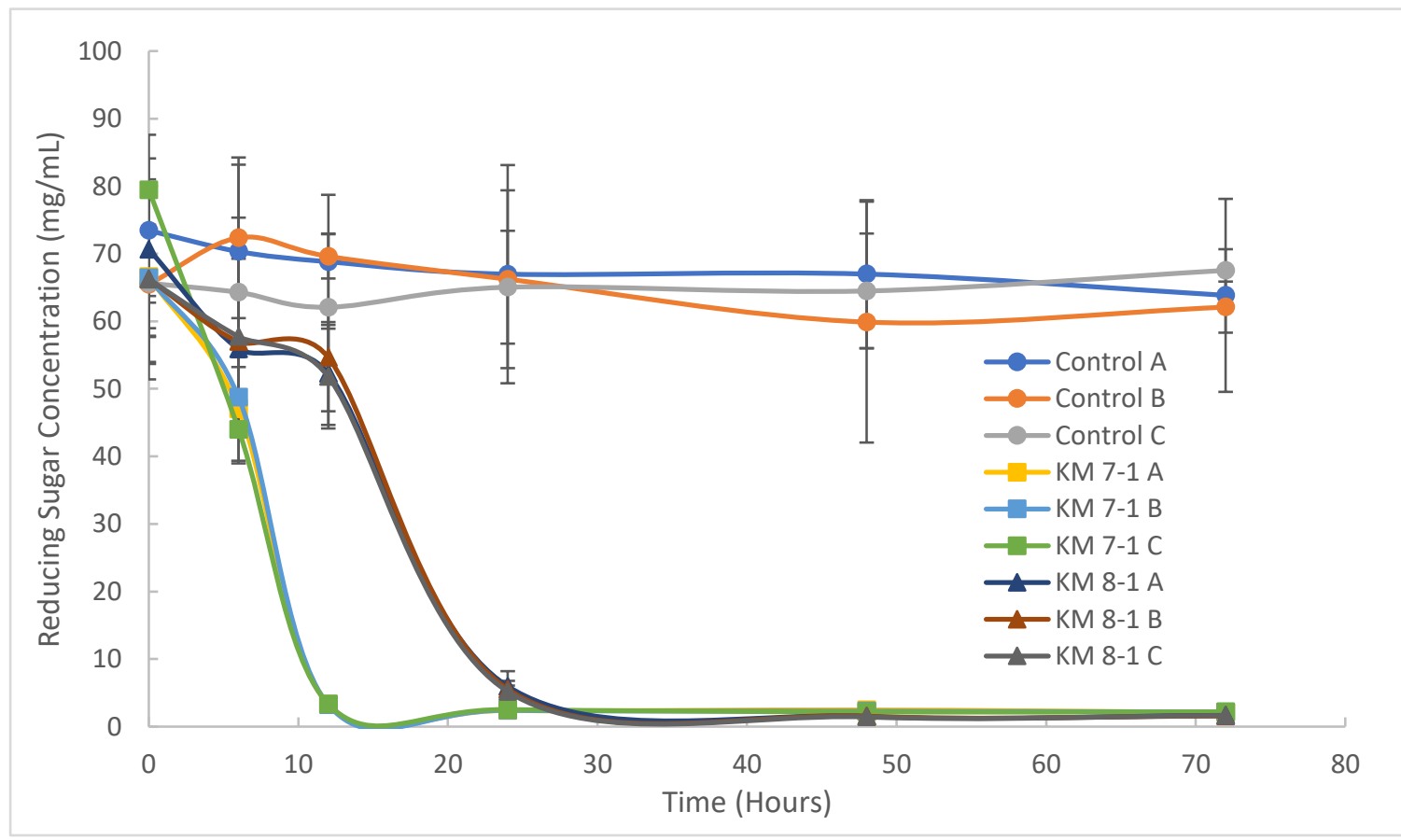

Figure 25. Graph of agave leaf juice fermentation reducing sugars. Reducing sugar concentrations $\pm S D$ ( $n=3$ replicates from each fermentation) as a function of fermentation time with aaave leaf iuice fermentations. 


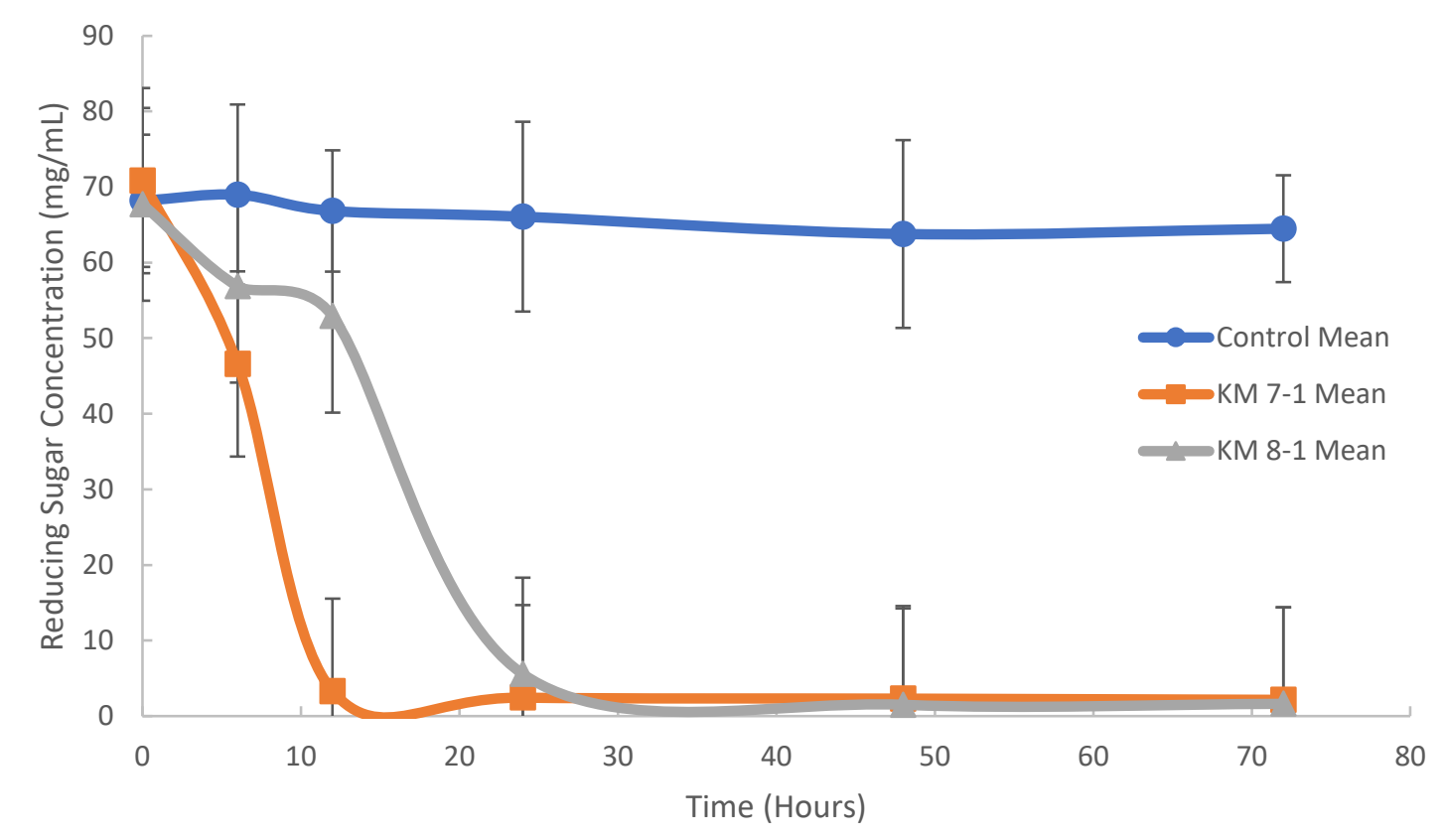

Figure 26. Graph of agave leaf juice fermentation reducing sugar mean. Mean $\pm S D$ ( $n=9 ; 3$ replicates from each of the 3 fermentations) reducing sugar concentrations as a function of fermentation time with agave leaf juice fermentations.

\section{Soluble Proteins}

\section{Cocoa Pod Husk Fermentations}

Soluble proteins in the $\mathrm{CPH}$ fermentations remained fairly constant throughout the entire fermentations as shown in Figure 27. K. marxianus strains ferment mostly sugars, consuming only a small amount of protein. The available protein in the sterilized $\mathrm{CPH}$ in water fermentation broths was substantially more than what these yeast strains need in relation to the amount of available sugars. Soluble proteins were measured with the Bio-Rad ${ }^{\circledR}$ Protein assay as described in the materials and methods section. 


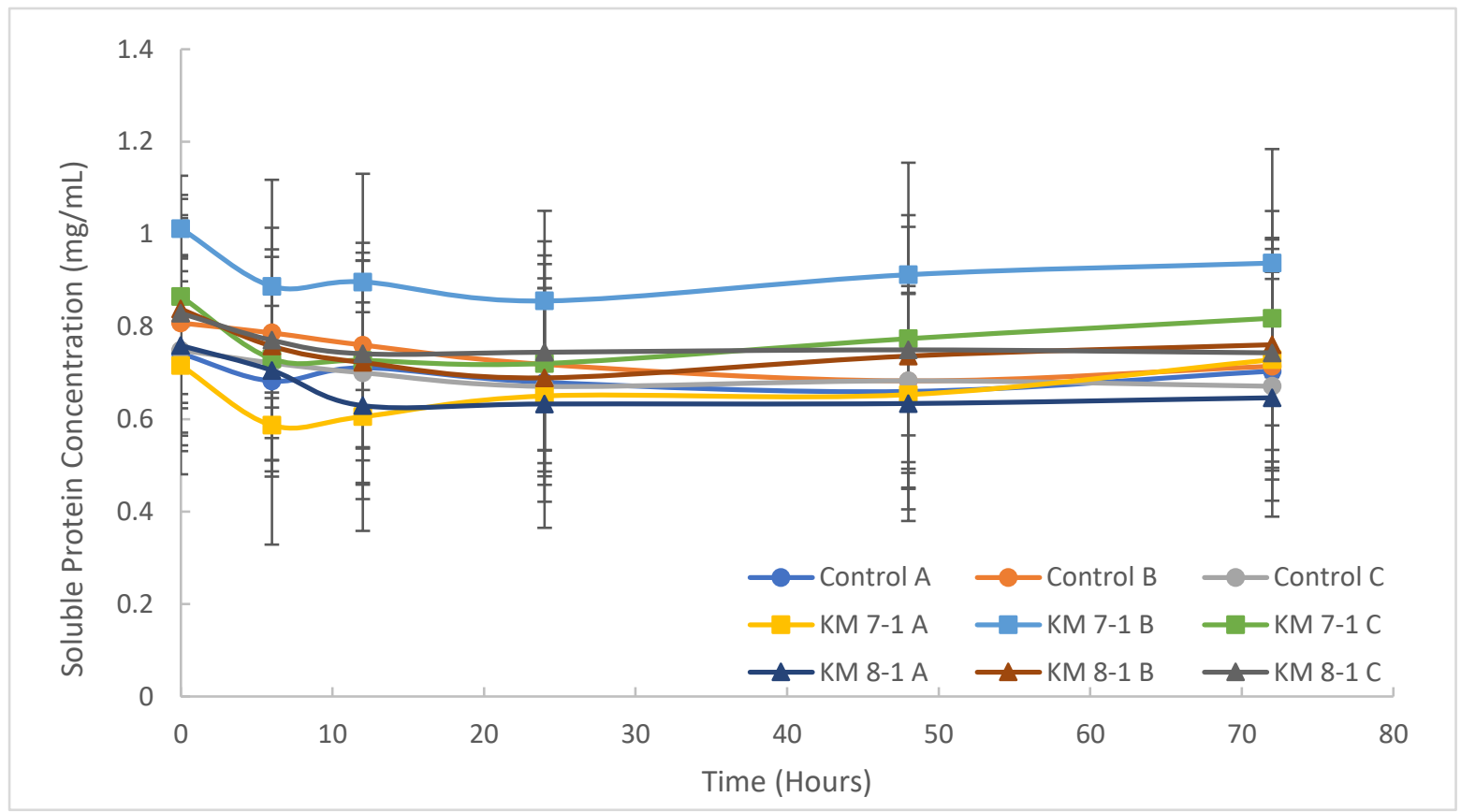

Figure 27. Graph of cocoa pod husk fermentation soluble proteins. Soluble protein concentration $\pm S D$ ( $n=3$ replicates from each fermentation) as a function of fermentation time for $\mathrm{CPH}$ in water fermentations.

A graph of the mean \pm standard deviation of soluble protein concentrations with the $\mathrm{CPH}$ fermentations is shown in Figure 28. Soluble protein seemed to increase slightly but standard deviations were large enough that there are no substantial differences. These yeast strains prefer sugars when metabolizing a substrate, though small amounts of protein are likely necessary as a source of nitrogen as reported by Galindo-Leva et al. ${ }^{42}$. The nearly constant concentration of soluble protein can be explained by the ten times greater initial concentration of soluble protein, and that there are nearly 100 times fewer yeast cells present in $\mathrm{CPH}$ fermentation broths. Also, the $\mathrm{CPH}$ protein appears to be stable with time under these experimental conditions (no spontaneous degradation). 


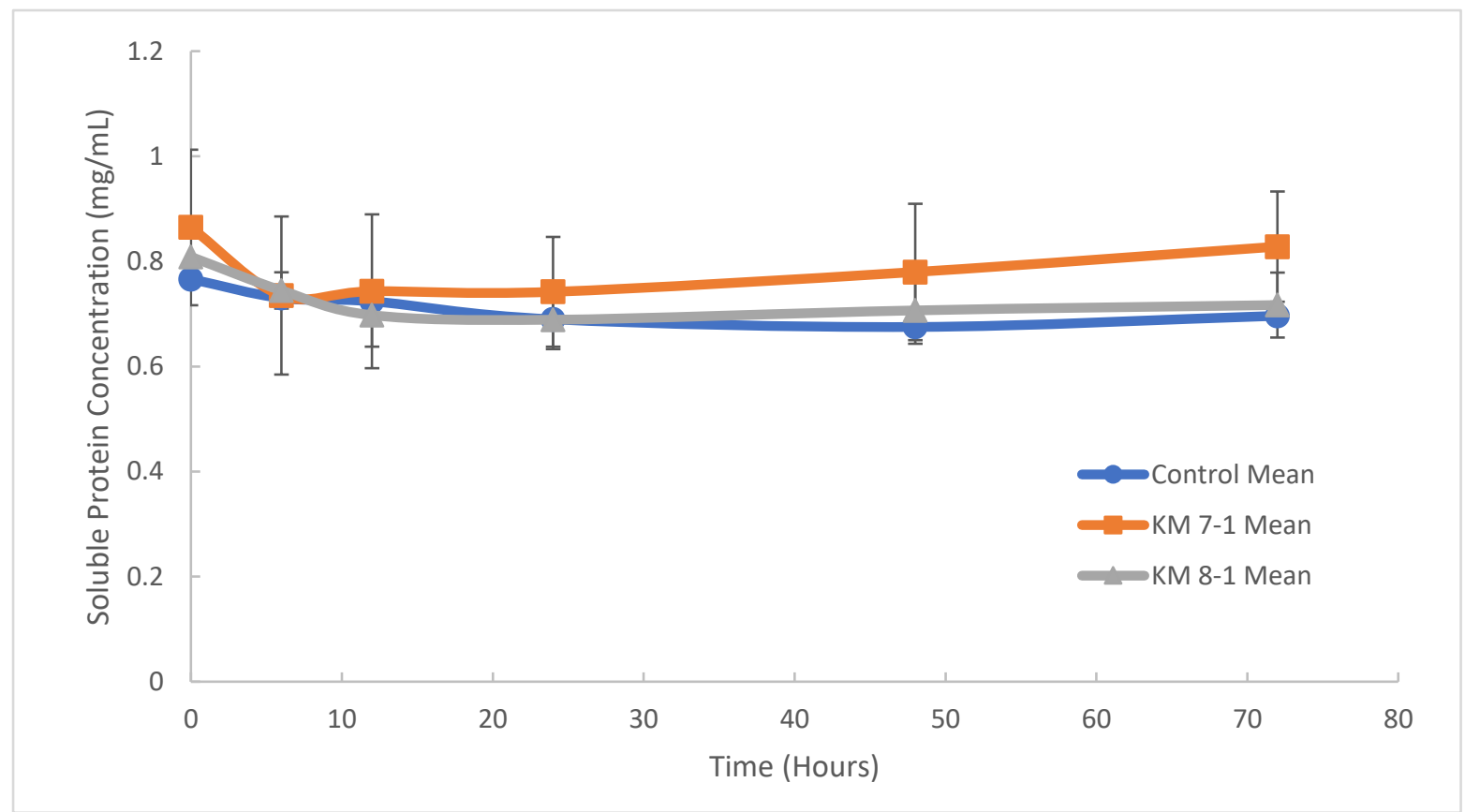

Figure 28. Graph of cocoa pod husk fermentation soluble protein mean. Mean $\pm S D$ ( $n=9 ; 3$ replicates from each of the 3 fermentations) soluble protein concentrations as a function of fermentation time for $\mathrm{CPH}$ in water fermentations.

\section{Agave Leaf Juice Fermentations}

Soluble protein concentrations in the agave juice fermentation broths decreased as a function of time with the agave leaf juice fermentations. The $K$. marxianus strains used in these fermentations consumed the soluble proteins of agave leaf juice nearly as quickly as they consumed the reducing sugars. These trends, at first glance, appear very dissimilar to those of $\mathrm{CPH}$ fermentation samples. Again, the fewer yeast cells and greater soluble protein concentration can easily explain these apparent differences.

The yeast in these agave fermentations consumed the available soluble proteins almost completely before the fermentations were terminated. The exponentially greater number of viable yeast cells present in the agave juice fermentations compared to the $\mathrm{CPH}$ fermentations and the availability of these proteins to the yeast likely contributed to 
their rapid consumption of protein. The graph of soluble proteins in the samples collected from agave juice fermentations is shown in Figure 29. These values were very different from those of $\mathrm{CPH}$ in water fermentation samples. The yeast in these fermentations consumed the available soluble proteins almost completely before the fermentations were terminated.

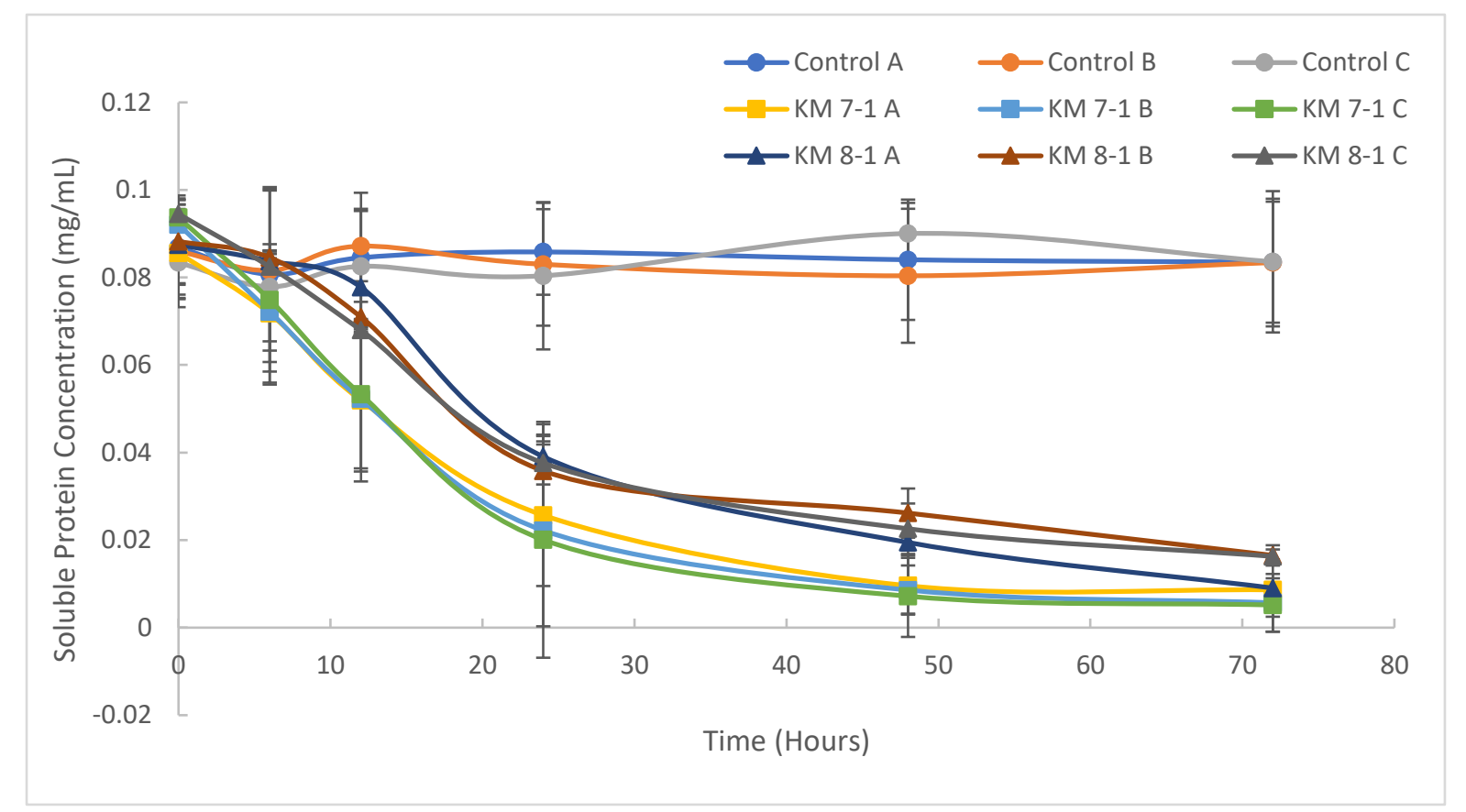

Figure 29. Graph of agave leaf juice fermentation soluble proteins. Graph of agave leaf juice fermentation soluble proteins. Soluble protein concentrations $(n=3$ replicates from each fermentation) as a function of time for agave leaf juice fermentations.

Mean \pm standard deviation $(n=9)$ for soluble protein concentrations for agave leaf juice fermentations are shown in Figure 30. Again, these data indicate that the KM 7-1 fermentations were consuming available nutrients more quickly than were KM 8-1 yeast fermentations. By 24 hours, KM 7-1 had reduced soluble protein concentrations by about $90 \%$, while $\mathrm{KM} \mathrm{8-1}$ had reduced soluble protein concentrations 
by only about $62 \%$. These concentrations started out at approximately the same value, but were not similar again until concentrations were nearly depleted at 72 hours from inoculation with yeast strains and the termination of the fermentations. It is of interest to note that $\mathrm{CPH}$ fermentations had $\approx 10$ fold more soluble protein than did agave leaf juice fermentations. Additionally, agave leaf juice protein with no added yeast appears to be stable with time as the concentration remains constant throughout fermentation.

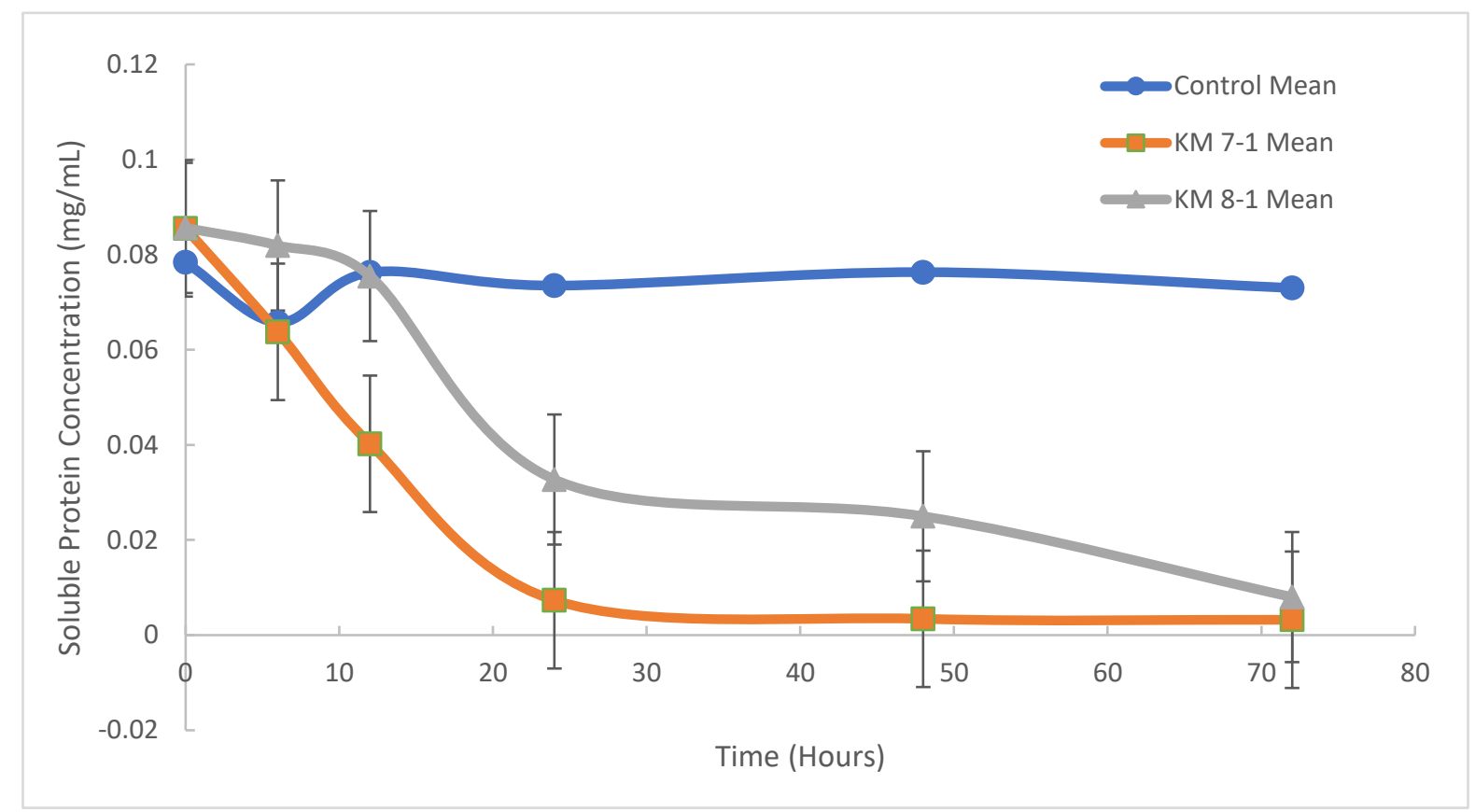

Figure 30. Graph of agave leaf juice fermentation soluble protein mean. Mean $\pm S D(n=9 ; 3$ replicates from each of the 3 fermentations) soluble protein concentration as a function of fermentation time in agave leaf juice fermentations.

\section{Ethanol}

\section{Cocoa Pod Husk Fermentations}

Ethanol concentrations for the $\mathrm{CPH}$ fermentations with either $\mathrm{KM} \mathrm{7-1}$ or KM 8-1 were very low; so low, in fact, that no ethanol values were detected after the preliminary fermentations with the $\mathrm{CPH}$ substrate (data not shown). Only one sample 
with any of the $\mathrm{CPH}$ fermentations registered an ethanol concentration above that of the controls with no added yeast. The KM 7-1 fermentation sample that had the highest ethanol concentration was collected at 24 hours; however, the concentration was less than $1.0 \mathrm{mg} / \mathrm{mL}$. The ethanol concentration in the $\mathrm{KM} \mathrm{8-1} \mathrm{fermentation} \mathrm{samples} \mathrm{was}$ considerably lower, no higher than that measured in control flasks. Ethanol concentrations in the agave leaf juice fermentations were much more substantial.

\section{Agave Leaf Juice Fermentations}

The agave leaf juice fermentations, with both $K$. marxianus strains, resulted in substantially higher ethanol concentrations than did $\mathrm{CPH}$ in water fermentations. Relative to flasks with no yeasts, ethanol concentrations started to increase first in KM 7-1 fermentations in the 12-hour samples. These data correlated well with the visual appearance of the fermentation flasks and the CFU data. At 12 hours, KM 7-1 contained about $1.25 \%$ ethanol, while the KM 8-1 fermentation vessels only contained $0.16 \%$ at the same, 12 -hour time point. At the 24-hour time point, KM 8-1 had approximately the same detectable amount of ethanol as the KM 7-1 fermentations at approximately $2.4 \%$ ethanol. Both strains stayed fairly even through the remainder of the fermentation time points at approximately $2.6 \%$ ethanol. A graph of the mean \pm standard deviation $(n=3)$ ethanol concentrations in the agave leaf juice fermentations is shown in Figure 31. 


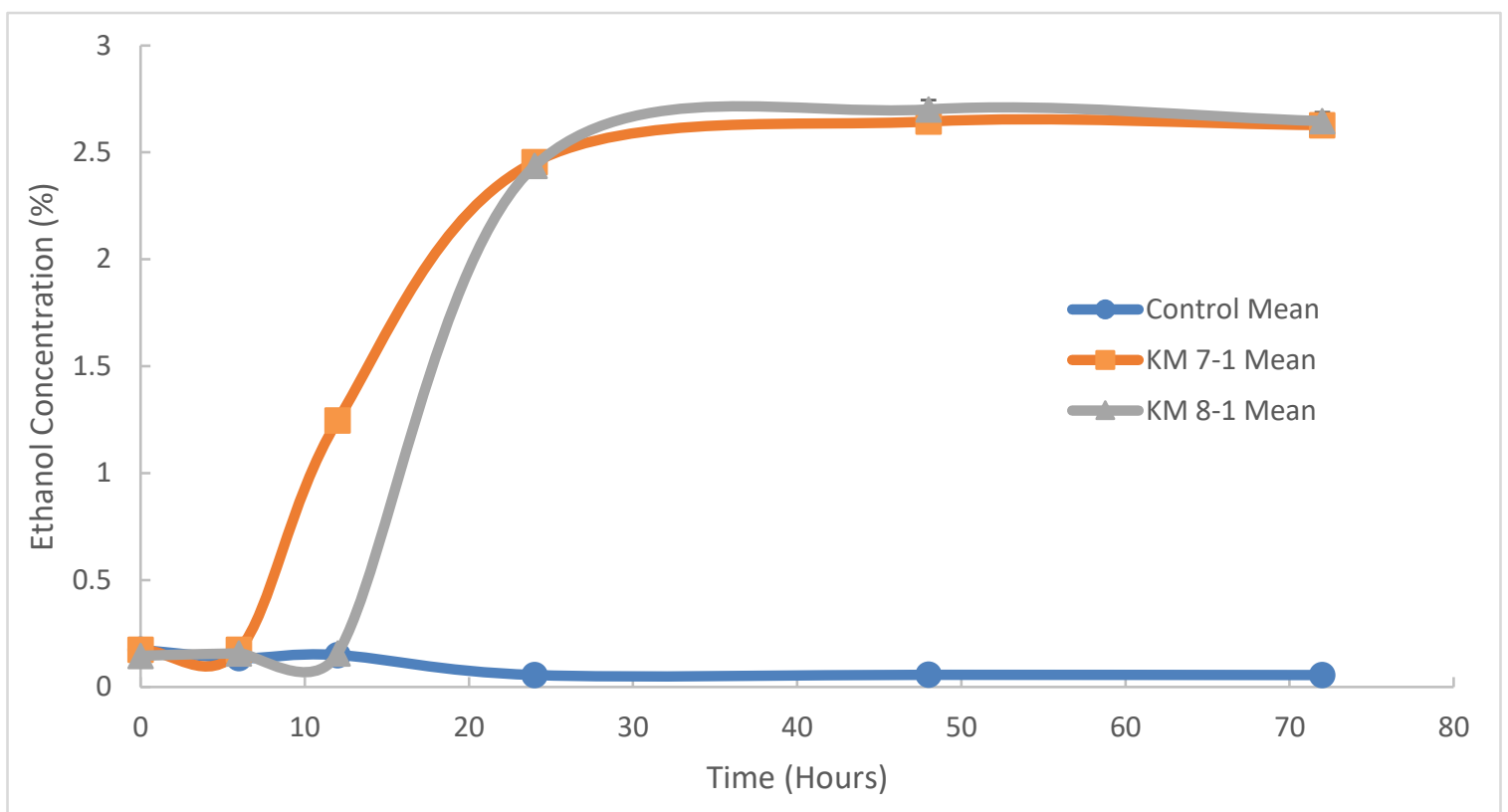

Figure 31. Graph of agave leaf juice fermentation ethanol mean. Mean \pm standard deviation ( $n=3$ replicates from each fermentation) ethanol concentration graphed as a function of fermentation time with the agave leaf juice fermentations.

\section{Data Overlays}

Data overlays were put together so that the possible relationships between separate data sets can be more easily seen. The data overlaid for $\mathrm{CPH}$ fermentations include CFUs and reducing sugars, as well as CFUs and soluble proteins. With agave juice fermentations, CFUs are overlaid with reducing sugars, CFUs with soluble proteins and CFUs with ethanol. In general, as CFUs increased, these nutrients decreased while ethanol concentration increased. Since ethanol is a yeast waste product, it increased as CFUs increased, but did not decrease substantially when the yeast populations reached senescence phase and started to die off. This indicated that the ethanol is stable under these conditions and not being spontaneously degraded or metabolized. 


\section{Cocoa Pod Husk Fermentations}

With $\mathrm{CPH}$ fermentations, either reducing sugar concentration or protein concentration are overlaid with CFUs. While decreasing reducing sugars compared with CFUs are indicative of fermentation progress, the soluble protein with CFUs is not as interesting because $\mathrm{CPH}$ proteins were not substantially consumed as a function of fermentation time and CFU growth. Both CFU concentration with average reducing sugar concentration (Figure 32) and CFU concentration with average soluble protein concentration (Figure 33) graphs are shown.

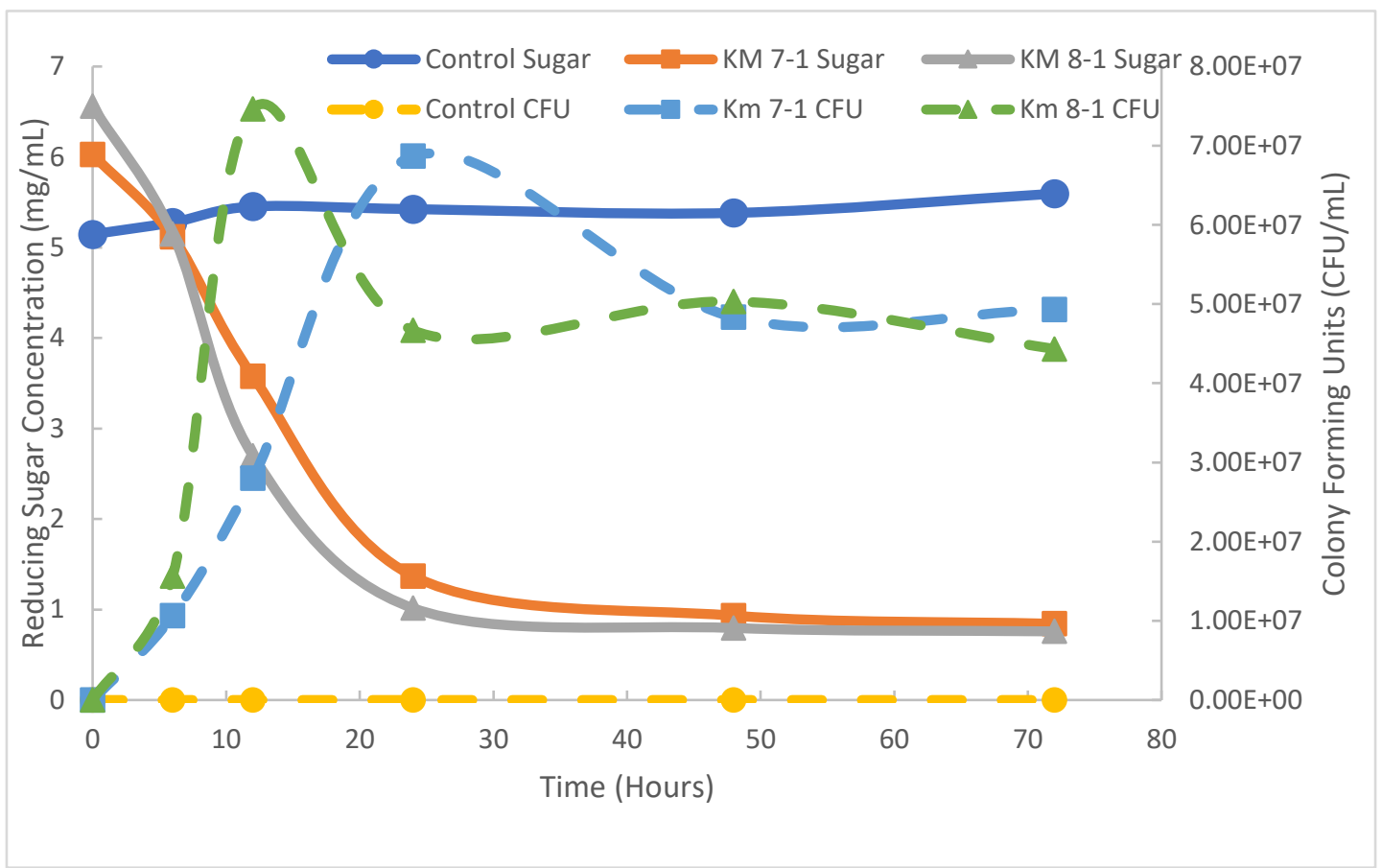

Figure 32. Overlay of cocoa pod husk colony forming units and reducing sugar. CFU concentration mean ( $n=3$ replicates from each fermentation) overlaid with mean reducing sugar concentration $(n=9 ; 3$ replicates from each of the 3 fermentations) as a function of fermentation time for $\mathrm{CPH}$ in water fermentations. 


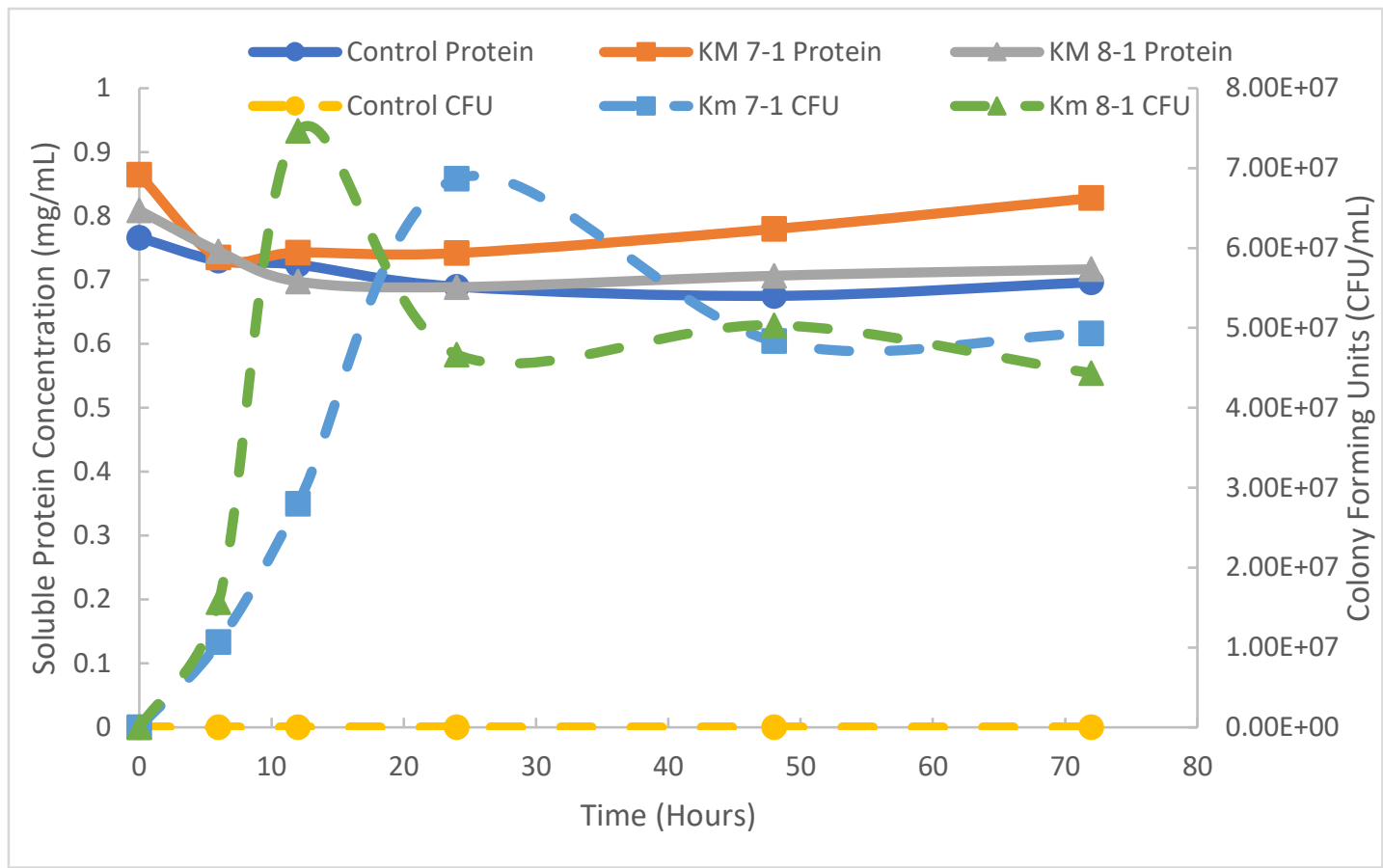

Figure 33. Overlay of cocoa pod husk colony forming units and soluble protein. CFU concentration mean ( $n=3$ replicates from each fermentation) overlaid with mean soluble protein concentration $(n=9 ; 3$ replicates from each of the 3 fermentations) as a function of fermentation time for $\mathrm{CPH}$ in water fermentations.

\section{Agave Leaf Juice Fermentations}

Data overlays for agave leaf juice fermentations are shown. These overlays help to compare the various data that were collected with these fermentations. CFU concentration with average reducing sugar concentration (Figure 34), CFU concentration with average soluble protein concentration (Figure 35) and CFU concentration with average ethanol concentrations (Figure 36) are indicative of fermentation progress. Reducing sugars and soluble proteins were consumed while colony forming units and ethanol concentration both increased as a function of fermentation time. 


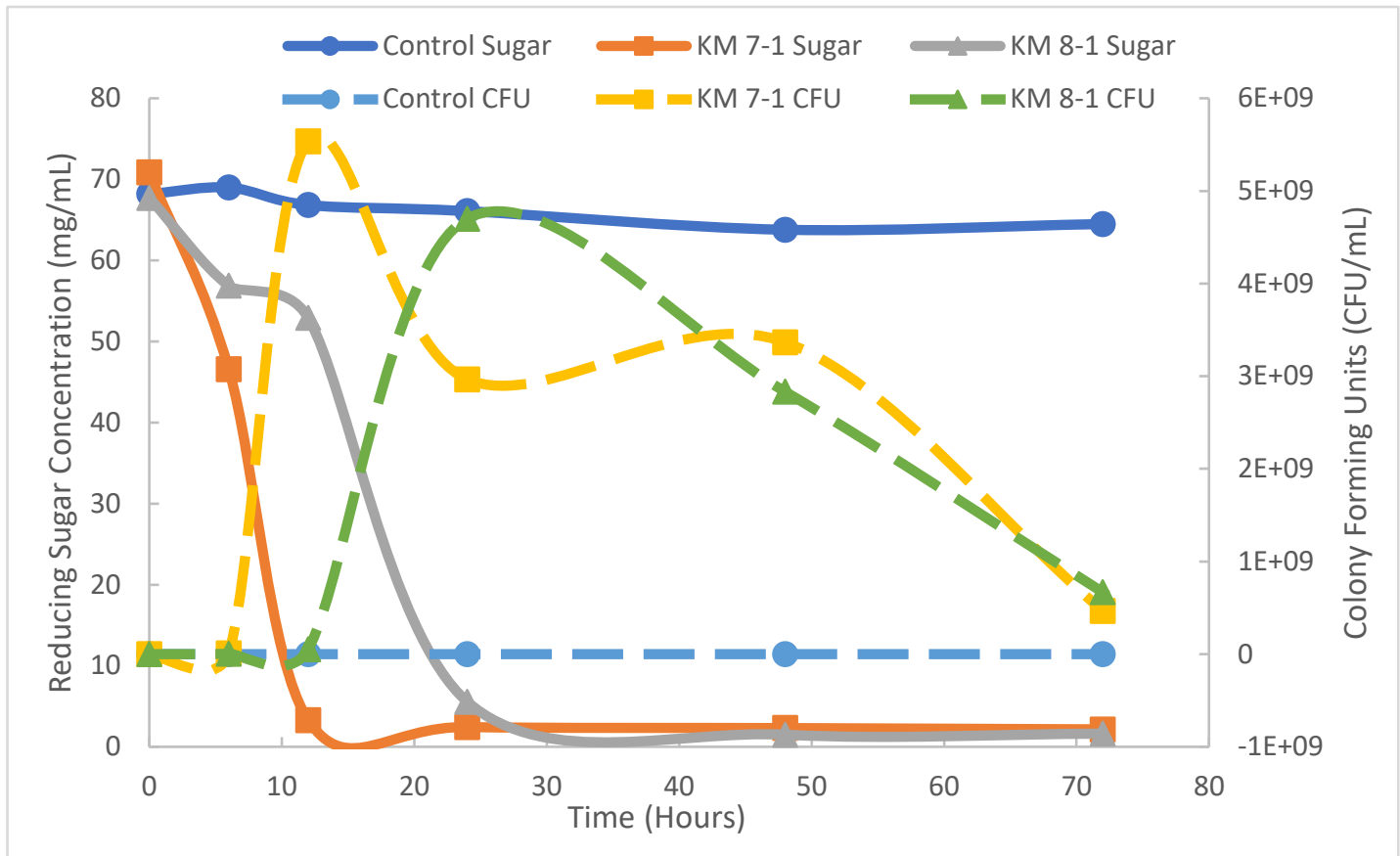

Figure 34. Overlay of agave leaf juice colony forming units and reducing sugar. CFU concentration mean ( $n=3$ replicates from each fermentation) overlaid with mean reducing sugar concentration ( $n=9 ; 3$ replicates from each of the 3 fermentations) as a function of fermentation time for agave leaf juice fermentations.

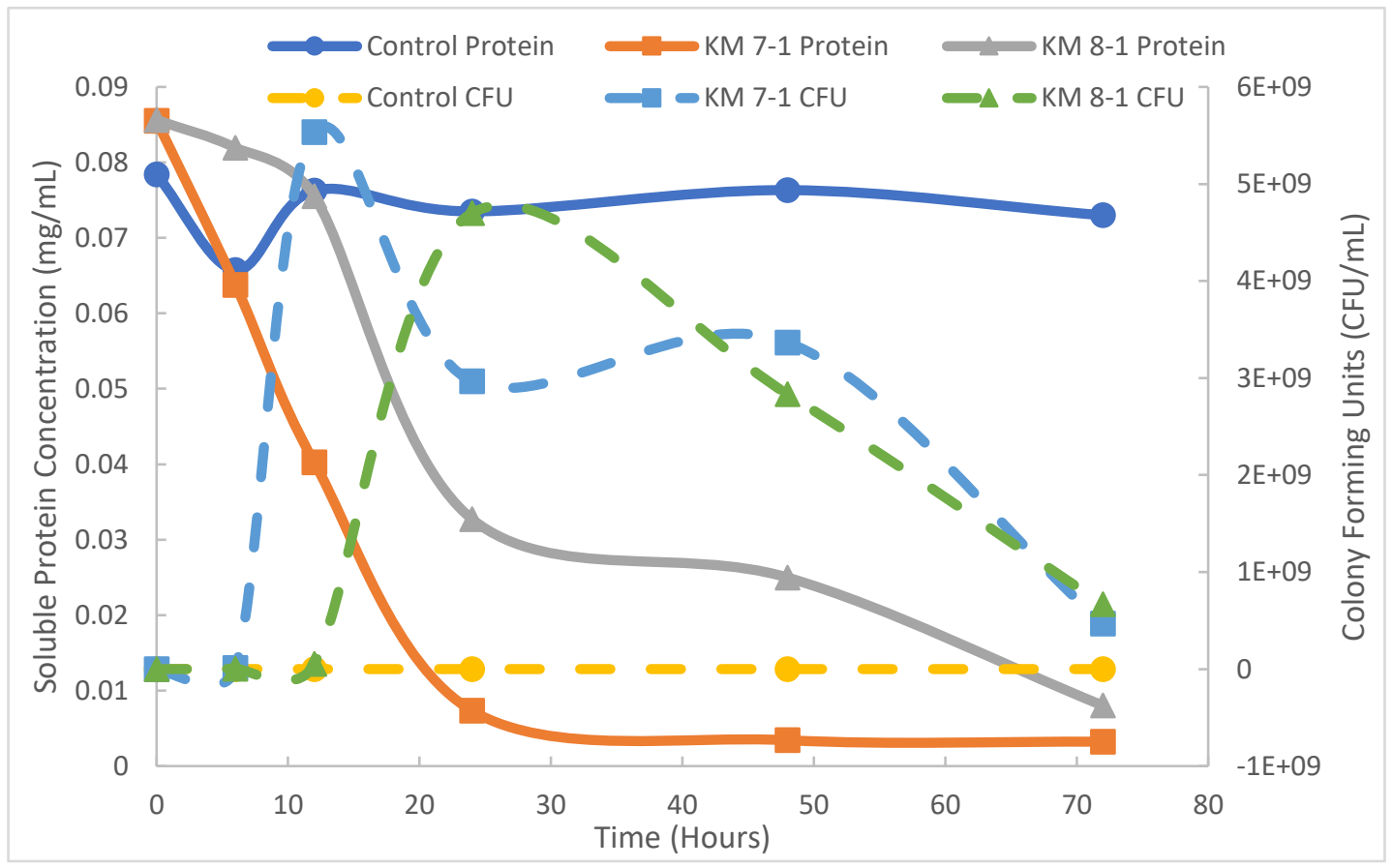

Figure 35. Overlay of agave leaf juice colony forming units and soluble protein. CFU concentration mean ( $n=3$ replicates from each fermentation) overlaid with mean soluble protein concentration $(n=9 ; 3$ replicates from each of the 3 fermentations) as a function of fermentation time for agave leaf juice fermentations. 


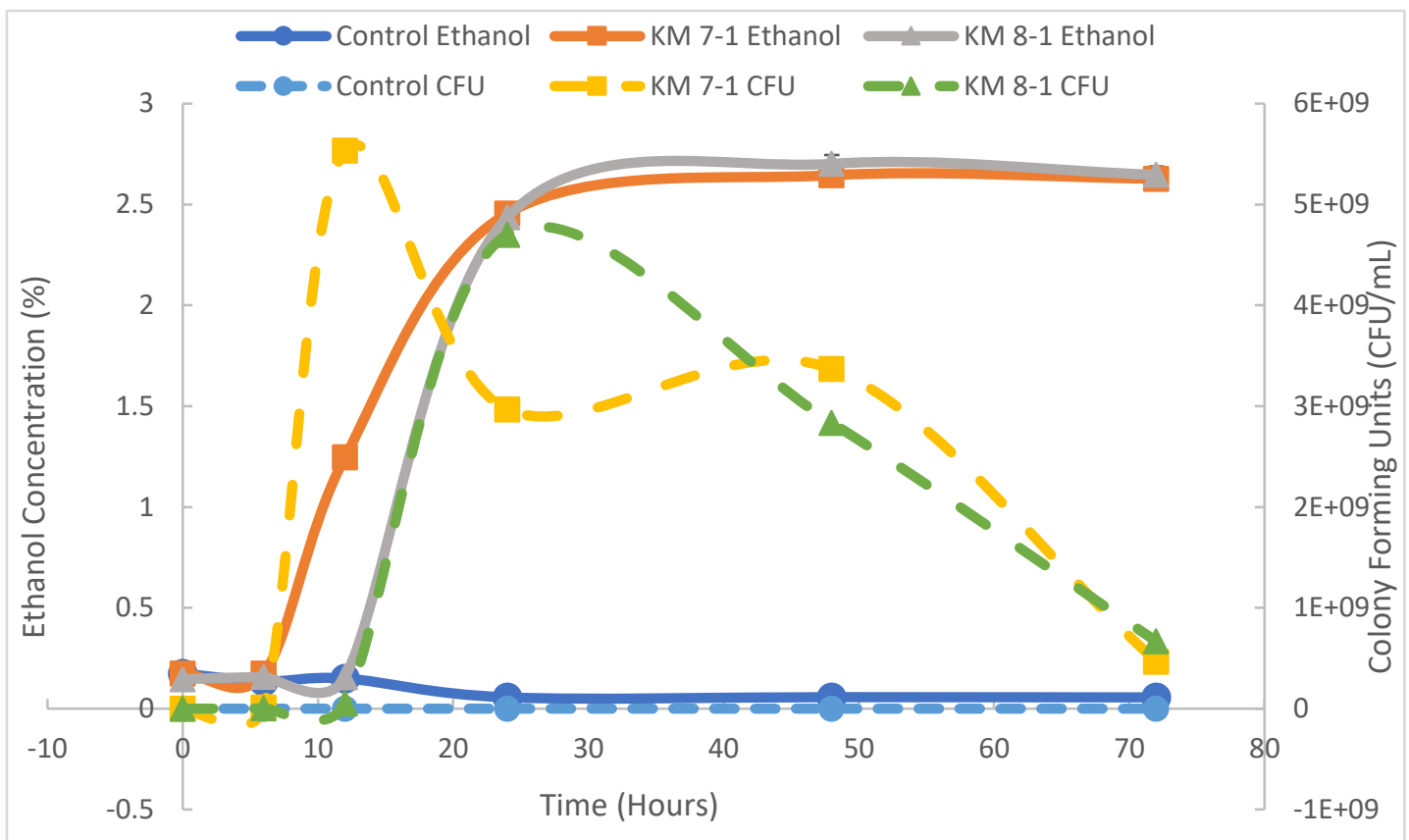

Figure 36. Overlay of agave leaf juice colony forming units and ethanol. CFU concentration mean ( $n=3$ replicates from each fermentation) overlaid with mean ethanol concentration $(n=3)$ as a function of fermentation time for agave leaf juice fermentations.

\section{Data Normalizations}

These data normalizations were performed so that the data could be compared more effectively. The data normalization, in this case, consists of dividing CFUs by either reducing sugar concentration or soluble protein concentration. These normalizations were performed for both $\mathrm{CPH}$ fermentations and agave leaf juice fermentations, resulting in four graphs in total which are included and described below. CFU concentration divided by ethanol concentration was not performed, as ethanol is produced by fermentation as opposed to being consumed. 


\section{Cocoa Pod Husk Fermentations}

With $\mathrm{CPH}$ fermentations, CFUs are divided by both reducing sugar concentration (Figure 37) and soluble protein concentration (Figure 38). Both these data normalizations do not separate the data any more than the data were separated before normalization. With the CFU data and reducing sugar data, normalization actually results in trends from the two yeast strains being more similar than when data are not normalized. The CFU and protein data normalization has little effect on the values graphed; plots of CFUs divided by protein concentrations appear almost identical to the CFU plots. This indicates that both of these yeast strains perform very similarly with the $\mathrm{CPH}$ in water fermentations. These normalizations, therefore, do not show that either $K$. marxianus species are clearly better than the other at fermenting $\mathrm{CPH}$ as a substrate.

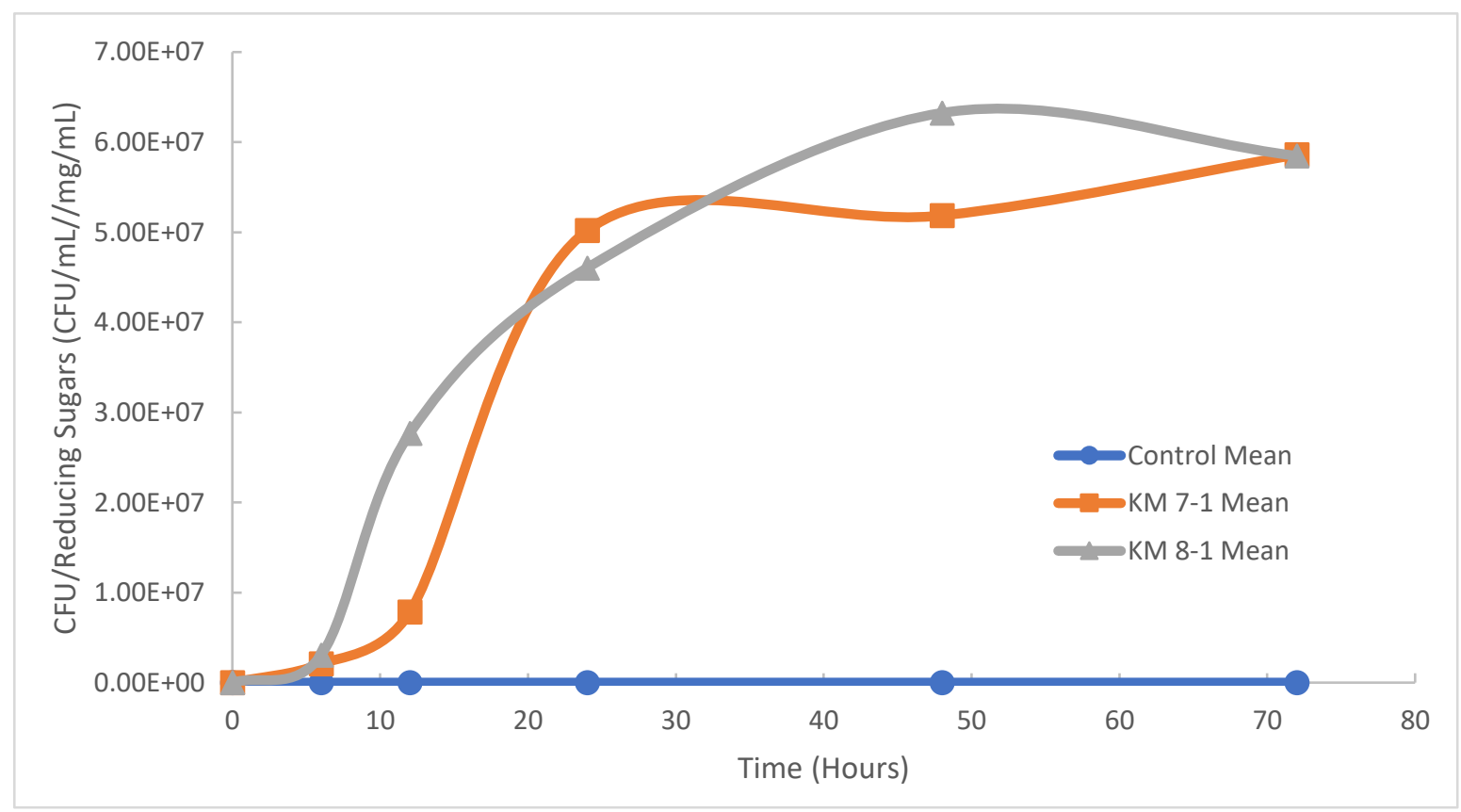

Figure 37. Graph of cocoa pod husk normalized colony forming units. CFU concentration mean ( $n=3$ replicates from each fermentation) divided by reducing sugar concentration mean ( $n=9 ; 3$ replicates from each of the 3 fermentations) as a function of fermentation time for $\mathrm{CPH}$ fermentations. 


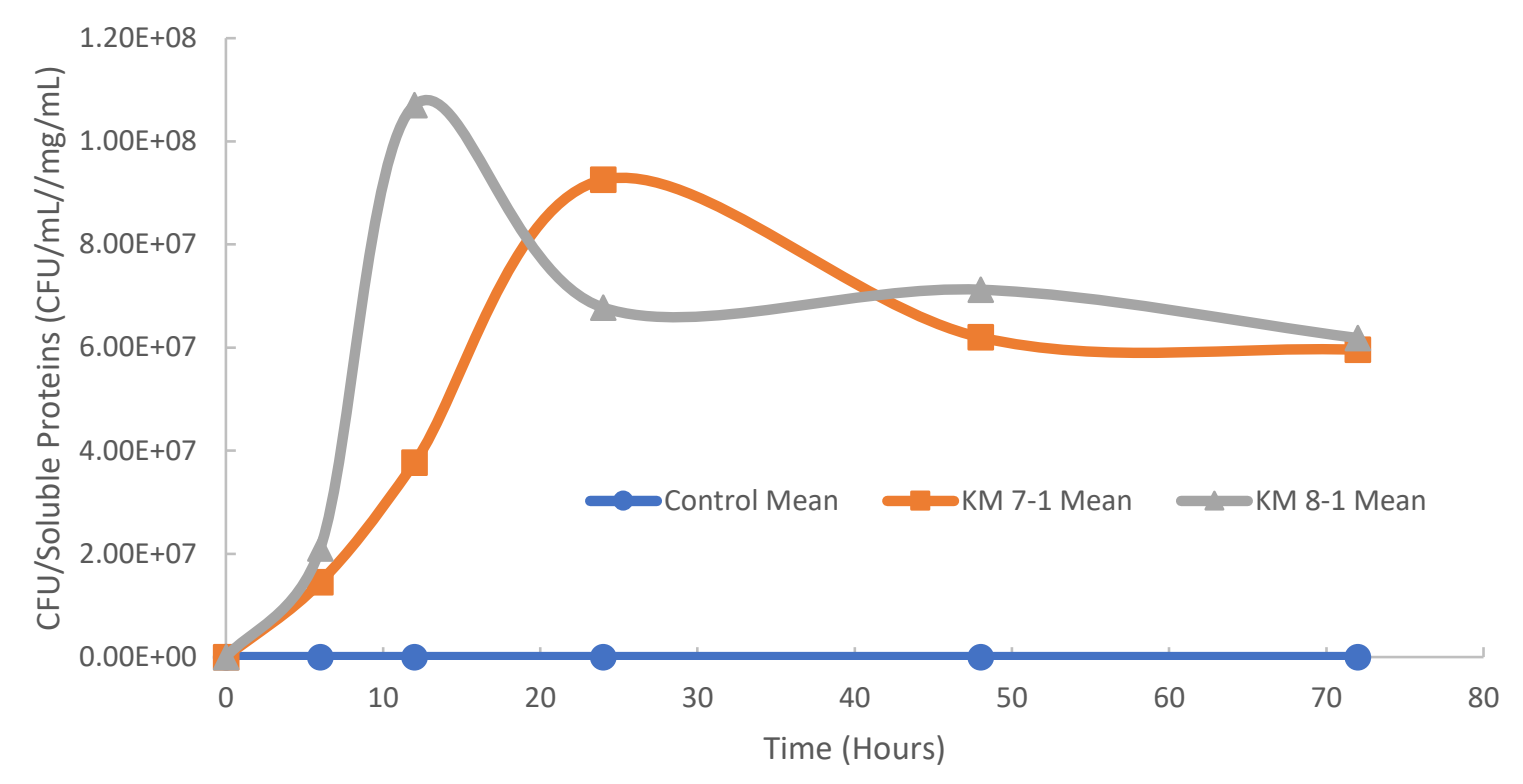

Figure 38. Graph of cocoa pod husk normalized colony forming units. CFU concentration mean ( $n=3$ replicates from each fermentation) divided by soluble protein concentration mean ( $n=9 ; 3$ replicates from each of the 3 fermentations) as a function of fermentation time for $\mathrm{CPH}$ fermentations.

\section{Agave Leaf Juice Fermentations}

With agave leaf juice fermentations, the data normalizations were performed in the same manner as described above. With the CFU concentration divided by the reducing sugar concentration (Figure 39), data points are not much more separated than they were before they are normalized. With the CFU concentration divided by the soluble protein concentration normalization (Figure 40), however, data points do have greater separation than seen without normalization. This data normalization allows for greater separation of the graphical representation of the growth cycle of these yeast strains. Additionally, especially when the CFU data were divided by the soluble protein data (Figure 40), KM 7-1 appears, again, to be superior to KM 8-1 at fermenting agave leaf juice as when the data were not normalized. 


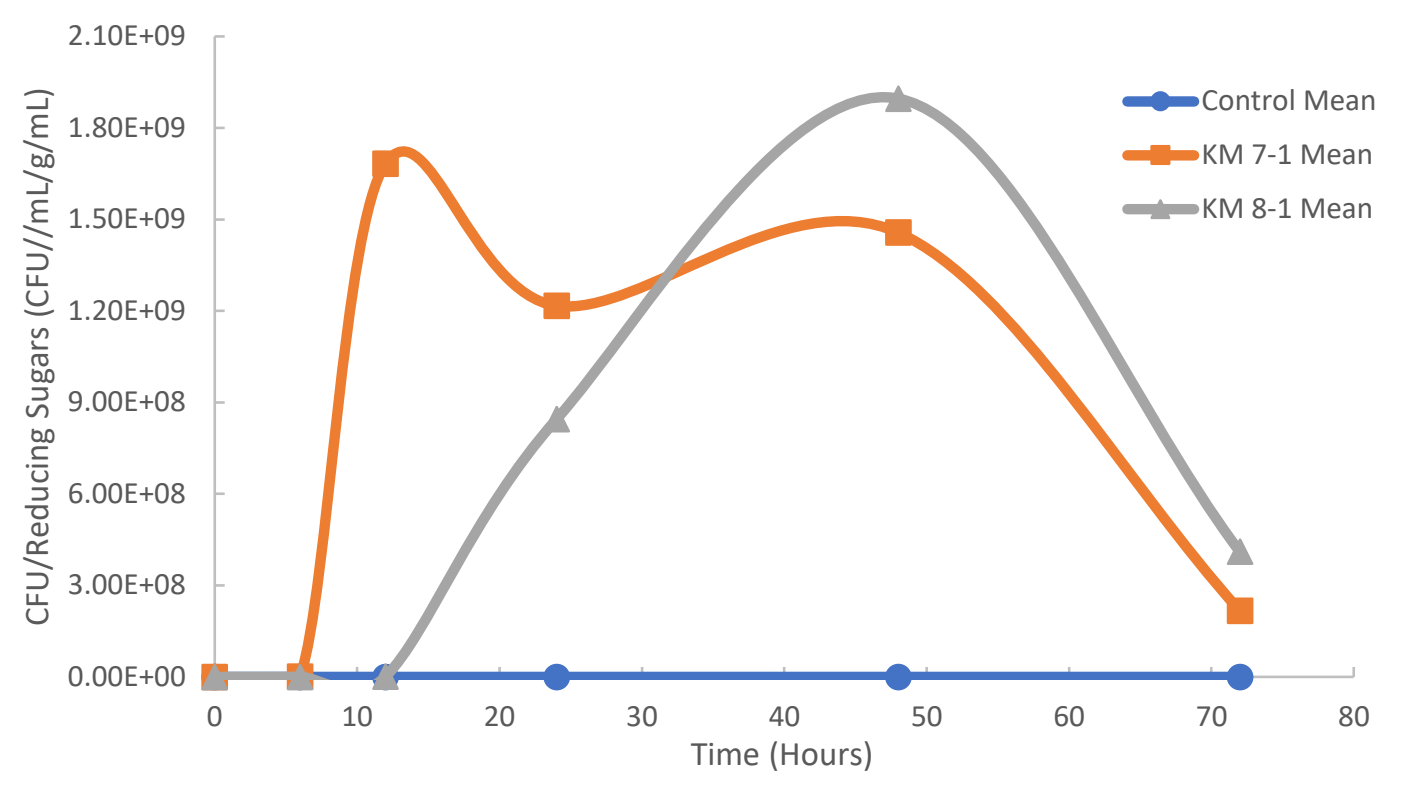

Figure 39. Graph of agave leaf juice normalized colony forming units. CFU concentration mean ( $n=3$ replicates from each fermentation) divided by reducing sugar concentration mean ( $n=9 ; 3$ replicates from each of the 3 fermentations) as a function of fermentation time for agave leaf juice fermentations.

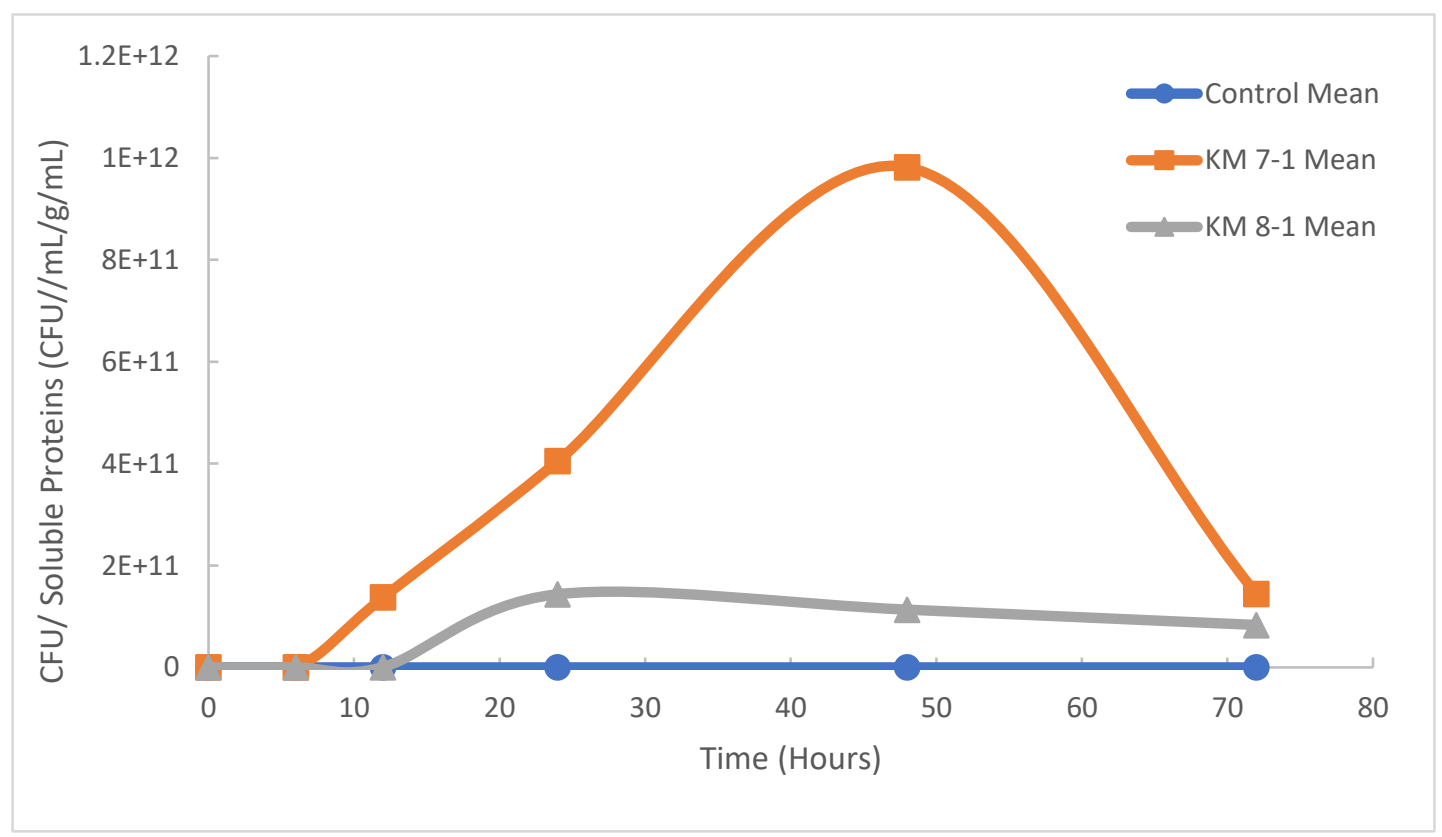

Figure 40. Graph of agave leaf juice normalized colony forming units. CFU concentration mean ( $n=3$ replicates from each fermentation) divided by soluble protein concentration mean ( $n=9 ; 3$ replicates from each of the 3 fermentations) as a function of fermentation time for agave leaf juice fermentations. 


\section{pH}

\section{Cocoa Pod Husk Fermentations}

The $\mathrm{pH}$ associated with these fermentations was evaluated for each sample taken. To measure $\mathrm{pH}$, approximately $60 \mu \mathrm{L}$ of each sample was spotted onto a Whatman ${ }^{\circledR} \mathrm{pH}$ Indicator Paper ( $\mathrm{pH}$ range: 4.5 to 10.0; no error listed). The $\mathrm{CPH}$ fermentations all started out with a $\mathrm{pH}$ of approximately 6 . The $\mathrm{pH}$ of control flasks changed only slightly; from initial $\mathrm{pH}$ value of 6.0 to $\mathrm{pH} 6.5$ by 12 hours, where it remained throughout the fermentation. As shown in Figure 41, the $\mathrm{pH}$ of the flasks that contained added yeast cells changed throughout the fermentation; the $\mathrm{pH}$ of the $\mathrm{KM}$ 8-1 fermentations (shown on right) had the largest change, from 5.0 to 7.5 , thus, over $2 \mathrm{pH}$ units. The $\mathrm{pH}$ of the $\mathrm{CPH}$ fermentation broths changed as the fermentations progressed. The $\mathrm{pH}$ value decreased at 6 hours from inoculation with KM 8-1. This $\mathrm{pH}$ shift is likely, in part, due to the production of carbon dioxide gas as a result of anaerobic fermentation. When $\mathrm{CO}_{2}$ reacts with water, carbonic acid is formed and $\mathrm{pH}$ values decrease. Metabolism of the polysaccharide pectin could have also contributed to this $\mathrm{pH}$ change, as pectin is comprised of galacturonic acid monomers. At approximately the same time as the CFUs were at their highest level, $\mathrm{pH}$ was at its most acidic; indicating the highest concentration of protons in fermentation broths. The $\mathrm{pH}$ value increased from $\mathrm{pH} 5.0$ with 12 -hour samples to $\mathrm{pH} 7.0$ or 7.5 at 72 hours. The $\mathrm{pH}$ of the fermentation broths started to rise when the CFUs values have begun to decrease; decreased metabolic activity allows for the buffering ability of the $\mathrm{CPH}$ to sequester the protons in solution. By 72 hours and termination of fermentations, the $\mathrm{pH}$ of fermentation broths was more alkaline than the levels which were monitored when 
fermentations began. The same trend is evident for the KM 7-1 strain, but the alkalization is, perhaps, somewhat lower. The change in $\mathrm{pH}$ with $\mathrm{CPH}$ fermentations is of interest, especially when the high (nearly 10 -fold when compared to agave leaf juice) protein concentration of the $\mathrm{CPH}$ fermentations were considered. Proteins in solution typically act as a buffer and, thus, stabilize $\mathrm{pH}$ values.

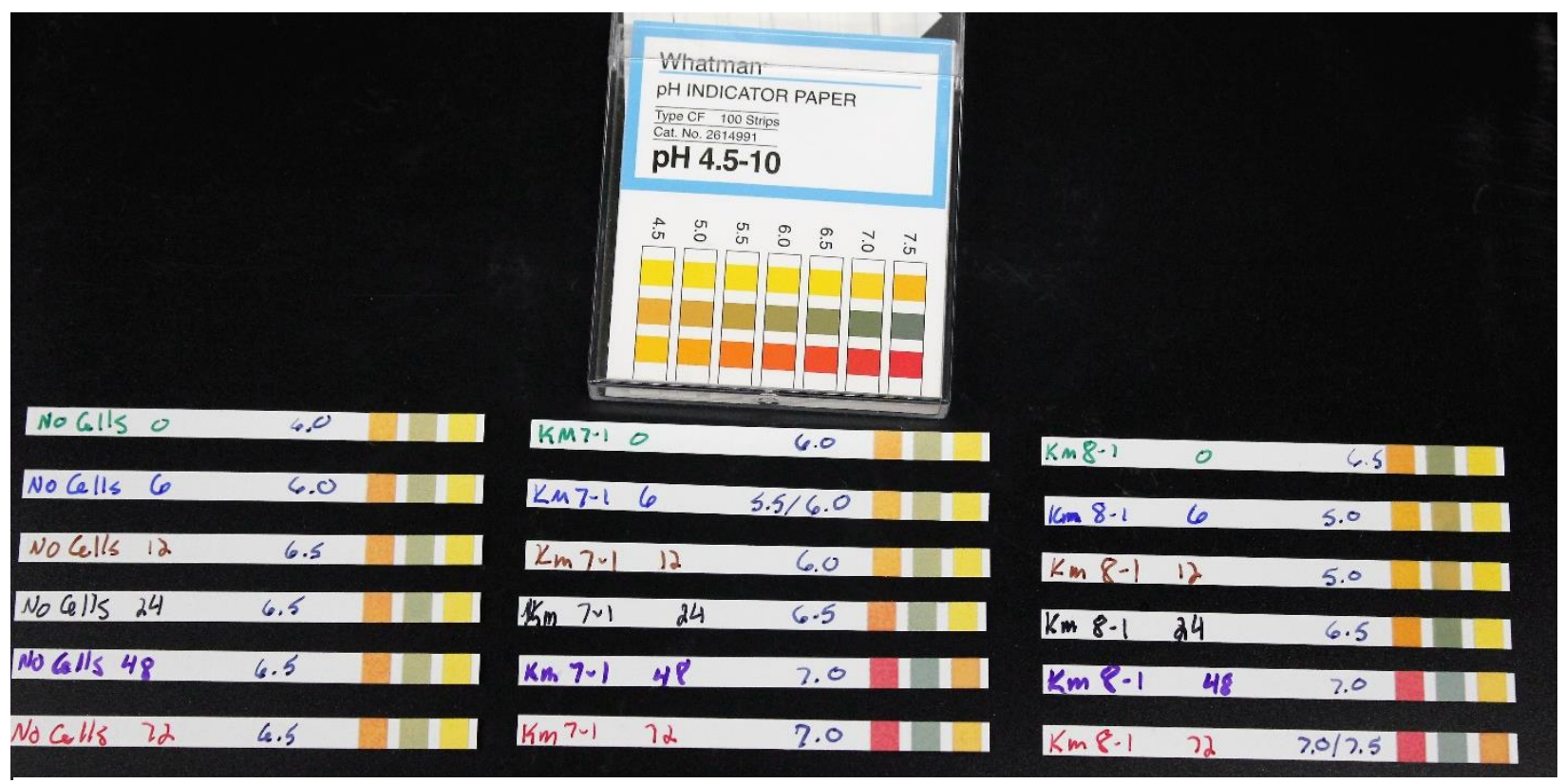

Figure 41. Picture of cocoa pod husk pH strips. The strips on the left show control fermentations with no cells at 0 to 72 hours. The center column shows $\mathrm{pH}$ strips used to measure KM 7-1 fermentations of $\mathrm{CPH}$ and strips in the right column show $\mathrm{pH}$ strips used to measure KM 8-1 fermentations of $\mathrm{CPH}$. Fermentation, sample time and $\mathrm{pH}$ are labeled on the $\mathrm{pH}$ strip.

\section{Agave Leaf Juice Fermentations}

The $\mathrm{pH}$ of agave leaf juice fermentations was monitored in the same manner as was the $\mathrm{pH}$ of $\mathrm{CPH}$ fermentations. With agave leaf juice fermentations, however, the $\mathrm{pH}$ did not change throughout the fermentation (data not shown). The $\mathrm{pH}$ measured approximately 4.5 with the Whatman® $\mathrm{pH}$ Indicator Paper. The $\mathrm{pH}$ values did not 
change throughout the fermentations in any flasks, regardless of the contents. This implies that agave juice has a large buffering ability since $\mathrm{CO}_{2}$ is produced when carbohydrates are fermented to ethanol.

\section{Thin Layer Chromatography}

Thin layer chromatography was used to test for the presence of monosaccharides, polysaccharides and amines in both $\mathrm{CPH}$ and agave leaf juice fermentations as shown in Figure 42 (a \& b). The standards used to compare $\mathrm{CPH}$ fermentation, agave leaf juice fermentation and control fermentation samples were orange peel pectin, inulin from chicory, laboratory grade fructose and BSA. All standards were dissolved in nanopure water at a concentration of $1.0 \mathrm{mg} / \mathrm{mL}$, spotted onto a TLC plate and analyzed as described in the materials and methods section. The results indicated the presence of polysaccharides, monosaccharides and proteins (and potentially amino acids) in both $\mathrm{CPH}$ and agave leaf juice fermentations. The plate in which amines were most evident, after spraying with ninhydrin solution, in $\mathrm{CPH}$ fermentations was the one with $6 \mu \mathrm{L}$ of sample spotted into each lane [Figure $42(\mathrm{a})$ ]. The plate in which sugars were evident, but not overloaded with the agave leaf juice fermentations, was the plate with only $3 \mu \mathrm{L}$ of sample per lane [Figure 42 (b)]. In Figure 42 (a), the pink color indicated the presence of amines. In Figure 42 (b), the dark, char marks indicated the presence of both monosaccharides and polysaccharides in the samples. The larger molecular weight polysaccharides, such as inulin and pectin [lanes 2 and 3 in Figures $42(a \& b)]$ did not migrate in this solvent system. 


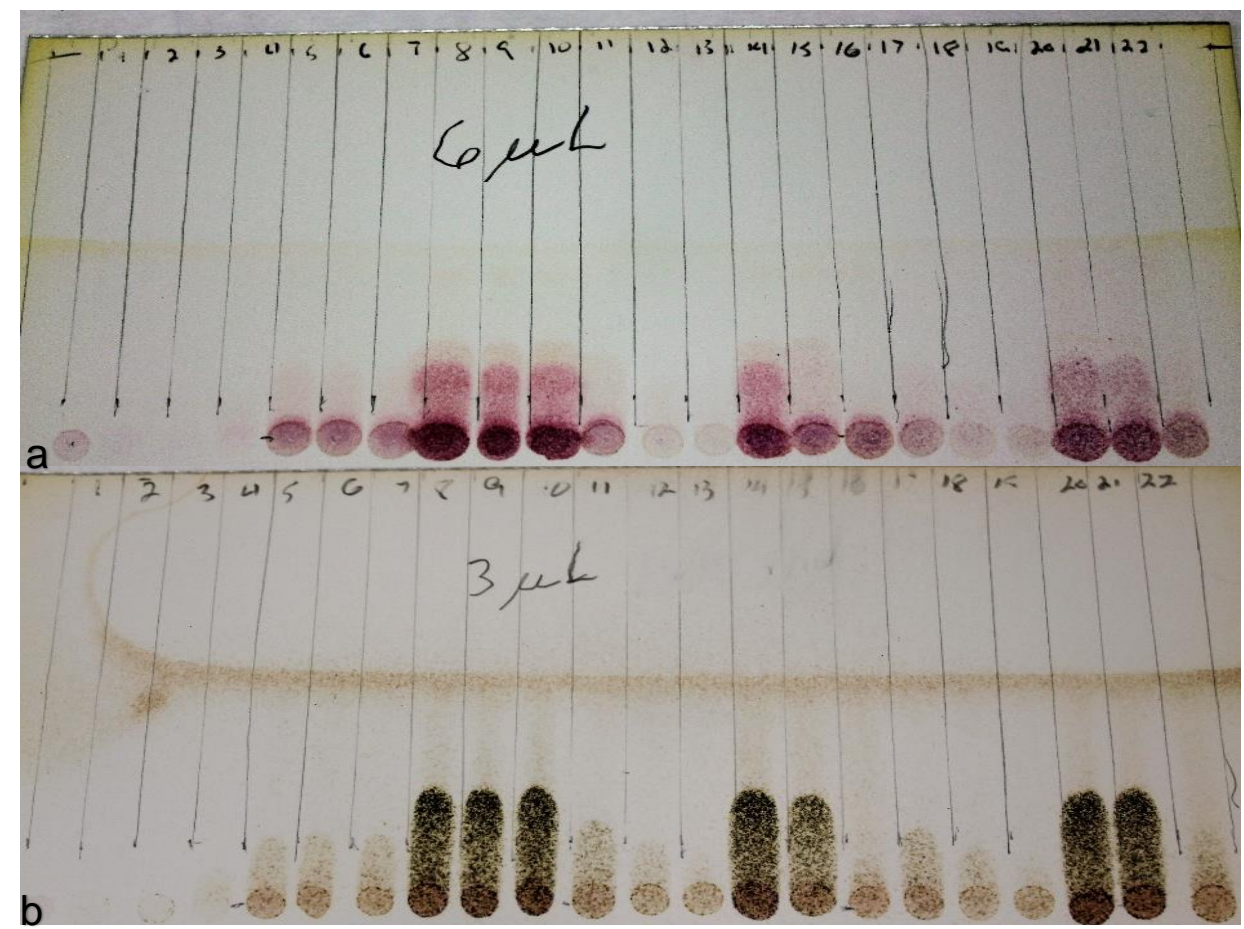

Figure 42 a \& b. Picture of developed TLC plates. These plates were used to analyze the presence of amines (a), and sugars (b) in both types of fermentations.

Table 1. TLC Plates Key

\begin{tabular}{cc}
\hline Lane Number & Sample Description \\
\hline 1 & BSA Standard \\
2 & Pectin Standard \\
3 & Inulin Standard \\
4 & Fructose Standard \\
5 & CPH No Cells (0 Hour) \\
6 & CPH No Cells (12 Hour) \\
7 & CPH No Cells (24 Hour) \\
8 & Agave Leaf Juice No Cells (0 Hour) \\
9 & Agave Leaf Juice No Cells (12 Hour) \\
10 & Agave Leaf Juice No Cells (24 Hour) \\
11 & CPH Plus KM 7-1 (0 Hour) \\
12 & CPH Plus KM 7-1 (12 Hour) \\
13 & CPH Plus KM 7-1 (24 Hour) \\
14 & Agave Leaf Juice Plus KM 7-1 (0 Hour) \\
15 & Agave Leaf Juice Plus KM 7-1 (12 Hour) \\
16 & Agave Leaf Juice Plus KM 7-1 (24 Hour) \\
17 & CPH Plus KM 8-1 (0 Hour) \\
18 & CPH Plus KM 8-1 (12 Hour) \\
20 & CPH Plus KM 8-1 (24 Hour) \\
21 & Agave Leaf Juice Plus KM 8-1 (0 Hour) \\
22 & Agave Leaf Juice Plus KM 8-1 (12 Hour) \\
Agave Leaf Juice Plus KM 8-1 (24 Hour) \\
\hline
\end{tabular}




\section{Two Stage Fermentations}

These agave leaf juice or $\mathrm{CPH}$ fermentations, after progressing for 72 hours and being frozen at $-80^{\circ} \mathrm{C}$ to terminate the activity of the $K$. marxianus yeast strains, were fermented again with another organism: Yarrowia lipolytica $F$. This two-stage fermentation was made possible through a collaborative effort with Dr. Jones' research lab and the United States Department of Agriculture, specifically, Dr. Stephen Hughes and Mr. Mitchell Lindquist. While both K. marxianus species ferment sugars very well, this Yarrowia strain is reported to utilize proteins much more efficiently than does either of the $K$. marxianus species used in this thesis ${ }^{35}$. The first stage $K$. marxianus fermentations were sterilized by autoclave to kill the yeasts and, subsequently, inoculated with Yarrowia, fermented for another 72 hours, and sampled at predetermined time intervals. Mr. Lindquist conducted these secondary fermentations at the USDA facility in Peoria, IL. He monitored the concentrations of ammonia and CFUs and sent the data to Dr. Jones' lab. With the Yarrowia fermentations, colony forming units, and soluble ammonia concentrations were assessed from the samples collected. The results of these Yarrowia fermentations are included in Table 2; also included in the Table 2 are selected data from both strains of the K. marxianus first stage fermentations. 
Table 2. First and Second Stage Fermentation Results

\begin{tabular}{|c|c|c|c|c|c|c|c|}
\hline \multirow{2}{*}{\multicolumn{2}{|c|}{$\begin{array}{l}\text { First } \\
\text { Stage } \\
\text { Fermentation }\end{array}$}} & \multicolumn{2}{|c|}{ Control } & \multicolumn{2}{|c|}{ KM 7-1 } & \multicolumn{2}{|c|}{ KM 8-1 } \\
\hline & & Value & $\begin{array}{c}\text { Time } \\
\text { (h) }\end{array}$ & Value & $\begin{array}{c}\text { Time } \\
\text { (h) }\end{array}$ & Value & $\begin{array}{c}\text { Time } \\
\text { (h) }\end{array}$ \\
\hline \multirow{3}{*}{$\begin{array}{l}\text { Blue } \\
\text { Agave } \\
\text { Juice }\end{array}$} & CFU Max & 0 & All & $5.5 \times 10^{9}$ & 12 & $4.7 \times 10^{9}$ & 24 \\
\hline & $\begin{array}{c}\text { Sugars } \\
\text { Min }\end{array}$ & $\begin{array}{c}70 \\
\mathrm{mg} / \mathrm{mL}\end{array}$ & All & $\begin{array}{c}2.3 \\
\mathrm{mg} / \mathrm{mL}\end{array}$ & $24-72$ & $\begin{array}{c}1.5 \\
\mathrm{mg} / \mathrm{mL}\end{array}$ & $48-72$ \\
\hline & $\begin{array}{l}\text { Proteins } \\
\text { Min }\end{array}$ & $\begin{array}{c}0.07 \\
\mathrm{mg} / \mathrm{mL}\end{array}$ & All & $\begin{array}{c}0.003 \\
\mathrm{mg} / \mathrm{mL}\end{array}$ & 48-72 & $\begin{array}{c}0.008 \\
\mathrm{mg} / \mathrm{mL}\end{array}$ & 72 \\
\hline \multirow[t]{2}{*}{$\begin{array}{l}\text { Cocoa } \\
\text { Pod } \\
\text { Husk }\end{array}$} & $\begin{array}{l}\text { CFU Max } \\
\text { Sugars } \\
\text { Min }\end{array}$ & $\begin{array}{c}0 \\
5.0 \\
\mathrm{mg} / \mathrm{mL}\end{array}$ & $\begin{array}{l}\text { All } \\
\text { All }\end{array}$ & $\begin{array}{c}6.9 \times 10^{7} \\
0.9\end{array}$ & $\begin{array}{c}24 \\
48-72\end{array}$ & $\begin{array}{c}7.5 \times 10^{7} \\
0.8 \\
\mathrm{mg} / \mathrm{mL}\end{array}$ & $\begin{array}{c}12 \\
48-72\end{array}$ \\
\hline & $\begin{array}{c}\text { Proteins } \\
\text { Min }\end{array}$ & $\begin{array}{c}0.7 \\
\mathrm{mg} / \mathrm{mL}\end{array}$ & All & $\begin{array}{c}0.7 \\
\mathrm{mg} / \mathrm{mL} \\
\end{array}$ & All & $\begin{array}{c}0.7 \\
\mathrm{mg} / \mathrm{mL} \\
\end{array}$ & All \\
\hline \multicolumn{8}{|c|}{----Sterilized and inoculated with Y. lipolytica $F$ for a second fermentation---- } \\
\hline Blue & CFU Max & $4.5 \times 10^{7}$ & 72 & $3.3 \times 10^{6}$ & 72 & $2.7 \times 10^{6}$ & 72 \\
\hline $\begin{array}{l}\text { Agave } \\
\text { Juice }\end{array}$ & $\underset{\text { Max }}{\text { Ammonia }}$ & $\begin{array}{c}0.039 \\
\mathrm{mg} / \mathrm{mL}\end{array}$ & 72 & $\begin{array}{c}0.066 \\
\mathrm{mg} / \mathrm{mL}\end{array}$ & 72 & $\begin{array}{c}0.052 \\
\mathrm{mg} / \mathrm{mL}\end{array}$ & 72 \\
\hline Cocoa & CFU Max & $5.1 \times 10^{8}$ & 72 & $2.4 \times 10^{8}$ & 72 & $1.8 \times 10^{8}$ & 72 \\
\hline $\begin{array}{l}\text { Pod } \\
\text { Husk }\end{array}$ & $\underset{\operatorname{Max}}{\text { Ammonia }}$ & $\begin{array}{c}0.040 \\
\mathrm{mg} / \mathrm{mL}\end{array}$ & 72 & $\begin{array}{r}0.019 \\
\mathrm{mg} / \mathrm{mL}\end{array}$ & 72 & $\begin{array}{l}0.0095 \\
\mathrm{mg} / \mathrm{mL}\end{array}$ & 72 \\
\hline
\end{tabular}

Table 2. This shows the colony forming units, soluble proteins and reducing sugars for the first stage fermentations. For second stage, Yarrowia fermentations, colony forming units are presented as well as ammonia. The control column are results with first stage fermentations with no $K$. marxianus yeast added.

Two-stage fermentation results show that the KM 7-1 fermented in agave juice yielded the highest soluble ammonia numbers $(0.066 \mathrm{mg} / \mathrm{mL})$ when all second stage fermentations were compared. With cocoa pod husk, the best ammonia production $(0.040 \mathrm{mg} / \mathrm{mL})$ came from the flasks that were not fermented with $K$. marxianus yeast; they were used as control flasks with first stage fermentations. The flasks used as controls in the K. marxianus fermentations were divided in half; one part was used to ferment the Yarrowia strain and the other was used as a control as it had no cells added to it in either fermentation. These flasks that had not been fermented with either K. marxianus strain in the first fermentation but were fermented with Yarrowia in the 
second stage fermentation produced the most ammonia by 72 hours and termination of the second stage fermentations. These flasks produced more than double that of the flasks that were first fermented with KM 7-1, and four times more ammonia than was measured in flasks that contained KM 8-1 in the first fermentation.

\section{Separations}

\section{Cocoa Pod Husk}

After the initial processing of the $\mathrm{CPH}$, freezing it at $-80^{\circ} \mathrm{C}$, and thawing it for use in fermentation studies, distinct layers became visible in the husk. These layers had different characteristics and each layer, presumably, has a different function. This assumption led to the mechanical separation of these layers from each other using a hobby knife. The observed characteristics of each layer and the process by which they were separated are shown in Figure 43 and described below.

The total mass of the section of husk used to separate was $4.2800 \mathrm{~g}$. The outermost layer of the cocoa pod husk (\#5 in Figure 43) was quite thin and tough. The mass of the outermost layer was $0.5660 \mathrm{~g}(\approx 13 \%)$ of the total $4.2800 \mathrm{~g}$ section of husk. It was the thinnest layer and the easiest to separate, but also very tough and resistant to tears and punctures (data not shown). The color of this layer was tan to dark brown. The layer directly beneath the skin (\#4) was the thickest layer; it was comprised of spongy fibers which made pockets. Inside these pockets was a shiny, sticky material, presumably pectin-rich deposits. This largest layer (\#4 in Figure 43) had a mass of $1.6337 \mathrm{~g}(\approx 38 \%)$ of the total $4.2800 \mathrm{~g}$; it was quite sticky when handled and was tan to dark brown in color. The layer inside the fibrous layer (\#3 in Figure 43) was the only 
layer that was discontinuous; it was present throughout the $\mathrm{CPH}$, but was not complete or was so thin in places that it was not apparent. This layer was gelatinous and appeared to be the richest in pectin. The color was off white and clarity was opaque; its mass was $0.5870 \mathrm{~g}(\approx 14 \%)$ of the total $4.2800 \mathrm{~g}$ sample. Inside this gelatinous layer was a thin, hard layer (\#2 in Figure 43). This thin layer was the hardest of the five layers separated and the most brittle. It was easily separated from the layer outside it, but difficult to separate from the layer inside it. The brittle layer weighed $0.8690 \mathrm{~g}$ $(\approx 20 \%)$ of the total $4.2800 \mathrm{~g}$ sample, and was tan in color. The layer (\#1 in Figure 43) which lined the cavity that contained the beans was fairly thin but not as thin as the outermost layer. It was dark brown with a leathery texture; this layer was very resistant to tearing, but was not as resistant to puncture (data not shown) as the outermost layer. The innermost layer weighed $0.6243 \mathrm{~g}(\approx 15 \%)$ of the total $4.2800 \mathrm{~g}$ sample; it clung to the hard, brittle layer beneath it making the separation of these two layers the most difficult of all the layers of the husk. These individual layers were sterilized by autoclave, then added to plates containing YPD + agar growth medium and spread with KM 7-1 or KM 8-1 to see if any of the layers had an inhibitory effect with the two $K$. marxianus yeast strains. Thus far, these tests show no inhibitory properties with respect to the K. marxianus yeasts (data not shown). 


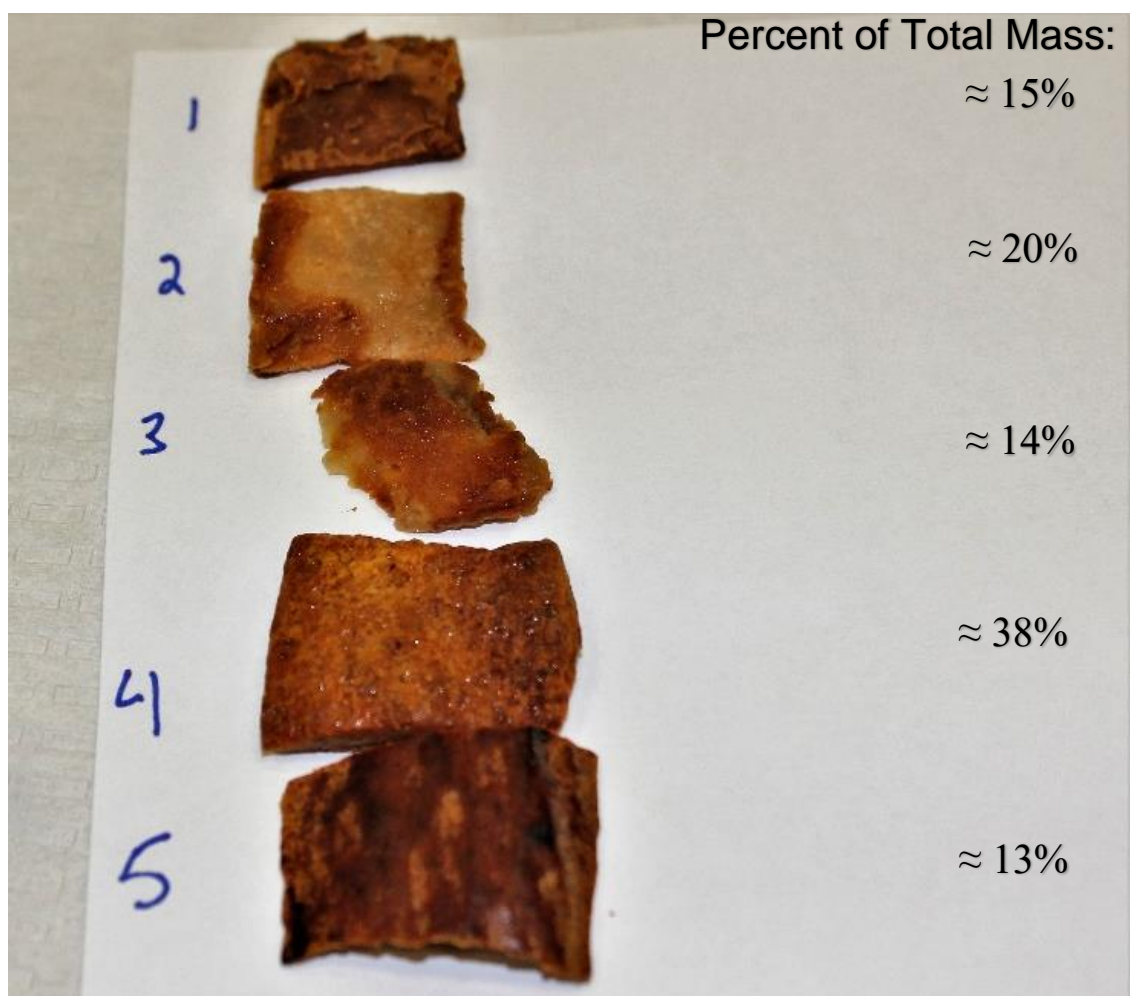

Figure 43. Picture of cocoa pod husk layer separations. Layer \#1 is the innermost layer while layer \#5 is the outermost. The other 3 are laid out in the order in which they appeared in the $\mathrm{CPH}$.

\section{Agave Leaf}

Blue Agave leaf skin, after removal as described in the materials and methods section, was used to test its inhibitory properties with $K$. Marxianus yeast strains. As with the cocoa pod husk layers, the agave leaf skin was added to solid support petri dishes that had been spread with either KM 7-1 or KM 8-1. These plates were then sealed, labeled and incubated at $35^{\circ} \mathrm{C}$ until plates were heavily loaded with yeast colonies. The agave leaf skin did not cause any noticeable inhibition with either $K$. marxianus species (data not shown). 


\section{CHAPTER IV: DISCUSSION AND CONCLUSIONS}

\section{Fermentations}

Important conclusions can be made about these fermentations in general. The method by which these fermentation inoculations were made equal and consistent was reasonably effective; with fermentation starter cultures, KM 7-1 was the more prolific yeast every time. Additionally, KM 7-1 outperformed KM 8-1 every time with agave leaf juice fermentations based on all parameters used to assess these fermentations. Until cocoa pod husk fermentations began, the technique with which these fermentations were equalized could not have been ruled out as the cause of the performance trends of the two closely related yeast strains. With the agave leaf juice, KM 7-1 was, almost always, the "better" yeast strain at fermenting the substrate. The validity and effectiveness of using spectrometry to equalize inoculations was reinforced with fermentations of $\mathrm{CPH}$. Inoculations were performed in the same manner and, with the different substrate, KM 8-1 was consistently the "better" yeast strain to use. KM 8-1 consistently had a higher CFU maximum, shorter lag phase and quicker depletion of available, monitored nutrients than did $\mathrm{KM} 7-1$ with $\mathrm{CPH}$ in water as the substrate. This consistent but different outcome with differing substrates reinforced the validity of using the method by which these inoculations were equalized.

\section{Agave Leaf Juice Fermentations}

Several conclusions can be drawn from the agave juice fermentations carried out in this thesis. First of all, these yeast strains, both KM 7-1 and KM 8-1, did ferment the juice pressed from the leaves of Blue Agave plants. Both strains thrived on the sugar- 
rich agave juice; both reached a CFU maximum by 24 hours and at a concentration of billions of cells per milliliter of Blue Agave juice. These yeast cell growth populations, when compared to fermentations of leaf solids under similar fermentation conditions ${ }^{15}$, resulted in approximately 100 times more cells per $\mathrm{mL}$ of culture. This implies that the nutritional content of these leaves is much more readily available to the yeasts when it is pressed as juice from the leaves. Availability of these nutrients, as well as the near complete consumption of the nutrients by these yeasts, make this type of fermentation more appealing when practical applications are considered. Additionally, pressing the juice for fermentation also makes available the agave leaf fibers for other applications. Thus, in an industrial setting, pressing the leaves to extract juice may be of large value. Change in appearance of the fermentations as a whole and of individual samples is a useful characteristic to monitor in fermentations of agave leaf juice. With fermentations conducted for research, analysis of several criteria was conducted to monitor the progress of metabolic processes. If these leaves were to be fermented on an industrial scale or fermented without analyzing the fermentation progress, color change could be used as an inexpensive indicator of when to terminate the fermentations. With both K. marxianus strains, most every nutrient that was monitored was depleted by 12 to 24 hours after the first noticeable color change occurred. As well as near complete consumption of nutrients, concentration of ethanol formed by the metabolism of sugars by the yeast was at or very near its maximum value in the same timeframe as nutrient depletion. By 48 hours after the color change was first noticed in these agave leaf juice fermentations, the yeast had entered senescence phase. If a fermentation were performed in which inexpensive indicators are desirable, color 
change and time from which these changes are first noticed are excellent indicators of progress in agave leaf juice fermentations.

The strain of K. marxianus that fermented the juice pressed from the leaves of Blue Agave plants the best was KM 7-1. This yeast strain reached its CFU maximum quicker and had the highest CFU maximum. The KM 7-1 CFU reached its peak with the 12-hour samples and achieved a maximum of around 5.5 billion cells per $\mathrm{mL}$ of broth, while KM 8-1 grew to a maximum of about 4.7 billion cells per $\mathrm{mL}$ and took 24 hours. A shorter lag phase, as well as an approximately $15 \%$ population increase, make KM 7-1 the moderately better yeast at fermenting Blue Agave leaf juice based on their CFU

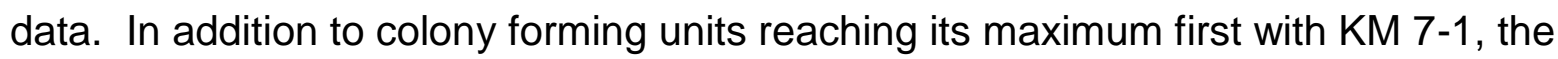
reducing sugars and soluble proteins were consumed, and ethanol production began to increase earlier in the fermentations with the KM 7-1 species. This is of interest, especially if production of the yeast is a long-term goal of the fermentations in addition to the degradation of the biomass.

Reducing sugar concentration of samples can be used to gauge the performance of the yeasts when fermenting agave leaf juice. Reducing sugars were consumed, almost completely, in the KM 7-1 fermentations by 12 hours. The KM 8-1 yeast required an additional 12 hours to reach similar reduction in concentrations of reducing sugars. KM 7-1 consumed approximately $95 \%$ of available reducing sugars by 12 hours; KM 8-1 took 24 hours to consume approximately $93 \%$ of the reducing sugars available in the fermenting juice. Once complete consumption of these sugars was achieved, these yeasts started to die out. With reducing sugar criteria in mind, KM 7-1 is, again, the better choice for fermentation of the Blue Agave leaf juice. 
Soluble protein concentrations of agave leaf juice fermentations followed trends similar to those observed with reducing sugars. As CFU increased, protein concentrations decreased; shortly after depletion of soluble proteins and reducing sugars, the yeast strains entered senescence phase. With the yeast populations dying out, the fermentations were terminated so that the broth could be prepared for the next phase of fermentation. Although the K. marxianus strains prefer sugars and carbohydrates, a small amount of protein or another source of nitrogen is necessary; therefore, the depletion of proteins and sugars as well as the buildup of metabolic wastes are important to consider with these fermentations ${ }^{33,34,42}$.

Ethanol production is an important process in the fermentation of this sugar-rich, agave leaf juice. Anaerobic fermentation of sugars by these yeasts produced ethanol and carbon dioxide; the ethanol can be harvested from the fermentation broth at the end of fermentation with these K. marxianus species. Ethanol is a valuable commodity; it can be used for biofuel or catalyzed into more complex hydrocarbons. Production of ethanol started first in the KM 7-1 fermentation flasks at 12 hours, but did not show its peak concentration until 48 hours from inoculation. The KM 8-1 fermentations, at 12 hours, did not show significantly different ethanol concentrations from control fermentations with no added yeast cells, but did reach a similar maximum concentration as KM 7-1 by 48 hours. While KM 7-1 did start to produce ethanol earlier in the fermentation than the KM 8-1 fermentations did, these data do not support either strain as a better ethanol producer if maximum ethanol concentration is used for comparison. Both strains of $K$. marxianus reached a similar maximum concentration of ethanol; approximately $2.6 \%$ ethanol (v/v) for KM 7-1 and $2.7 \%$ ethanol $(\mathrm{v} / \mathrm{v})$ for $\mathrm{KM} 8-1$ at 48 
hours from the inoculation of the agave leaf juice with K. marxianus yeast strains. At 72 hours and the termination of the fermentations, the ethanol concentrations were still at approximately the same values in all fermentation flasks.

Comparison of these ethanol data to fermentations of another waste product can make these values more noteworthy. In a fermentation of coffee waste with KM 7-1, ethanol data were collected ${ }^{34}$. These values reached their peak by 24 hours, similar to the agave leaf juice fermentations; however, there were two substantial differences. First, the ethanol did not appear to be stable in the coffee waste fermentation. The ethanol concentration peaked with the 24-hour samples, but quickly tapered off to below the initial values by 48 hours from inoculation. Additionally, while more than three times the amount of soluble sugars have been reported in coffee waste $(322.1 \mathrm{mg} / \mathrm{g})^{34}$ as in agave leaf waste $(9.7 \% \text { or } 97 \mathrm{mg} / \mathrm{g})^{7}$; substantially more ethanol was produced with agave leaf juice fermentations. Ethanol concentrations in both types of fermentations were at or near their respective maximums at the 24-hour mark. However, the concentration of ethanol in the agave leaf juice fermentations, which had much less soluble sugars, measured about a four times greater ethanol concentration $(26 \mathrm{mg} / \mathrm{mL}$ with agave leaf juice; 6.5 to 7.0 with coffee waste ${ }^{34}$ ). This discrepancy is likely due to the availability of the sugars in the agave leaf juice, as opposed to the sugars being located in the solids of the coffee waste, as well as the types of sugars present in these two wastes.

Data overlays were a convenient way to look at and compare the data. These overlays allowed for the comparison of the CFU concentration with the consumption of nutrients and/ or the production of metabolic waste. While these overlays are not 
necessary, they are convenient for the direct comparison of data sets. The data normalization with reducing sugar concentration was no more revealing than was the graphed, individual data. The data normalization with soluble protein concentration, on the other hand, was a more useful graph as it separated the performance of the two K. marxianus yeast strains more so than did the graphs of the individual data.

The $\mathrm{pH}$ values for these agave leaf juice fermentations were collected; however, the $\mathrm{pH}$ remained constant from start to finish with these fermentations. Sample $\mathrm{pH}$ values were assessed by spotting $60 \mu \mathrm{L}$ of the appropriate sample onto $\mathrm{pH}$ paper as described in the materials and methods section. The $\mathrm{pH}$ analyses with the agave leaf juice fermentations indicate that there was considerable buffering ability in the agave leaf juice, as the $\mathrm{pH}$ remained constant at 4.5 throughout fermentation during which substantial amounts of $\mathrm{CO}_{2}$ are generated.

Comparison of the second stage Yarrowia fermentations was carried out by CFU comparison and comparison of ammonia production. All the second stage fermentations were conducted, sampled and analyzed by Mr. Mitchell Lindquist of the USDA in Peoria, Illinois. Samples were collected at inoculation, and every 24 hours after being inoculated until the fermentations were terminated at the 72-hour mark. Colony forming units were still increasing at 72 hours in all Yarrowia containing flasks; the Yarrowia flasks that had not been previously fermented with $K$. marxianus species supported the highest number of yeast cells per $\mathrm{mL}$. These fermentations reached a CFU maximum of approximately 40 million cells per $\mathrm{mL}$ of fermenting agave juice. The second phase fermentations that had been fermented first with either $K$. marxianus species were approximately $5 \%$ to $10 \%$ that of the fermentations that were used as a 
control (i.e. with no K. marxianus species added to the incubation) fermentations at between 2 and 4 million cells per $\mathrm{mL}$. Based on colony forming units, Yarrowia growth was more prolific if the juice was not fermented first with $K$. marxianus yeast strains. This indicates that the K. marxianus yeasts reduced the nutritional content of the juice.

The only other data available at this time for the second stage fermentations was ammonia production. Yarrowia does not ferment sugars as readily as it does proteins ${ }^{35}$. As sugars are not the substrate, ethanol is not a major product of the metabolism of fermentations with Yarrowia. However, such fermentations do produce ammonia which can be a valuable commodity. Dissolved ammonia was measured and data were provided by Mr. Mitchell Lindquist through a collaboration between the Jones' Lab and the USDA in Peoria. Dissolved ammonia, by the end of the fermentations at 72 hours, had reached its highest concentration of $0.066 \mathrm{mg} / \mathrm{mL}$ in the vessels that had been fermented first with KM 7-1. Fermentations from first stage KM 8-1 fermentations finished at about $66 \%$ as high as $\mathrm{KM} 7-1$ with $0.043 \mathrm{mg} / \mathrm{mL}$. Flasks that were not fermented with $K$. marxianus yeast finished at a concentration of $0.039 \mathrm{mg} / \mathrm{mL}$ or $60 \%$ as high as those from KM 7-1 fermentations. This suggests that the Yarrowia consumed the yeast cells left in the broth but killed by sterilization in an autoclave and preferred KM 7-1 over KM 8-1. The KM 7-1 yeast cells appeared to provide more available proteins than did the agave leaf juice alone or KM 8-1 fermentations and, therefore, more ammonia was produced. The K. marxianus yeasts may also provide other important nutrients such as B vitamins for the Yarrowia.

To put the ammonia production of this biphasic fermentation in perspective, we can compare these results to another biphasic fermentation in which Yarrowia was used 
to ferment coffee waste after KM 7-1 was used for a first stage fermentation ${ }^{34}$. When the same Yarrowia strain was used to ferment coffee waste, a similar though slightly higher concentration of ammonia was reported at the 72-hour time point. With the agave leaf juice, approximately $0.066 \mathrm{mg} / \mathrm{mL}$ of ammonia was measured at 72 hours; with coffee waste that had been fermented in the same manner, approximately 0.08 $\mathrm{mg} / \mathrm{mL}$ was reported at the same, 72 -hour time point. While this value is slightly higher, the reported error was substantially greater with the coffee waste $( \pm \approx 0.035 \mathrm{mg} / \mathrm{mL})$ fermentation analysis ${ }^{34}$ than with this, agave leaf juice $( \pm \approx 0.018 \mathrm{mg} / \mathrm{mL})$ fermentation analysis.

When ethanol production is discussed, it is beneficial to compare these results with not only fermentations of other waste products, but also fermentations of common commodities used to produce ethanol. A recently published review article reported ethanol conversion factors from common commodities used to produce ethanol ${ }^{44}$. These estimates used the amount of sugars contained in several cash crops used to ferment ethanol, and estimated the amount of substrate needed to produce one gallon of ethanol if the sugars are all converted into ethanol ${ }^{44}$. These data from the ethanol estimates and the actual results and calculations from this research are included in Table 3. It is important to consider the amount of available sugars as well. With the agave leaf juice, only approximately $40 \%$ of the available sugars are being carried out of the leaf in the juice; therefore, agave leaf juice values are compared twice, once with actual values, and once with estimates based on approximately $100 \%$ of the leaf sugars being contained in the juice and similar fermentation performance. 
Table 3. Tons of Substrate Required to Produce 1 Gallon of Ethanol.

\begin{tabular}{lccccccc}
\hline Corn $^{44}$ & Sugarcane $^{44}$ & $\begin{array}{c}\text { Sugar } \\
\text { Beets }^{44}\end{array}$ & Molasses $^{44}$ & $\begin{array}{c}\text { Raw } \\
\text { Sugar }^{44}\end{array}$ & $\begin{array}{c}\text { Refined } \\
\text { Sugar }^{44}\end{array}$ & $\begin{array}{c}\text { Agave } \\
\text { Leaf } \\
\text { Juice }\end{array}$ & $\begin{array}{c}\text { Agave Leaf } \\
\text { Juice } \\
\text { optimized } \\
\text { (estimate })^{\star}\end{array}$ \\
\hline $\begin{array}{c}0.0101 \\
(0.36 \mathrm{Bu})\end{array}$ & 0.051 & 0.040 & 0.0144 & 0.0074 & 0.0071 & 0.2828 & 0.1131 \\
\hline \multicolumn{7}{c}{${ }^{*}$ Using data from this thesis for the calculations. } \\
\hline
\end{tabular}

Comparison of all these data discussed above and described in the results section indicate that the best yeast strain to use to ferment the juice pressed from these Blue Agave leaves first is KM 7-1. Not only does it have a shorter lag time and a marginally higher CFU maximum, it also consumes the nutritional reducing sugar and protein content and starts to produce ethanol earlier in the fermentation. This yeast strain was also shown to be the better yeast to use to ferment Blue Agave leaf pieces in water ${ }^{15}$. Additionally, with a second stage fermentation in which Yarrowia was used as the fermenting microorganism, dissolved ammonia reached its highest concentration if the agave leaf juice was first fermented with KM 7-1. A table (Table 4) summarizing the results from agave leaf juice fermentations is included below. In contrast with the data collected from agave leaf juice fermentations, KM 7-1 was not as good at fermenting cocoa pod husk.

Table 4. Summary of Agave Leaf Juice Extraction and Fermentations. Kilograms Leaf per Gallon Juice Maximum CFUs per $\mathrm{mL}$ Juice Maximum Ethanol $(\mathrm{mg})$ per $\mathrm{mL}$ Juice Maximum Ammonia $(\mathrm{mg})$ per $\mathrm{mL}$ Juice Tons Leaf per Gallon Ethanol Ethanol Value (\$) per Gallon Juice Yeast Value (\$) per Gallon Juice* Ammonia Value (\$) per Gallon Juice ${ }^{\star *}$ ${ }^{*}$ Calculated from brewer's yeast sold commercially in bulk as a livestock feed additive. ${ }^{* *}$ Calculated from anhydrous ammonia commercial value. 


\section{Cocoa Pod Husk Fermentations}

$\mathrm{CPH}$ fermentations were assessed by monitoring the same type of data as were collected with the agave juice samples. With $\mathrm{CPH}$ in water, $\mathrm{KM}$ 8-1 reached a higher CFU maximum and had a shorter lag phase than did KM 7-1. KM 8-1 reached an average CFU maximum of around 75 million per $\mathrm{mL}$ by 12 hours, while KM 7-1 fermentation required 24 hours to reach a CFU maximum of 69 million cells per $\mathrm{mL}$ of broth. Thus, these fermentations did not support nearly as many yeast cells of either strain as did the agave juice fermentations. Additionally, CFUs did not taper off with time as drastically as was seen with agave juice fermentations. This suggests that the nutritional content of $\mathrm{CPH}$ is both less dense and less readily available than are the nutrients in agave leaf juice. It may also suggest that $\mathrm{CPH}$ as a substrate may not be as toxic to these yeasts. Based on comparison of the CFU data, KM 8-1 is the better yeast strain to ferment cocoa pod husks, though both ferment the $\mathrm{CPH}$ substrate adequately. The CFU maxima in these fermentations reached similar maxima to those reported to have been achieved with the fermentation of Blue Agave leaf solids in water $^{15}$. Thus, these K. marxianus strains may be most useful for bioremediation to reduce waste and less useful for value added products.

While colony forming units were as indicative with $\mathrm{CPH}$ as they were with agave leaf juice, the physical appearances of the fermentations were not as telling. Appearance of these fermentations changed as a function of time with $\mathrm{CPH}$ fermentations, but the appearances did not change differently from one another as they did with agave leaf juice fermentations. The flasks which contained no added yeast changed similarly to those which had been inoculated with yeast. This indicates that 
some spontaneous, likely oxidative reactions are occurring. With samples, there were yeast cells visible in the pellet after separation by centrifugation and decantation, but this observation would not be useful as any sort of indicator of the progress of these fermentations.

Cocoa pod husk fermentation reducing sugar data, as assessed by the DNS assay, showed trends similar to those observed with the Blue Agave leaf juice fermentations. By the 24 -hour time point, both strains had consumed nearly all available reducing sugars in the broth. The KM 8-1 fermentations showed nearly 1 $\mathrm{mg} / \mathrm{mL}$ less reducing sugars remaining than did the $\mathrm{KM}$ 7-1 fermentations starting with the 12-hour samples (3.6 mg/mL with $\mathrm{KM} 7-1$ and $2.7 \mathrm{mg} / \mathrm{mL}$ with $\mathrm{KM} 8-1$ ); this trend continued through the 48 -hour samples. At 72 hours, the reducing sugars were depleted to below $1 \mathrm{mg}$ per $\mathrm{mL}$ of fermentation broth with either $\mathrm{KM}$ 7-1 or $\mathrm{KM}$ 8-1 strains. This suggests that the only remaining source of sugars left in these fermentations were non-reducing polysaccharides; with $\mathrm{CPH}$, the major polysaccharide is pectin ${ }^{20}$. These $\mathrm{KM}$ yeasts seem to utilize pectin very well ${ }^{33}$, and tolerate the $\mathrm{pH}$ change that accompanied the carbonic acid production and utilization of the galacturonic acid monomers that come from the degradation of pectin.

Soluble $\mathrm{CPH}$ protein concentrations did not change as a function of fermentation time as it did in the agave leaf juice fermentations. This could be due to the smaller yeast populations present in CPH fermentations, about 100 -fold fewer CFU per $\mathrm{mL}$, or a possible false positive with the $\mathrm{CPH}$ fermentations. In addition to the soluble protein assay results not being indicative of fermentation progress, overlays with soluble protein were equally non-useful. The overlay of CFU concentration and reducing sugar 
concentration was a useful way to more easily compare the growing yeast populations and declining reducing sugar concentrations as a function of fermentation time. The data normalizations were not effective at providing further separation of the monitored criteria with $\mathrm{CPH}$ fermentations.

While soluble proteins and low detectable ethanol concentrations did not change considerably throughout these fermentations, $\mathrm{pH}$ did change as a function of time in the $\mathrm{CPH}$ fermentations. For the control flasks that contained no added yeast cells, the $\mathrm{pH}$ remained constant with time. The $\mathrm{pH}$ started out with an approximate value of 6 or 6.5 and stayed at approximately the same value throughout the fermentations. KM 8-1 fermentation flasks resulted in the most noticeable $\mathrm{pH}$ change; $\mathrm{pH}$ in $\mathrm{KM}$ 8-1 fermentations started at the same value as did the control flasks, then dropped to an approximate $\mathrm{pH}$ value of 5.0 at the 12 -hour mark. By 72 hours, $\mathrm{pH}$ in these fermentations rose to around 7.0 or 7.5 ; this shows a change in the concentration of protons in solution of more than 10 -fold from start to finish. The change in $\mathrm{pH}$ was most drastic from the 12-hour time point through 72 hours and the completion of these fermentations. This change of approximately $2.5 \mathrm{pH}$ units indicates that there are less than 100 times fewer protons in solution at the end of the fermentation than there were at the 12-hour time point where $\mathrm{pH}$ was at its lowest.

Soluble protein concentrations were fairly constant throughout the fermentations of $\mathrm{CPH}$ with either strain of $\mathrm{K}$. marxianus yeast. Soluble proteins in $\mathrm{CPH}$ fermentations remained at approximately $1 \mathrm{mg} / \mathrm{mL}$; this implies that these yeasts did not consume a significant amount of the available, soluble protein at any point of the fermentation or that the flux of protein use by yeasts and solubilization of protein from the $\mathrm{CPH}$ were 
approximately the same. All analyses of samples for ethanol were essentially zero throughout these fermentations. While results with both ethanol and soluble proteins remained rather unexciting throughout these fermentations, the second stage fermentations with $\mathrm{CPH}$ did show more interesting results.

Second stage $\mathrm{CPH}$ fermentations with Yarrowia showed a decrease in overall ammonia production and CFUs when those flasks which had been fermented with either strain of $K$. marxianus yeast were compared to $\mathrm{CPH}$ flasks that had only been fermented with the Yarrowia yeast. CFUs for these fermentations that had been first fermented with either K. marxianus strain reached about $20 \%$ to $50 \%$ as high as did those that had not been fermented with a K. marxianus strain first. In addition to CFUs, ammonia concentrations in second stage fermentations were not as high as with $\mathrm{CPH}$ fermentations that were only fermented with Yarrowia. At 72 hours, ammonia concentrations in fermentations were $0.040 \mathrm{mg} / \mathrm{mL}$ for fermentations with only Yarrowia. Ammonia concentrations in fermentations from $\mathrm{KM} 7-1$ reached $0.019 \mathrm{mg} / \mathrm{mL}$ or $48 \%$ that of Yarrowia alone, and in fermentations from $\mathrm{KM} 8-1$ reached $0.0095 \mathrm{mg} / \mathrm{mL}$ or $24 \%$ that of fermentations that were only inoculated with Yarrowia.

These results suggest that while KM 7-1 and KM 8-1 fermented CPH adequately as assessed by CFU and reducing sugar data; no substantial commodities were harvestable from the fermentation product. If the goal of these fermentations is to grow yeast, $\mathrm{KM} 8-1$ is the better yeast. If nothing is gained by fermenting $\mathrm{CPH}$ with $K$. marxianus species, fermentation with only the ammonia producing Yarrowia seems the wiser choice. 


\section{CHAPTER V: FUTURE WORK}

Much future work remains of interest with these fermentations. The multistage fermentations show promise, especially with the Blue Agave leaf juice. These multistage fermentations need to be reproduced and, if the results show similar data as was shown with fermentations analyzed in this work, these fermentations would then need to be scaled up. With scaled-up fermentations in the 5-to-10-liter range, results should be even more consistent. If the concentrations of ethanol and ammonia are reproduced at similar levels as were observed with these small-scale fermentations, the harvesting and assessment of these commodities would be performed. Blue Agave leaves may, someday soon, be taken from fields where they were once left, and pressed to collect the juice. Research shows that the fibers from these leaves can be used for multiple applications like reinforcing and reducing the weight of plastics and building products like a fiberboard or even used to make paper, ropes or textiles $^{7}, 11,13,36$. This once proud plant that was used completely by native peoples may find itself used completely once again with continued research into these leaves.

The protein assay used to assess these fermentations is a measure of only soluble proteins. This is acceptable for the monitoring of the progress of the fermentations, but does not accurately describe the amount of total protein that is in the fermentations. The yeast themselves are mostly comprised of protein ${ }^{44}$; this protein is not measured with the protein assays used to assess these fermentations as the samples are separated by centrifugation and only the supernatant solution was assessed. Therefore, while the yeasts continue to multiply and consume nutrients in these fermentations, the nutritional value of these yeast, themselves, was not assessed. 
Yeast do add nutrients such as proteins and vitamins to fermentations; leftover yeasts and solids from breweries are often added to livestock feed ${ }^{37}$. These components are used as highly nutrient dense additives for increasing the nutritional value of the animal feed. These current fermentation assessments may benefit from an alternative protein assay in which the protein content of the fermentations, including the solid portions, is performed. Protein concentration was estimated from reported protein mass per yeast cell ${ }^{44}$. To estimate protein mass per cell, an average of the three values reported was taken; this average was multiplied by the number of cells calculated from each fermentation sample. The protein estimates were treated as a cumulative value, so each estimate was added to the calculation from the previous sample. These estimates for $\mathrm{CPH}$ fermentations (Figure 44) and agave leaf juice fermentations (Figure 45) are graphed. These graphs, especially with agave leaf juice fermentations, show large amounts of proteins in the fermentation product, especially with agave. We speculate that the pellets (remaining solid portion after centrifugation and decantation) from agave leaf juice fermentations may have good potential as an animal feed additive. 


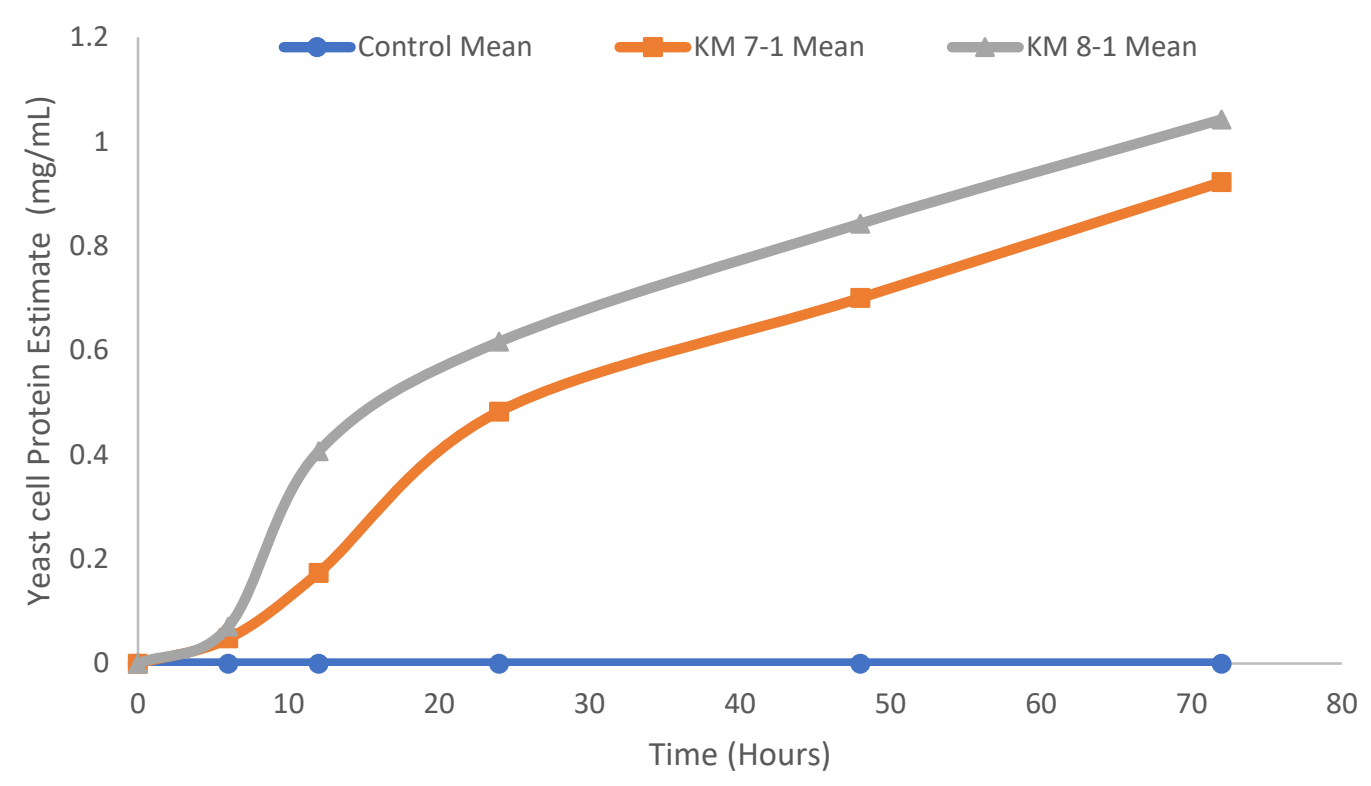

FIGURE 44. Graph of cocoa pod husk yeast cell added protein. Protein concentration estimates based on CFUs and reported protein per yeast cell ${ }^{44}$ for $\mathrm{CPH}$ in water fermentations.

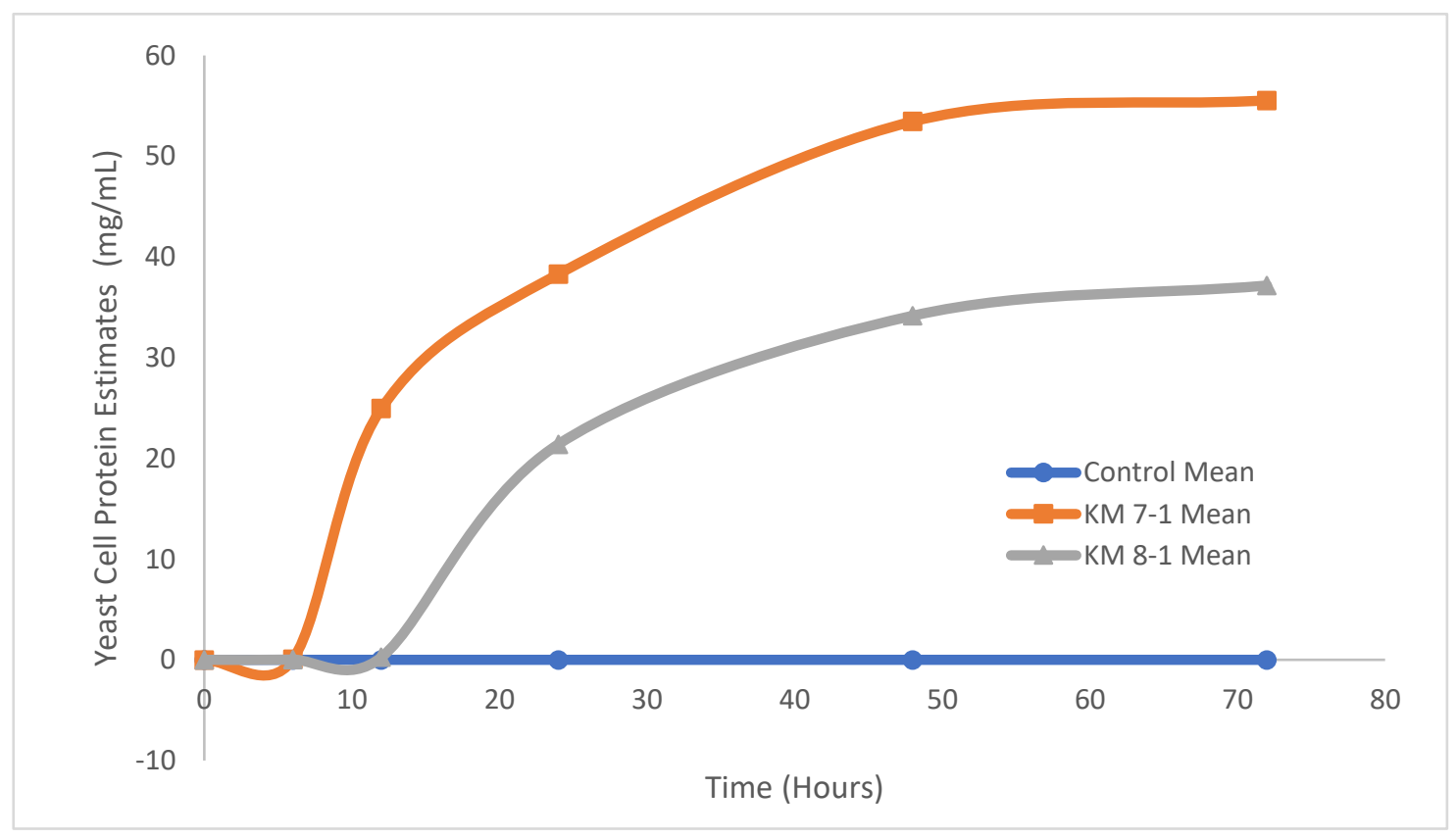

FIGURE 45. Graph of agave leaf juice yeast cell added protein. Protein concentration estimates based on CFUs and reported protein per yeast cell ${ }^{44}$ for agave leaf juice fermentations. 
With two-stage fermentations, the ethanol was removed from the flasks between the first and second stage fermentations. This ethanol was simply evaporated from the fermentations; ethanol is a waste product of yeast fermentations and, at elevated concentrations, is toxic to yeast. The removal of the ethanol was done only to prevent it from inhibiting the growth of the Yarrowia yeasts used in the second stage to ferment the substrates. This ethanol, in future fermentations, should be collected by distillation, assessed and characterized. Ethanol is a valuable commodity ${ }^{38}$; ethanol produced in these fermentations could be used as a biofuel and should be harvested as opposed to simply discarded. Thus, its value and probability of becoming a major commodity harvested from fermentations of these types of wastes can be assessed. Another valuable commodity that can potentially be harvested from these fermentations is the ammonia that is produced with the second fermentation with Yarrowia. Ammonia is a valuable commodity ${ }^{39}$ as it is used for the production of agricultural fertilizers.

Ethanol is a major waste product produced by the $K$. marxianus yeast strains, while ammonia is a major waste product produced by the metabolic activity of Yarrowia. Ammonia is used as a fertilizer for most agricultural operations; much of the energy produced globally goes into the production of ammonia to be used as a fertilizer ${ }^{39}$. If this commodity can be produced by microorganisms through fermentation of a waste product such as the second stage of agave leaf juice fermentations or with fermenting $\mathrm{CPH}$, there is a potential to supplement or even replace these industrial processes that consume massive amounts of energy. If enough ammonia can be harvested from these fermentations, it may offer an enticing alternative to traditional fertilizer manufacturing methods. 
In addition to these next-step concepts discussed above, the future work with the fermentation of $\mathrm{CPH}$ should include a different approach to some of the first steps taken. Specifically, these include: better consistency of the fermentation substrates, and possible alternative analytical methods. The methods used to analyze the $\mathrm{CPH}$ fermentations were adopted from the analysis of the agave fermentations; the opportunity to study these cocoa pod husks became available after research with the agave leaves was underway. The reducing sugar assay seems to be fairly consistent with $\mathrm{CPH}$ as it is with the agave juice, but the protein assays may be providing false concentrations with the $\mathrm{CPH}$ fermentations. The protein assay gives a response similar to that of the agave juice; however, when TLC plates are used to separate the components of the fermentation samples from the first stage fermentation, the results are very different.

When the same amount of fermentation broth was spotted onto a TLC plate, separated and developed under identical conditions, the plates made with agave leaf juice samples looked very different relative to plates made with the $\mathrm{CPH}$ fermentation broth. If we assume that the ninhydrin positive results are due to the presence of protein, then these results contradicted the results from the BioRad® Protein Assay. The initial protein concentrations with $\mathrm{CPH}$ in water were about 10 -fold that of initial concentrations of agave leaf juice fermentations. The plates used to separate Blue Agave juice turned a bright pink color after being allowed to separate, dried with gentle heat from a hot plate, sprayed with ninhydrin solution and, again, heated gently on a hot plate. The plates used to separate the fermentation broth from the $\mathrm{CPH}$ samples did turn pink, but not to the extent as the same volume of agave leaf juice fermentation 
samples. Additionally, the 0 -time samples showed more of a response to the ninhydrin solution than did samples later in the fermentations. This indicates that the yeasts are consuming the proteins that are present. However, results from the BioRad® Protein Assay showed no substantial decrease in protein concentration throughout $\mathrm{CPH}$ in water fermentations. This observation is evidence for the possibility that the BioRad® Protein Assay may not be as appropriate with $\mathrm{CPH}$ as it is with agave leaf juice fermentations.

A more consistent fermentation substrate of $\mathrm{CPH}$ could be achieved in many ways. The best way to homogenize the husk from one cocoa pod may be to dry and crush the husk into a powder. Once powdered, the husk could be thoroughly mixed and, presumably, homogenized with respect to the content of each sample. Layers in the husk are inconsistent, some are thick in some areas and thin in others; some layers seem to be discontinuous, not appearing throughout the entire husk. These inconsistencies lead to data and conclusions that may be inaccurate as the substrate used may not be representative of the pool of $\mathrm{CPH}$ waste that could eventually be broken down and converted to useful commodities by microorganisms. Therefore, homogenizing the entire husk should improve consistency within the experiments that used the same husk. The best way to represent $\mathrm{CPH}$ waste as a whole would be to obtain a large pool of cocoa pods; dry and powder all of the husks together and mix many husks that are taken from ripe pods.

In addition to future work that focuses on the substrates discussed in this thesis, a lot remains to be learned about the yeasts used in this work. Both $K$. marxianus species ferment agave juice very well, and they produce a substantial amount of 
ethanol. This is unarguable as the data are both reproducible and reported by other researchers $33,34,42$. However, it is not known what metabolic pathways these K. marxianus yeast strains used to produce ethanol; it is only known that fructose and inulin are the major nutrients in the juice ${ }^{6}$. Similarly, with Yarrowia fermentations, it is not known what metabolic pathway these yeasts use to produce ammonia; it is known that the ammonia is produced as available proteins are consumed ${ }^{34,35}$. If the enzymes that these species use to metabolize their respective, preferred substrate could be identified and the metabolic pathways mapped, fermentations could be further enhanced, and/ or several additional potential commodities could be explored.

Concepts explored with preliminary fermentations but not examined in this thesis should be re-visited. Specifically, these include: dilution of the agave leaf juice and fermentations that are not sterilized before inoculation with $K$. marxianus yeast strains. By hand wringing the leaves, more juice is collected and reducing sugar concentration is much higher than with the methods used in prior work in the Jones' Lab. Dilution of the juice in preliminary fermentations did not seem to affect the CFUs of these fermentations up to about $50 \%$ water (data not shown). Now that the concentration of reducing sugars is much higher, a greater number of CFUs were expected, but were not observed in these fermentations. Dilution of this richer juice may be beneficial to the yeast being used to ferment it due to decreased osmotic pressure. Furthermore, if similar ethanol concentrations and subsequent fermentation parameters are relatively unaffected with non-sterile juice, this costly and time-consuming step may be unnecessary and potentially eliminated. 


\section{REFERENCES}

1. Tequila Regulatory Council; Consejo Regulador del Tequila (CRT); [Internet]; accessed June 22, 2017; available at: https://www.crt.org.mx/index.php/en.

2. Tequila Production in Mexico from 1995 to 2016, by Type (in million liters); Statista, 2017; [Internet]; accessed June 20, 2017; available at: https://www.statista.com/statistics/311737/mexico-s-tequila-production-by-type/.

3. Cocoa Production Worldwide from $1980 / 81$ to $2016 / 17$ (in 1,000 tons). Statista, 2017; [Internet]; accessed June 24, 2017; available at:

https://www.statista.com/statistics/262620/global-cocoa-production/.

4. About Cocoa. World Cocoa Foundation; 2015; [Internet]; accessed June 24, 2017; available at: http://www.worldcocoafoundation.org/about-cocoa/.

5. Chadwick, I., In Search of the Blue Agave: Tequila and the Heart of Mexico. February, 2011; [Internet]; accessed June 12, 2017; available at: http://www.ianchadwick.com/tequila/index.htm.

6. Corbin, K. R.; Betts, N. S.; van Holst, N.; Jiranek, V.; Chambers, D.; Byrt, C. S.; Fincher, G. B.; Burton, R. A., Low-Input Fermentations of Agave Tequilana Leaf Juice Generate High Returns on Ethanol Yields; BioEnergy Research 2016, 9 (4), 1142-1154.

7. Iñiguez-Covarrubias, G.; Díaz-Teres, R.; Sanjuan-Dueñas, R.; AnzaldoHernández, J.; Rowell, R. M., Utilization of By-products from the Tequila Industry. Part 2: Potential Value of Agave Tequilana Weber Azul Leaves. Bioresource Technology 2001, 77 (2), 101-108.

8. $\quad$ Corbin, K. R.; Byrt, C. S.; Bauer, S.; DeBolt, S.; Chambers, D.; Holtum, J. A. M.; Karem, G.; Henderson, M.; Lahnstein, J.; Beahan, C. T.; Bacic, A.; Fincher, G. B.; Betts, N. S.; Burton, R. A., Prospecting for Energy-Rich Renewable Raw Materials: Agave Leaf Case Study. PLoS One 2015, 10 (8), e0135382.

9. Salinas, M. L.; Ogura, T.; Soffchi, L., Irritant Contact Dermatitis Caused by Needle-like Calcium Oxalate Crystals, Raphides, in Agave Tequilana Among Workers in Tequila Distilleries and Agave Plantations. Contact Dermatitis 2001, 44 (2), 94-6.

10. Valenzuela, A., A New Agenda for Blue Agave Landraces: Food, Energy and Tequila. Global Change Biology Bioenergy 2011, 3 (1), 15-24.

11. Idarraga, G.; Ramos, J.; Zuñiga, V.; Sahin, T.; Young, R. A., Pulp and Paper from Blue Agave Waste from Tequila Production. Journal of Agricultural and Food Chemistry 1999, 47 (10), 4450-4455. 
12. Simpson, J.; Martinez Hernandez, A.; Abraham Juarez, M. J.; Delgado Sandoval, S.; Sanchez Villarreal, A.; Cortes Romero, C., Genomic Resources and Transcriptome Mining in Agave Tequilana. Global Change Biology Bioenergy 2011, $3(1), 25-36$.

13. Tullo, A. H., Ford to Mix Drinking and Driving; Chemical and Engineering News; 2016, 94,(30) 16.

14. Narváez-Zapata, J.; Sánchez-Teyer, L., Agaves as a Raw Material: Recent Technologies and Applications. Recent Patents on Biotechnology 2010, 3 (3), 185-191.

15. Jarodsky, J. An Approach to an Agave Problem: the Bioremediation of Agricultural Waste by Yeast Fermentations. MS Thesis; Illinois State University, Normal, Illinois, 2016.

16. Growing Cocoa; International Cocoa Organization (ICCO) 2013; [Internet]; accessed June 24, 2017; available from: https://www.icco.org/aboutcocoa/growing-cocoa.html.

17. Daud, Z.; Kassim, M.; Sari, A.; Mohd Aripin, A.; Awang, H.; Hatta, M.; Zainuri, M., Chemical Composition and Morphological of Cocoa Pod Husks and Cassava Peels for Pulp and Paper Production. Australian Journal of Basic and Applied Sciences 2013, 7 (9), 406-411.

18. Martinez-Angel, J.; Villamizar-Gallardo, R.; Ortiz-Rodriguez, O., Characterization and Evaluation of Cocoa (Theobroma cacao L.) Pod Husk as a Renewable Energy Source. Agrociencia 2015, 49 (3), 329-345.

19. Mull, L. D.; Kirkhorn, S. R., Child Labor in Ghana Cocoa Production: Focus Upon Agricultural Tasks, Ergonomic Exposures, and Associated Injuries and Illnesses. Public Health Reports 2005, 120 (6), 649-655.

20. Adomako, D., Cocoa-D Pod Husk Pectin. Phytochemistry (Oxford) 1972, 11 (3), 1145-1148.

21. Devendra, C., The Utilization of Cocoa Pod Husk by Sheep. Malaysian Agricultural Journal 1977, 51 (2), 179-186.

22. Adebowale, E. A.; Orskov, E. R.; Shand, W. J., Use of Ash of Cocoa Pod Husk as a Source of Alkali for Upgrading Agricultural Residues With or Without Hydrogen Peroxide. Tropical Agriculture 1991, 68 (1), 27-32.

23. Schnell, R.; Olano, C.; Brown, J.; Meerow, A.; Cervantes-Martinez, C.; Nagai, C.; Motamayor, J., Retrospective Determination of the Parental Population of Superior Cacao (Theobroma cacao L.) Seedlings and Association of Microsatellite Alleles with Productivity. Journal of the American Society for Horticultural Science 2005, 130 (2), 181-190. 
24. Franzen, M.; Mulder, M. B., Ecological, Economic and Social Perspectives on Cocoa Production Worldwide. Biodiversity and Conservation 2007, 16 (13), 3835-3849.

25. Sobamiwa, O., Response of Broiler Chicks to Dietary Inclusion of Alkali-treated and Washed Cocoa-pod Husk. Journal of Applied Animal Research 1999, 15 (2), 191-196.

26. Aregheore, E. M., Chemical Evaluation and Digestibility of Cocoa (Theobroma cacao) Byproducts Fed to Goats. Tropical Animal Health and Production 2002, 34 (4), 339-348.

27. Wong, H. K.; Zahari, M. W., Nutritive Value of Palm Kernel Cake and Cocoa Pod Husks for Growing Cattle. Journal of Tropical Agriculture and Food Science 1997, 25 (1), 125-131.

28. Ashade, O. O.; Osineye, O. M., Effect of Replacing Maize with Cocoa Pod Husk in the Nutrition of Oreochromis niloticus. Journal of Fisheries and Aquatic Science 2013, 8 (1, Sp. Iss. SI), 73-79.

29. Fagbenro, O. A., Evaluation of Heat-processed Cocoa Pod Husk Meal as an Energy Feedstuff in Production Diets for the Clariid Catfish, Clarias isheriensis (Sydenham). Aquaculture Nutrition 1995, 1 (4), 221-225.

30. Fagbenro, O. A., Utilization of Cocoa-pod Husk in Low-cost Diets by the Clariid Catfish Clarias-isheriensis Sydenham. Aquaculture and Fisheries Management 1992, 23 (2), 175-182.

31. Alemawor, F.; Oddoye, E. O. K.; Dzogbefia, V. P.; Oldham, J. H.; Donkoh, A., Broiler Performance on Finisher Diets Containing Different Levels of either Pleurotus ostreatus-Fermented Dried Cocoa Pod Husk or Dried Cocoa Pod Husk Supplemented with Enzymes. Tropical Animal Health and Production 2010, 42 (5), 933-939.

32. Alemawor, F.; Dzogbefia, V. P.; Oldham, J. H.; Oddoye, E. O. K., Effect of Pleurotus ostreatus Fermentation on Cocoa Pod Husk Composition: Influence of Fermentation Period and Mn2+ Supplementation on the Fermentation Process. African Journal of Biotechnology 2009, 8 (9), 1950-1958.

33. Hughes, S. R.; Bang, S. S.; Cox, E. J.; Schoepke, A.; Ochwat, K.; Pinkelman, R.; Nelson, D.; Qureshi, N.; Gibbons, W. R.; Kurtzman, C. P.; Bischoff, K. M.; Liu, S.; Cote, G. L.; Rich, J. O.; Jones, M. A.; Cedeño, D.; Doran-Peterson, J.; RiañoHerrera, N. M.; Rodriguez-Valencia, N.; López-Núñez, J. C.; Automated UV-C Mutagenesis of Kluyveromyces marxianus NRRL Y-1109 and Selection for Microaerophilic Growth and Ethanol Production at Elevated Temperature on Biomass Sugars. Journal of Laboratory Automation 2013, 18 (4), 276-290. 
34. Hughes, S. R.; López-Núñez, J. C.; Jones, M. A.; Moser, B. R.; Cox, E. J.; Lindquist, M.; Galindo-Leva, L. Á.; Riaño-Herrera, N. M.; Rodriguez-Valencia, N.; Gast, F.; Cedeño, D. L.; Tasaki, K.; Brown, R. C.; Darzins, A.; Brunner, L., Sustainable Conversion of Coffee and Other Crop Wastes to Biofuels and Bioproducts using Coupled Biochemical and Thermochemical Processes in a Multi-stage Biorefinery Concept. Applied Microbiology and Biotechnology 2014, 98 (20), 8413-8431.

35. Lindquist, M. R.; López-Núñez, J. C.; Jones, M. A.; Cox, E. J.; Pinkelman, R. J.; Bang, S. S.; Moser, B. R.; Jackson, M. A.; Iten, L. B.; Kurtzman, C. P., Irradiation of Yarrowia lipolytica NRRL YB-567 Creating Novel Strains with Enhanced Ammonia and Oil Production on Protein and Carbohydrate Substrates. Applied Microbiology and Biotechnology 2015, 99 (22), 9723-9743.

36. Iñiguez, C.; Bernal, C.; Ramírez, M.; Villalvazo, N., Recycling Agave Bagasse of the Tequila Industry. Advances in Chemical Engineering and Science 2014, 4 (02), 135.

37. Dos Santos Mathias, T. R.; De Mello, P. P. M.; Ervulo, E. F. C., Solid Wastes in Brewing Process: A Review. Journal of Brewing and Distilling 2014, 5 (1), 1-9.

38. Ethanol Futures Latest Price \& Chart for Ethanol Futures End of Day Commodity Futures Price Quotes for Ethanol Futures; NASDAQ, 2017; [Internet]; accessed June 22, 2017; available at: http://www.nasdaq.com/markets/ethanol.aspx?timeframe $=18 \mathrm{~m}$.

39. Apodaca, L., Nitrogen (fixed) - Ammonia; United States Geological Society (USGS), 2017; [Internet]; accessed June 20, 2017; available at:

https://minerals.usgs.gov/minerals/pubs/commodity/nitrogen/mcs-2017-nitro.pdf.

40. Miller, G. L., Use of Dinitrosalicylic Acid Reagent for Determination of Reducing Sugar. Analytical Chemistry 1959, 31 (3), 426-428.

41. Bradford, M., Bio-Rad Protein Assay Overview; Bio-Rad Laboratories Inc.; Copyright 2017.

42. Galindo-Leva, L. Á.; Hughes, S. R.; López-Núñez, J. C.; Jarodsky, J. M.; Erickson, A.; Lindquist, M. R.; Cox, E. J.; Bischoff, K. M.; Hoecker, E. C.; Liu, S.; Jones, M. A.; Growth, Ethanol Production, and Inulinase Activity on Various Inulin Substrates by Mutant Kluyveromyces marxianus Strains NRRL Y-50798 and NRRL Y-50799. Journal of Industrial Microbiology \& Biotechnology 2016, 43 (7), 927-939.

43. Robyt, J.; White, B., Amino Acids, Peptides and Proteins; Biochemical Techniques, Theory and Practice. Waveland Press, Inc. 1990, 407. 
44. Azhar, S. H. M.; Abdulla, R.; Jambso, S. A.; Marbawi, H.; Gansau, J. A.; Faik, A. A. M.; Rodrigues, K. F., Yeasts in Sustainable Bioethanol Production: A Review; Biochemistry and Biophysics Reports 2017, 10, 52-61.

45. Thomsen, S. T.; Londono, J. E. G.; Schmidt, J. E.; Kadar, Z., Comparison of Different Pretreatment Strategies for Ethanol Production of West African

Biomass. Applied Biochemistry and Biotechnology 2015, 175 (5), 2589-2601. 